UNIVERSIDADE DE SÃO PAULO

ESCOLA DE ENGENHARIA DE SÃO CARLOS

DEPARTAMENTO DE ENGENHARIA DE SÃO CARLOS

CARLOS EDUARDO SOARES CAMPAROTTI

INCLUSÃO DO CONCEITO DE SIMBIOSE INDUSTRIAL NA DEFINIÇÃO DO LAYOUT: UMA PROPOSTA CONCEITUAL

São Carlos

2015 



\section{INCLUSÃO DO CONCEITO DE SIMBIOSE INDUSTRIAL NA DEFINIÇÃO DO LAYOUT: UMA PROPOSTA CONCEITUAL}

Dissertação apresentada à Escola de Engenharia de São Carlos, ao programa de Pós-Graduação em Engenharia de Produção, Universidade de São Paulo, como requisito para obtenção do título de Mestre em Engenharia de Produção.

Área de concentração: Processos de Gestão e Operações

Orientador: Prof. Dr. Kleber Francisco Esposto

São Carlos 
AUTORIZO A REPRODUÇÃO TOTAL OU PARCIAL RESTE TRABALHO POR QUALQUER MEIO ĆONVENCIONAL OU ELETROONICO, PARA FINS DE ESTUDO E PESQUISA, DESDE QUE CITADA A FONTE.

Camparotti, Carlos Eduardo Soares

Inclusão do conceito de Simbiose Industrial na

definicão do layout: uma proposta conceitual / Carlos Eduardo Soares Camparotti; orientador Rleber Erancisco Esposto. Säo Carlos, 2015.

Dissertạ̧ão (Mestrado) - Programa de Pós-Graduạ̧ão em Engenharia de Produção e Area de Concentração em Processos e Gestão de Operacôes -- Escola de Engenharia de Săo Carlos da Universidade de São Paulo, 2015.

1. Simbiose Industrial. 2. Planejamento de layout. 3. Fluxo de resíduos. 4. Trocas simbióticas. 5. Inter-relações. I. Titulo. 


\section{FOLHA DE JULGAMENTO}

Condidgto: Engenheiro CARLOS EDUARDO SOARES CAMPAROTTI.

Título do dssertoçoo: "Inclusāo do conceito de simbiose industrial no definicó do loyout: uma proposta conceitual".

Dota da defera: 10/04/2015

Comissáo Julgadora:

Resullado:

Prot. Dr. Kleber Francisco Espósto (Oientador)

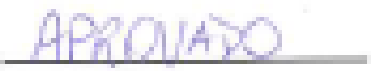

(Escola de Engenharia de Soo Carlcs/EESC)

Prof. Dr. Aldo Roberlo Ometto

[Escola de Engenhario de Sōo Carks/EesC]

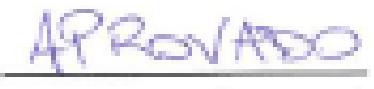

Prof. Dr. Nilton Luiz Menegon

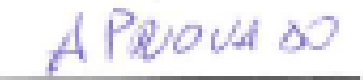

(Universidode Federal de Sä CarlowUFCar)

Coordenadora do Frograma de Pós-Graduacoo em Engenharia de Produço:

Profa. Asșociada Daisy Aparecida do Nascimento Rebelalto

Presidente da Comissoo de Pos-Groduccoo:

Prol. Associodo Paulo Cesar Lima Seganiline 



\section{RESUMO}

\section{CAMPAROTTI, C. E. S. Inclusão do conceito de simbiose industrial na definição do layout: uma proposta conceitual. Dissertação (mestrado) - Escola de Engenharia de São Carlos, Universidade de São Paulo, São Carlos, 2015.}

O aspecto ambiental está cada vez mais presente no cotidiano das empresas, as quais necessitam reduzir custos e diminuir seus impactos ambientais sempre, concomitantemente a isso tem a necessidade de diminuir a disposição de resíduos na natureza e a extração desenfreada de recursos naturais finitos. Um conceito importante encontrado na literatura é a Simbiose Industrial (SI), a qual busca reutilizar resíduos para obter um sistema fechado com a diminuição de impactos ambientais. A SI ocorre entre empresas e estas são preferíveis que estejam dentro de um parque para maior eficiência, portanto pode-se considerar que a proximidade geográfica influencia no sucesso dela e que o arranjo físico do parque deve ser planejado para atingir melhores resultados. Este trabalho propõe um procedimento composto por seis passos, baseados principalmente no modelo Systematic Layout Planning (SLP) de Muther (1973) para planejar o layout de empresas que participam da SI dentro de um sistema com limites definidos, de forma a encontrar o melhor arranjo físico que favoreça as trocas simbióticas e os relacionamentos criados. O procedimento proposto direciona desde a coleta de dados, passando pelo matching, análise e fluxo, até o estabelecimento das inter-relações das empresas dentro do espaço. Para demonstrar a aplicação do procedimento e os possíveis resultados, realizou-se uma aplicação deste através da coleta de dados de empresas que irão participar de um parque ecológico no interior de São Paulo. Os dados foram utilizados e o procedimento resultou em um arranjo físico das empresas, com foco naquelas que realizam trocas simbióticas. O resultado foi analisado teoricamente, principalmente em relação a SI, que necessita ser o centro do layout final, sendo considerado satisfatório por atender o objetivo proposto, além disso foram colocadas algumas ideias para melhorar a questão da proximidade geográfica ao máximo. Os trabalhos futuros necessitam considerar o fluxo de produtos, em caso da presença de uma cadeia logística no parque e a necessidade de implementação do resultado para maiores análises.

Palavras-chave: Simbiose Industrial. Planejamento de layout. Fluxo de resíduos. Trocas simbióticas. Inter-relações 



\begin{abstract}
CAMPAROTTI, C. E. S. Including the Industrial Symbiosis concept in layout definition: a conceptual proposal. Dissertação (mestrado) - Escola de Engenharia de São Carlos, Universidade de São Paulo, São Carlos, 2015.
\end{abstract}

The environmental aspect is increasingly present in daily companies routine, these companies always need to reduce costs and decrease their environmental impacts, concomitantly to that there is the need to reduce the residue disposal in the nature and the unbridled extraction of finite natural resources. An important concept found in literature is the Industrial Symbiosis (IS), which seeks to reuse residues to obtain a closed system with the environment impacts diminution. The IS occurs between companies and they are preferable to be inside a park for more efficiency, so it can be considered that geographical proximity influences in its success and that the park layout must be well planned to reach better results. This research proposes a procedure composed by six steps mainly based on Systematic Layout Planning (SLP) model from Muther (1973) to plan the layout of companies which participate in IS inside a system with defined limits, to find the best layout that favors the symbiotic exchanges and the created relationships. The proposed procedure directs since the data collection, passing by the matching, the flow analysis, until the establishment of the companies interrelationships inside the space. To demonstrate the procedure application and the possible results, this research held an application of the procedure through the data collection in the companies that are going to participate at an ecological park within the state of São Paulo. The data was used and the procedure resulted in the layout of the companies, focusing on that ones which perform symbiotic exchanges. The result was theoretically analyzed, mainly in relation to the IS, which needs to be the center of the final layout, it was considered satisfactory because attended the proposed objective, furthermore some ideas were given to improve the question of the geographic proximity to the maximum. The future researches need to consider the products flow, in case of the presence of a logistic chain in the park and the necessity of the implementation of the results to better analysis.

Keywords: Industrial Symbiosis. Layout planning. Waste stream. Symbiotic exchanges. Interrelationships. 



\section{LISTA DE FIGURAS}

Figura 1 - Metodologia utilizada na pesquisa...............................................................................

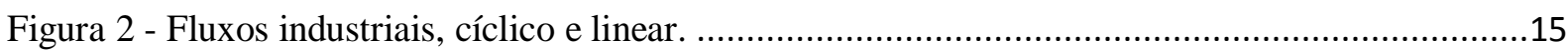

Figura 3 - Os três níveis da ecologia industrial. ........................................................................16

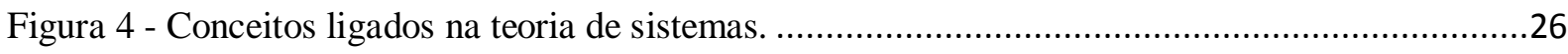

Figura 5 - Estrutura para modelar a SI baseado na teoria dos sistemas. ............................................27

Figura 6 - Estrutura para projeto e planejamento de layout...............................................................35

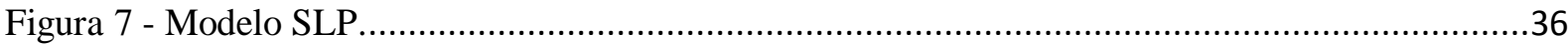

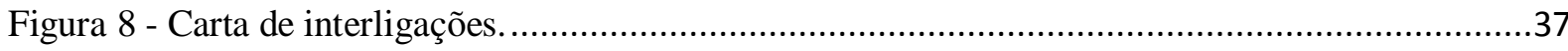

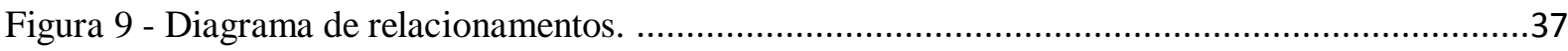

Figura 10 - Modelo de projeto de layout de Camarotto e Menegon. ……...........................................40

Figura 11 - Esquema de processo de projeto de layout....................................................................41

Figura 12 - Modelo de projeto de layout de Gonçalves filho. .........................................................42

Figura 13 - Conexão entre produto, processo e tipos de layout........................................................43

Figura 14 - Fluxograma para definição do arranjo físico global.................Erro! Indicador não definido.

Figura 15 - Processo cíclico para projeto e implantação de layout......................................................45

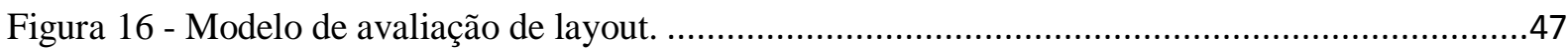

Figura 17 - Passo D1 e seus dados necessários. ...........................................................................52

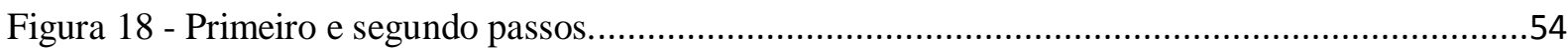

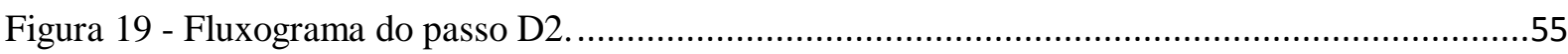

Figura 20 - Atividades que compõe a etapa de Fluxo dos resíduos. .................................................57

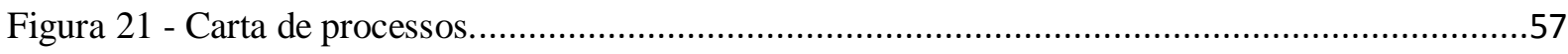

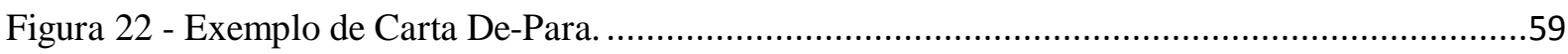

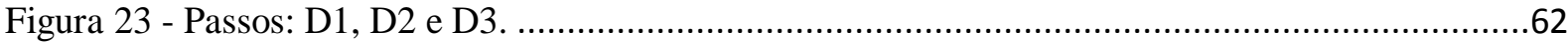

Figura 24 - Inter-relações das unidades produtivas e ferramentas que a compõe.................................62

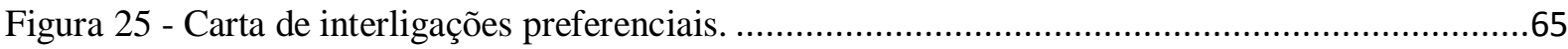

Figura 26 - Carta de interligações preferencias para unidades produtivas. ..........................................66

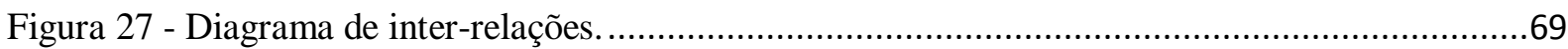

Figura 28 - Diagrama de interligações das unidades produtivas. .......................................................71

Figura 29 - Diagrama de interligações para o exemplo com o método dos elos. .................................71

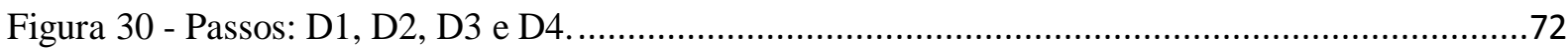

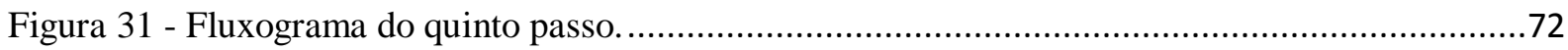

Figura 32 - Diagrama de inter-relação de espaço. ........................................................................73

Figura 33 - Layout a partir do diagrama de inter-relação de espaço....................................................74 
Figura 34 - Cinco passos: D1, D2, D3, D4 e D5.

Figura 35 - Passos para o planejamento de layout com aspectos de SI.............................................76

Figura 36 - Procedimento para planejamento de layout considerando a SI......................................78

Figura 37 - Carta de interligações preferenciais segundo a D3 desta aplicação. .................................86

Figura 38 - Diagrama de inter-relações das unidades produtivas desta aplicação................................87

Figura 39 - Diagrama de inter-relação das unidades produtivas com espaço desta aplicação................88

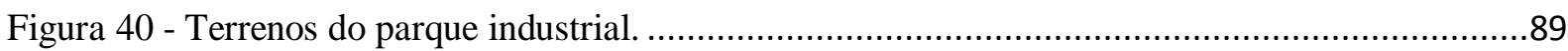

Figura 41 - Disposição final das empresas dentro do parque. ........................................................ 
LISTA DE TABELAS

Tabela 1 - Espaço requerido por cada tecnologia... .88 


\section{LISTA DE QUADROS}

Quadro 1 - Explicação para o diagrama de relacionamento, (MUTHER, 1973) ..................................37

Quadro 2 - Fases e procedimentos do modelo de Tompkis et al. (2010)............................................44

Quadro 3 - Critérios para avaliação de layout, traduzido de Lin e Sharp (1999). ...............................46

Quadro 4 - Verificação e ações para cada dado de entrada. ..............................................................55

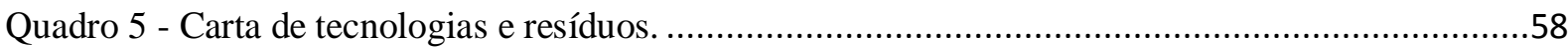

Quadro 6 - Carta De-Para com tecnologias e resíduos......................................................................59

Quadro 7 - Fluxos De e Para totais para cada tecnologia................................................................61

Quadro 8 - Intensidade de fluxo para cada par e classificação. .........................................................61

Quadro 9 - Tecnologias classificadas de acordo com a porcentagem de trocas. ..................................64

Quadro 10 - Exemplo da construção de um quadro dos elos.............................................................67

Quadro 11 - Quadro dos elos para o exemplo utilizado no decorrer desta pesquisa............................68

Quadro 12 - Ordem de diagramação de acordo com a classificação das trocas. .................................70

Quadro 13 - Classificação das trocas pela carta de interligações preferenciais e pelo número de

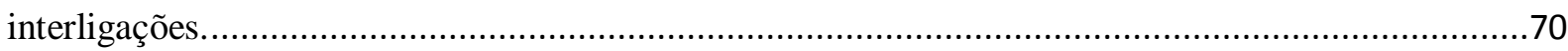

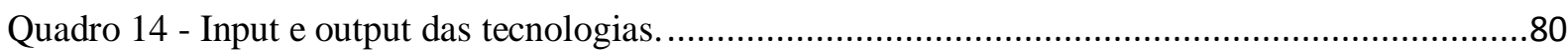

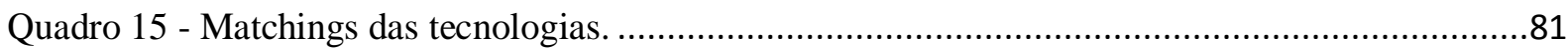

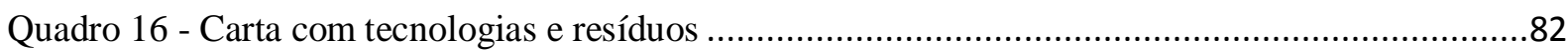

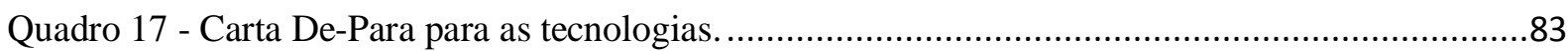

Quadro 18 - Classificação das tecnologias por intensidade de fluxo ..................................................83

Quadro 19 - Classificação das trocas segundo a intensidade de fluxo. ...............................................84

Quadro 20 - Classificação das tecnologias por número de trocas........................................................84

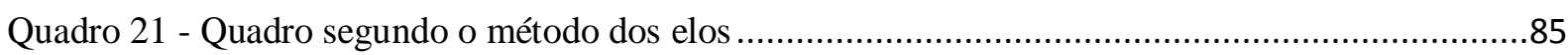

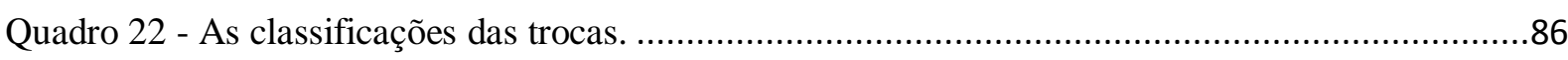

Quadro 23 - Classe dos resíduos, (FELÍCIO, 2013) ...............................................................113

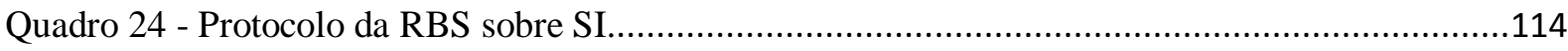

Quadro 25 - Formulário para cadastro dos dados de entrada. .........................................................116 


\section{LISTA DE ABREVIATURA E SIGLAS}

D1: Primeiro passo

D2: Segundo passo

D3: Terceiro passo

D4: Quarto passo

D5: Quinto passo

D6: Sexto passo

EI: Ecologia Industrial

EIP: Eco Industrial Parks

EPA: United States Environmental Protection Agency

PCSD: President's Council on Sustainable Development

RBS: Revisão Bibliográfica Sistemática

SI: Simbiose Industrial

SLP: Systematic Layout Planning

Tt: Total de trocas da unidade produtiva

UP: Unidade Produtiva 



\section{Sumário}

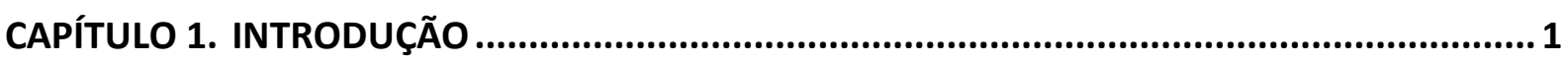

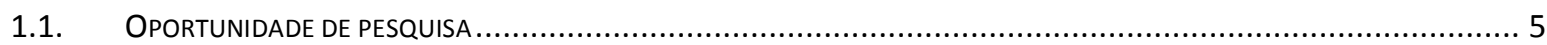

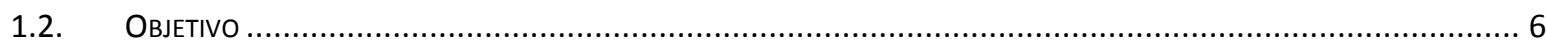

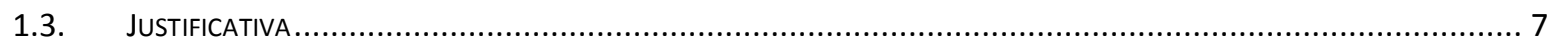

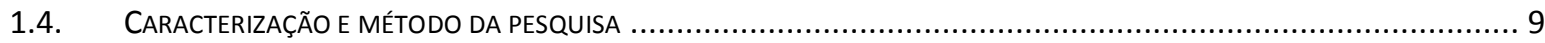

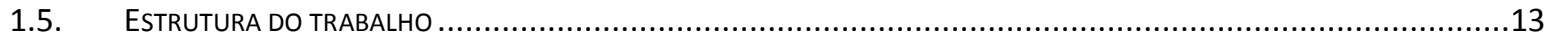

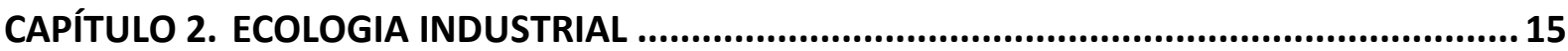

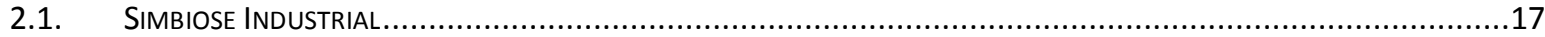

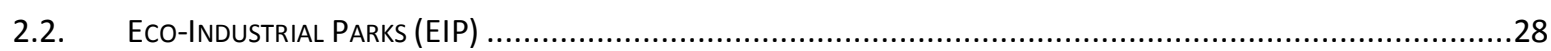

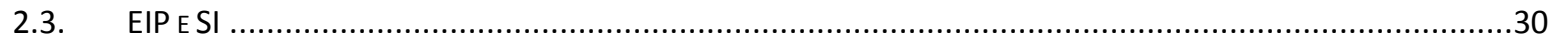

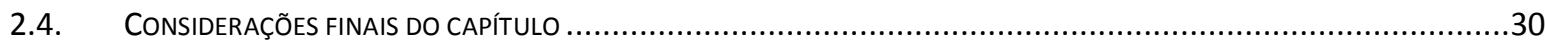

CAPÍTULO 3. LAYOUT - MODELOS E AVALIAÇÃO ........................................................ 33

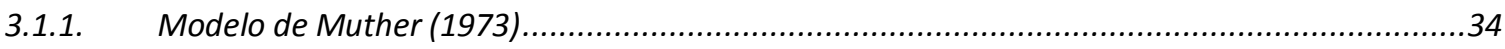

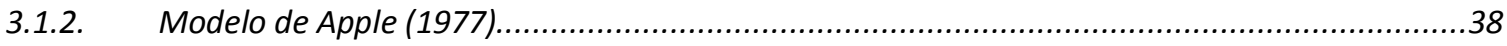

3.1.3. Modelo de Camarotto e Menegon (1996).................................................................40

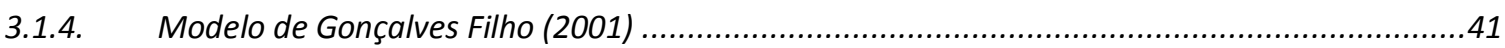

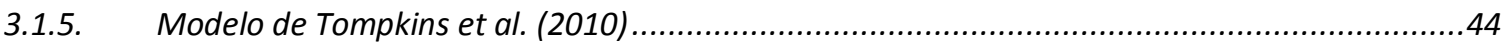

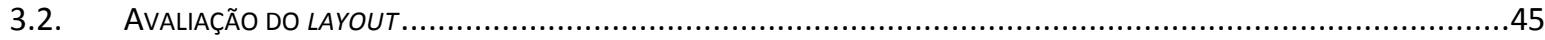

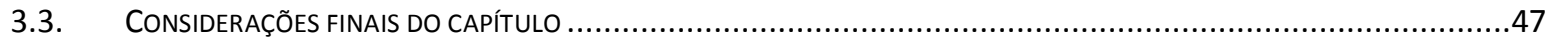

CAPÍTULO 4. ESTRUTURAÇÃO DO PROCEDIMENTO E SEUS PASSOS ................................ 49

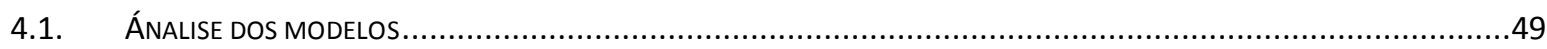

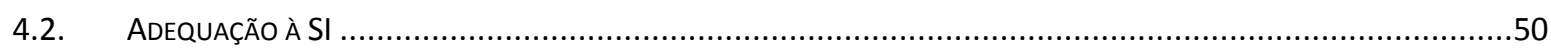

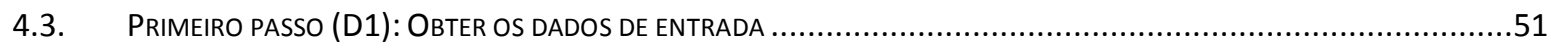

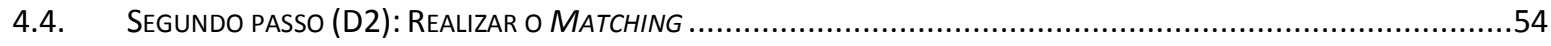

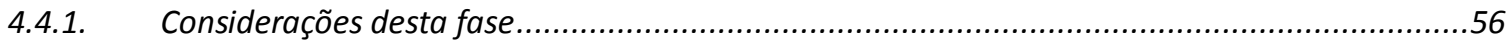

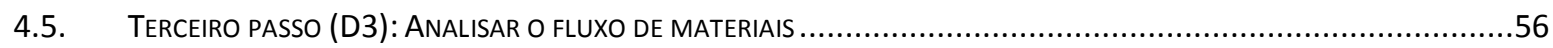

4.6. QUARTO PASSO (D4): ElABORAR A INTER-RELAÇÕES DAS UNIDADES PRODUTIVAS..........................................62

4.6.1. Classificação baseada no número de trocas simbióticas ..................................................63

4.6.2. Carta de inter-ligações preferenciais ....................................................................64

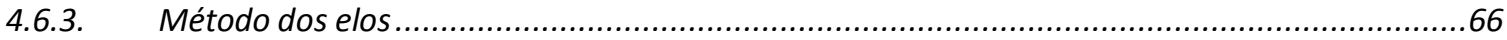

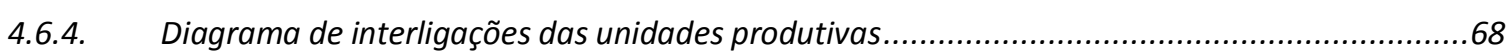

4.7. QUINTO PASSO (D5): ElABORAR A INTER-RELAÇÕES DAS UNIDADES PRODUTIVAS COM ESPAÇO .............................72 


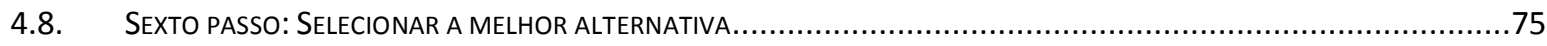

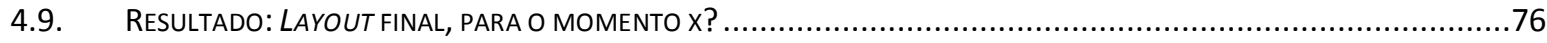

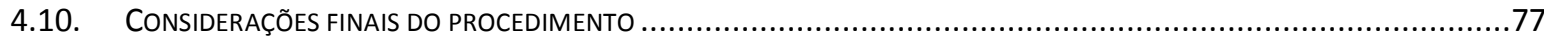

CAPÍTULO 5. APLICAÇÃO E DISCUSSÃO DO PROCEDIMENTO................................................ 79

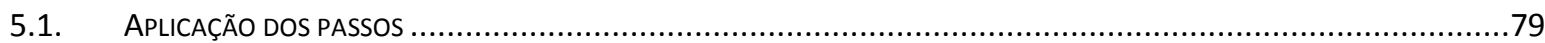

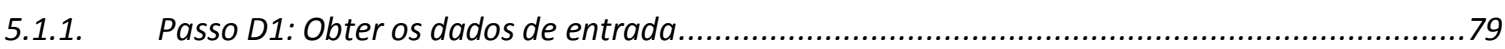

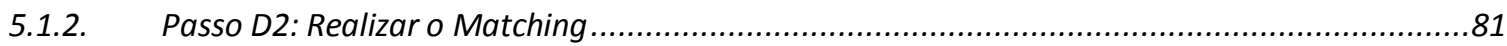

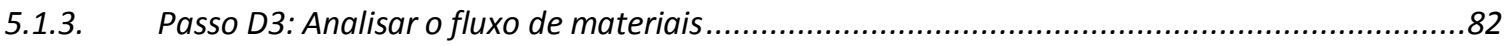

5.1.4. Passo D4: Elaborar as inter-relações das unidades produtivas ..........................................84

5.1.5. Passo D5: Elaborar a inter-relações das unidades produtivas com espaço..............................87

5.1.6. Passo D6: Selecionar a melhor alternativa..................................................................90

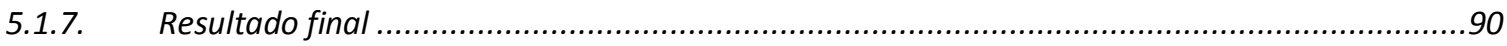

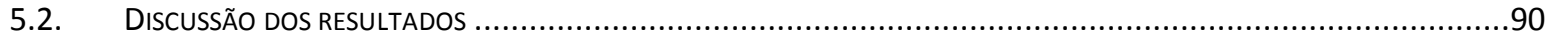

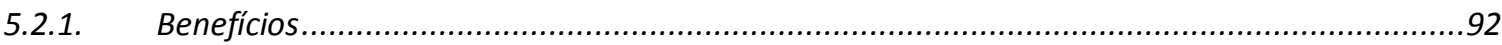

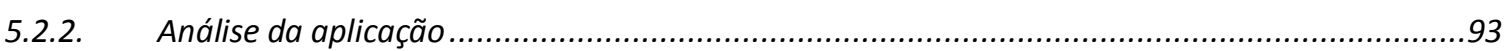

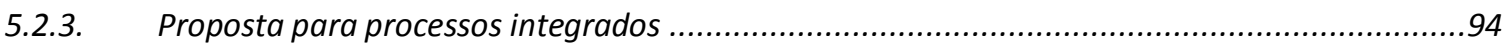

5.2.4. Considerando uma cadeia de suprimentos no sistema...............................................95

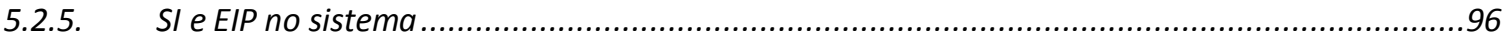

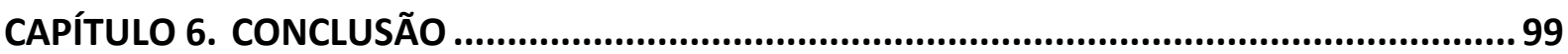

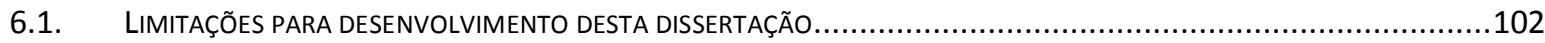

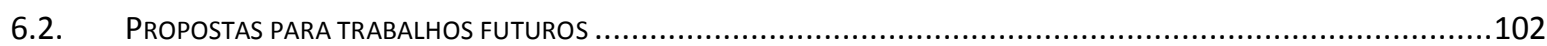

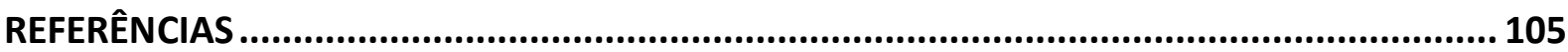




\section{Capítulo 1. INTRODUÇÃO}

A sociedade e a economia mundial estão mudando seus conceitos sobre os aspectos ligados a produção industrial, considerando aspectos ligados ao tema sustentabilidade. Desta forma, torna-se importante a adequação aos conceitos e práticas que reduzam impactos ambientais. Cada vez mais a academia, a mídia, o meio empresarial e outras esferas de discussão da sociedade mundial buscam mudanças no cenário atual que visem a redução dos índices de poluição, da utilização massiva de recursos naturais não-renováveis e da geração de resíduos.

Há uma forte preocupação com o meio ambiente por parte das pessoas ao redor do mundo que influencia diretamente no cenário empresarial atual (AMATO NETO, 2011). Assim, as organizações comprometem-se a atender as necessidades de hoje e garantir o atendimento de necessidades futuras, a partir de melhorias alinhadas com as exigências para um desenvolvimento sustentável, com utilização de fontes alternativas de energia, consumo responsável e conservação de recursos naturais e dos direitos humanos (MIRATA; EMTAIRAH, 2005).

Uma das soluções encontradas para obtenção de um desempenho mais sustentável para a sociedade e o planeta de acordo com os artigos pesquisados foi a Ecologia Industrial (EI). Allenby (2000) a define como sendo um conceito que integra sistemas de engenharia com princípios ecológicos, buscando redução de impactos ambientais com o uso efetivo de materiais, água e energia, com isso minimizando a geração de resíduos e reduzindo os impactos das atividades humanas no ecossistema.

Segundo Chertow (2000) surgiram dois conceitos importantes a partir da EI, sendo eles, a Simbiose Industrial (SI) e o Eco-industrial Park (EIP). Os dois conceitos são importantes para a adequação de empresas a um crescimento ambientalmente responsável, pois operam com a filosofia de redução de resíduos dispostos no planeta e minimização da poluição, com cooperação e integração entre organizações dentro de um ciclo de fluxo de materiais e informações fechado.

O conceito que será abordado nesta pesquisa é a SI, caracterizada como a troca de materiais, energia, água e subprodutos entre parceiros de negócios colaborativos para obter vantagem competitiva quando situados em locais próximos (CHERTOW, 2000). Implementala em um parque é algo necessário para obter uma produção ambientalmente mais responsável e obter ganhos ambientais. Segundo Sopha et al. (2010), pelo fato da SI ser considerada um 
processo complexo, ela precisa ser projetada e gerenciada, envolvendo engenharia e gestão, bem como ferramentas para suportá-la. O sucesso ou fracasso da SI depende de aspectos técnicos, econômicos, organizacionais, decisórios, dos processos, do "know-how", de cooperação e dos relacionamentos formados.

A simbiose acontece na natureza quando ocorre uma associação biológica entre seres vivos que permutam materiais, energia ou informações, conseguindo benefícios coletivos maiores que a soma dos benefícios individuais (STARLANDER, 2003). Portanto, conforme Chertow (2000), a SI pode ser entendida como uma metáfora de um ecossistema industrial que busca imitar um ecossistema natural, onde os recursos são utilizados de todas as formas possíveis dentro de um ciclo fechado.

A implementação do conceito de SI continua a evoluir, especialmente com o aumento do custo das matérias-primas devido à escassez de recursos naturais, bem como as restrições ambientais mais rigorosas que para Shi, Chertow e Song (2010), têm promovido esforços de pesquisa para a minimização dos custos de produção, a gestão de resíduos sólidos e a minimização do impacto ambiental.

O planejamento e projeto da SI favorece as trocas de recursos, o reuso de água e a cooperação, além de fortalecer os relacionamentos entre os elementos participantes dela (CHERTOW; EHRENFELD, 2012). Assim, é possível adicionar e remover trocas simbióticas, sempre buscando novas conexões e conseguir superá-las e alterá-las quando uma empresa passa por mudanças em seus processos ou acaba encerrando suas operações.

A SI é um conceito importante que consegue atingir vantagens competitivas e é extremamente benéfico para as empresas que adotam tal estratégia. Isso pode ser identificado e compreendido nos trabalhos de Shi, Chertow e Song (2010), Carr (1998), Zhang et al. (2013), Tudor, Adam e Bates (2007), Veiga e Magrini (2009), Golev, Corder e Giurco (2014), Zhu, Lowe e Barnes (2007), Yu, Jong e Dijkema (2014) e Gonela e Zhang (2014).

Para se conseguir eficiência no processo de desenvolvimento da SI, as empresas participantes precisam de um cenário adequado que favoreça a prospecção e evolução de trocas atuais e potenciais e o surgimento de relacionamentos, bem como o fortalecimento dos vínculos criados. Um fator importante para as organizações que aderem aos conceitos apresentados é a redução de custos e desperdícios, conseguidos através de trocas e compartilhamento de resíduos, cooperação, integração e ganhos obtidos por estarem localizadas próximas umas as outras.

Pode-se entender, então, que a localização é, portanto, uma questão chave no desenvolvimento eficiente da SI em qualquer sistema, pois ela é baseada nos fluxos dos 
materiais, energia e informações e, portanto, influencia diretamente no estabelecimento de relacionamentos, na integração e cooperação. Além disso, as distâncias percorridas em cada troca determinam os custos envolvidos e portanto a viabilidade dessa estratégia adotada.

Segundo a literatura estudada, pode-se dizer que a busca por eficiência e melhorias no transporte, distância percorrida e fluxos organizados para cada troca simbiótica, o planejamento do layout que procura minimizar os custos e favorecer o ciclo fechado perseguido pela SI, tem papel fundamental para estruturar o fluxo das trocas de materiais, energia e informações, bem como para obter redução de custos diretamente relacionados com a distância entre os elementos, ou seja, a localização dos elementos, tem-se a necessidade de projetar um layout adequado a esse sistema (YANG; FENG, 2008; MATTILA; PAKARINEN; SOKKA, 2010; JENSEN et al., 2011).

$\mathrm{Li}$ (2011) considera que a escolha do local e seu respectivo layout é um fator importante para se desenvolver uma economia circular, pois os participantes que realizam as trocas simbióticas devem estar próximos para assim favorecer a integração. Mattila, Pakarinen e Sokka (2010) defendem que trocas e cooperação são influenciadas diretamente pela proximidade geográfica num sistema de SI. Esta traz redução de poluentes no ar, menos extração de água e disposição desta, redução do uso de matéria prima, de resíduos e de impactos ambientais, além de aumentar a eficiência do uso de recursos.

O layout é um estudo sistemático que procura uma "combinação ótima" das instalações industriais que concorrem para a produção, dentro de um espaço disponível (OLIVÉRIO, 1985), ele estrutura o posicionamento físico e o fluxo dos recursos de transformação, determina a forma e aparência da produção (SLACK; CHAMBERS; JOHNSTON, 2008). Os fluxos são os caminhos que todos os recursos utilizam através da planta, por isso este deve ser mínimo (MEYERS; STEPHENS, 2000).

O layout dos elementos que compõe um sistema exerce um papel importante no seu desempenho, sendo um fator crítico de sucesso em busca da liderança de mercado e de produtividade. Desta forma, seu projeto deve ser conduzido de forma eficiente e eficaz. Layouts inadequados oneram o processo produtivo, a funcionalidade do sistema e trazem grandes perdas, tais como custo total alto, movimentações excessivas, estoques, defeitos e produtividade e qualidade baixas (SLACK; CHAMBERS; JOHNSTON, 2008).

Segundo Tompkins et al. (2010), 50\% dos custos operacionais das empresas por ele estudadas ocorrem com a movimentação dos materiais. Com isso, um layout bem planejado consegue diminuir ao menos de 10 a 30\% destes, pois é possível eliminar atividades desnecessárias e desperdícios, bem como aumentar a produtividade. 
Slack, Chambers e Johnston (2008), Olivério (1985), Muther (1978) e Apple (1977) apresentam algumas metas pretendidas com o planejamento adequado do layout: aumento do conforto e organização do trabalho, aumento da satisfação no trabalho, melhora do fluxo e consequente incremento à produção, balanceamento da produção, economia de espaço, redução de movimentações, melhora na utilização de recursos, redução de lead time e de custos indiretos, melhora da qualidade, aumento de flexibilidade.

Dessa forma, o planejamento de layout torna-se importante para dispor as empresas e seus recursos de forma a considerar ganhos em aspectos ambientais, pois direciona a eliminação dos desperdícios e facilita a integração e ligação das organizações participantes e o fluxo de materiais e de informações necessários para o melhor funcionamento do sistema.

Atualmente, como os aspectos ambientais estão sendo requisitados com mais frequência pelos clientes, questões mais rotineiras como segurança, estética e fluxo racional, devem ser considerados juntamente com um foco nas integrações com o ambiente de forma customizada e sustentável. A organização passa a adequar-se ao reuso de recursos e a eliminação de possíveis impactos ambientais, para isso desenvolve uma série de iniciativas no seu sistema produtivo, que envolve as pessoas, os equipamentos, os materiais e consequentemente o layout.

Portanto, um elemento que precisa ser considerado no planejamento de layout é o fator ambiental. Esta nova visão da relação ambiente-indústria cria a necessidade de novos estudos do layout para adequar a indústria ao meio ambiente em que está inserida para aproveitar ao máximo os recursos naturais utilizados e reduzir a disposição de materiais na natureza.

A adequação de um layout com conceitos que consideram e buscam melhorar o aspecto ambiental, pode resultar em economia para a empresa, através de menores custos com recursos e reaproveitamento de insumos e resíduos. Deste modo é provável que se consiga bons resultados com as organizações, não só conscientizando-as da necessidade, mas também informando-as das vantagens competitivas a médio e longo prazo que tal posicionamento em relação ao meio ambiente acarretará as indústrias (STARLANDER, 2003; CHERTOW, 2004)

O planejamento de layout para qualquer contexto, deve ser bem planejado, analisado e implantado devido sua participação nos resultados da organização (CAMAROTTO e MENEGON, 2006). Desta forma, é possível adequar algumas ideias e fases para favorecer o desenvolvimento da SI.

Para considerar aspectos de SI em um sistema de empresas, mais especificamente num parque, observa-se que é extremamente importante a otimização do fluxo de materiais, informação e de energia como estratégia na transição de um desenvolvimento não sustentável para um sustentável (YANG; FENG, 2008). Esses fluxos são influenciados de acordo com 
layout das empresas participantes da SI, onde as distâncias estabelecem as reais necessidades de transporte, controle, frequência de entrega e fornecimento e o volume movimentado.

O projeto de layout realizado com princípios de ecologia industrial, considerando a SI, objetiva a redução de impactos ambientais, de resíduos que saem do sistema para o meio ambiente, de desperdícios e de poluição e a eficiência de fluxos de materiais, água, energia e informação. Portanto, segundo Tompkins et al. (2010) o projeto de layout traz bons resultados quando faz parte do planejamento das empresas e principalmente em se tratando de empresas dentro de um parque industrial, para obter sucesso e desenvolvimento econômico, social e ambiental de forma sustentável.

O sistema a ser analisado é composto por elementos que possuam inputs e outputs, ou seja que tenham possibilidade de realizar a SI, onde o arranjo físico considera as empresas, centro de tratamento, centro de coleta, entre outros elementos dentro das limitações de um parque, onde essas necessitam de um local apropriado, espaço físico ideal, energia, água, locais para entrada e saída de materiais e para trocas de resíduos com os demais membros pertencentes ao parque e participantes da SI.

O arranjo físico "ideal" deve, portanto, obter um posicionamento que contemple as necessidades físicas de cada empresa, suas restrições e que principalmente promova trocas, compartilhamentos e integração entre os membros participantes da SI. Com isso, os benefícios citados anteriormente poderão melhorar o desempenho geral, a eficiência dos relacionamentos, o desenvolvimento da SI e o sucesso dos objetivos definidos pelas organizações participantes.

Com o intuito de integrar conceitos de planejamento de layout presente na literatura estudada para buscar o desenvolvimento do conceito de SI em um parque industrial, com consideração de questões ambientais, encontrou-se a oportunidade de pesquisa descrita a seguir.

\subsection{Oportunidade de pesquisa}

Os modelos de planejamento de layout começaram a ter repercussão com Muther em 1973 e até os dias atuais continuam a ser estudados e implementados para melhorar sistemas e adequá-los aos requisitos dos clientes atuais, para assim satisfazê-los. Outros modelos para planejamento e projeto de layout surgiram e obtiveram importância acadêmica: Apple (1977), Tompkins (2010), Gonçalves Filho (2001), Olivério (1985), Camarotto e Menegon (1996) e Meyers e Stephens (2000), porém apenas os modelos considerados convenientes a esta pesquisa foram estudados neste trabalho. 
Com o surgimento da SI, identificou-se a necessidade de estipular a melhor disposição das indústrias para que troquem recursos e integrem saídas e entradas das atividades de cada participante, buscando atingir estratégias atuais de mercado com foco na redução de impactos ambientais. Portanto, um procedimento para construir um layout geral que considere aspectos ambientais, especificamente a SI, deve ser desenvolvido para o correto planejamento e projeto de um sistema onde exista diferentes organizações, a integração e cooperação entre elas, com foco principal na preservação do ecossistema e redução de poluição.

$\mathrm{Na}$ literatura pesquisada para desenvolvimento deste trabalho não foi encontrado um modelo, que considerasse a SI e a relação entre os membros participantes desta, bem como os diferentes fluxos que ocorreriam entre eles para ampliar o compartilhamento de recursos produtivos na definição do layout geral.

Os modelos analisados neste trabalho por terem destaque na literatura, podem considerar aspectos da SI para assim conseguir desenvolver parques com maior consideração às questões ambientais, sociais e econômicas entre os participantes deste.

Com isso, ao analisar a literatura encontrada de SI e layout, e com a oportunidade de pesquisa identificada neste tópico tem-se o objetivo descrito a seguir.

\subsection{Objetivo}

Esta dissertação tem por objetivo propor um procedimento composto por passos a partir de análises e adaptações de modelos tradicionais relacionados ao tema layout geral para estruturar o planejamento do layout geral de unidades produtivas que sejam participantes da SI dentro de um sistema com limites definidos.

Esses passos buscam obter a disposição física das unidades em um parque industrial que otimize os fluxos das trocas simbióticas.

Tendo em vista o alcance desse objetivo geral, foram definidos alguns objetivos específicos para esta dissertação:

- Identificar e analisar através de um levantamento bibliográfico, os modelos de planejamento de layout;

- Realizar uma RBS para o tema SI;

- Propor um procedimento com passos para planejamento do layout considerando a SI entre as unidades de um sistema com limites definidos;

- Aplicar o procedimento com dados de empresas e de um parque real. 
O objetivo descrito é justificado por buscar eficiência em sistemas com unidades que realizem a SI, a partir do planejamento de layout dessas, buscando facilitar a utilização e desenvolvimento das trocas simbióticas, como descrito no tópico seguinte.

\subsection{Justificativa}

O conceito de ecologia industrial está se tornando cada vez mais importante no meio empresarial e acadêmico. Allenby (2000), Chertow (2004), Frosh e Gallopoulos (1989), O’Rourke, Connelly e Koshland (1996) atentam para a crescente preocupação para adequação de sistemas produtivos a fim de realizar um ciclo fechado de fluxo, reduzindo perdas e saídas dos processos para aumentar a eficiência ambiental, econômica e social das empresas.

Dentro da EI encontra-se o conceito de SI, que é um novo método que está sendo utilizado ao redor do globo (KOENIG, 2005). Seu desenvolvimento começa a merecer maior atenção pois alguns parques industriais que a utilizam começaram a falhar, não obtiveram êxito, foram fechados ou mudaram de estratégia de acordo com Chertow (2007), pois foram erroneamente projetados ou fracamente estabelecidos. Torna-se necessário voltar a atenção a um fator que influencia diretamente no desenvolvimento da SI, a localização dos seus participantes onde busca-se a proximidade geográfica ideal.

Jensen et al. (2011) fala sobre a proximidade geográfica como sendo uma característica chave para reuso e reciclagem de recursos dentro da SI. Ela é muito importante em relação ao planejamento e facilitação ativa da troca de subprodutos, na facilitação de sinergia de informações, nas características e necessidade de movimentações dos recursos e na facilidade de determinar as distancias envolvidas nas trocas. Os autores falam ainda em influências na movimentação de recursos: dificuldades logísticas, valor econômico, distancia mental (confiança) e conhecimento do local.

Pesquisas tem demonstrado o sucesso de empresas co-localizadas ou localizadas próximas, operando com transferências diretas de materiais residuais (CHERTOW, 2000; DESCHENES; CHERTOW, 2004). Em empresas próximas umas das outras, o potencial para desenvolver novos links de SI com melhorias ambientais e ganhos econômicos certamente existe (CHERTOW, 2004; YANG; LAY, 2004).

Shi, Chertow e Song (2010) observaram que de todas as trocas simbióticas ocorridas no parque estudado por eles, cerca de $76 \%$ eram de materiais e a distância média encontrada entre os participantes da SI era de 28 quilômetros. Esses dados comprovam a necessidade de planejar 
a distância média das organizações dentro do sistema, de modo a propiciar trocas de materiais mais efetivas.

Hiete, Ludwig e Schultmann (2012) afirmam que o processo de geração de energia em conjunto auxiliado pela SI possui dificuldades no uso integrado da energia por questões de distâncias, faltando gerenciamento e manutenção em caso específicos, cooperação e confiança. Para obter sucesso com a SI o sistema deve possuir uma estrutura macia e passível de alterações (flexível), custos baixos, cooperação e confiança.

Roberts (2004) difunde que localização leva ao desenvolvimento de novas sinergias e ganhos em eficiência, com fortes perspectivas para adicionar valor a cada firma e ao negócio coletivo, favorecendo a troca de empresas próximas e assim mais empresas poderão participar deste sistema.

Ainda para o mesmo autor, o sistema deve ser flexível, responsivo a mudanças em tecnologias e materiais, e prover incentivos para integração no processo de desenvolvimento, com um desenvolvimento industrial misto (com áreas comuns, natureza, considerando também o que cada empresa precisa e sua influência no sistema todo), serviços e manufaturas colocalizadas para aumentar a SI e melhorar a gestão, trazendo competitividade e adicionando valor.

Na pesquisa de Lyons (2007) um dos pontos para trabalho futuro é o de que mais estudos devem ser feitos em custos de transporte, economia de escala e localização. As características de fluxos input-output são apenas o começo para entender a conexão entre empresas. Os relacionamentos lucrativos encontrados por ele em SI ocorrem num contexto de fluxo de informações entre empresas que inclui elementos de ambiente de negócio local e natureza sociocultural.

A disposição física das organizações dentro um sistema com limites definidos estabelece de forma direta o caminho a ser percorrido pelos recursos, resíduos e informações, define onde ocorre as entradas e saídas de cada membro do parque, os caminhos que as saídas de um processo percorreram para serem entradas em outro processo de outra empresa, o quanto de transporte será utilizado, os custos para realizar os relacionamentos e trocas entre membros e as movimentações necessárias para que a SI ocorra. Enfim os esforços necessários para que as unidades desenvolvam integração, cooperação e compartilhamento.

As unidades que participam da SI necessitam entender os resíduos gerados e buscar a melhor forma de reutilizá-los. É importante compreender quais são eles, a quantidade produzida e principalmente o como eles serão transportados da unidade de origem até a destinação final, com o menor custo ao respeitar as possíveis restrições que podem surgir. 
Portanto, para que o processo de SI obtenha sucesso e eficiência nos seus resultados é preciso planejar um layout que suporte e facilite a busca pelos objetivos ambientais, econômicos e sociais. É através do layout que as organizações participantes da SI conseguirão estabelecer relacionamentos de forma favorável a custos mais baixos, com a eliminação de desperdícios e a conquista de benefícios mútuos.

Desta forma, este trabalho apresenta seu método no próximo tópico, onde os procedimentos realizados para desenvolvimento desta pesquisa são detalhados.

\subsection{Caracterização e método da pesquisa}

Este trabalho foi desenvolvido com os seguintes procedimentos metodológicos de pesquisa: revisão bibliográfica, revisão bibliográfica sistemática, análise teórica conceitual para proposição do procedimento com seus passos e a aplicação deste.

Esta pesquisa baseou-se na metodologia explicada por Martins (2010), a qual parte de um problema ou oportunidade de melhoria, coleta informações gerais deste, para assim criar um foco para concentração de esforços e recursos, procura entender o estado-da-arte, realiza um estudo teórico conceitual e assim solucionar o problema com a elaboração de passos neste caso em particular.

Para Martins (2010) um estudo pode ser quantitativo ou qualitativo. A abordagem quantitativa é o ato de mensurar variáveis de pesquisa, aqui testa-se hipóteses e preocupa-se com a mensurabilidade que é um conjunto de variáveis mensuráveis para testar hipóteses, causalidade que é o fato de explicar as coisas com causas e efeitos, generalização onde os resultados obtidos podem ou não ser usados além da pesquisa e replicação que é a possibilidade de repetir a pesquisa e encontrar os resultados requeridos.

$\mathrm{Na}$ abordagem qualitativa, ainda segundo Martins (2010), realiza-se observações, coleta-se evidências e considera-se a realidade subjetiva dos indivíduos envolvidos. Tem como características principais a ênfase na interpretação subjetiva dos indivíduos, o delineamento do contexto do ambiente de pesquisa, múltiplas fontes de evidências, importância da concepção da realidade organizacional e proximidade com o fenômeno estudado.

Essa pesquisa procurou criar passos, que compõe uma série de procedimentos que devem ser desenvolvidos para atingir o objetivo proposto. Elas foram baseadas na revisão bibliográfica realizada e na Revisão Bibliográfica Sistemática (RBS), e surgem através de uma análise teórica conceitual dos artigos encontrados na literatura específica utilizada. Segundo 
Fleury (2010), esse procedimento dá forma ao pensamento, estabelece sistemas de significados e cria padrões familiares que permitem a manipulação e trabalho. Por fim, pode-se considerar que os passos deste trabalho são um guia para conseguir obter os resultados esperados e uma estrutura construída para atingir o objetivo em questão.

A base deste estudo parte de uma revisão teórica que, segundo Silva e Menezes (2005), levanta e analisa o que foi publicado sobre o tema de pesquisa e assim explica o assunto com várias teorias, obtendo informações atuais e opiniões sobre o problema proposto. Esta foi realizada para identificar modelos de planejamento de layout e as principais referências em SI.

Para obtenção de maior detalhe sobre o conceito realizou-se uma RBS para o tema SI. Desta forma, foi possível encontrar benefícios e características que compõe este conceito. $\mathrm{O}$ desenvolvimento desta fase resultou em inputs para a proposição de passos que facilitassem o desenvolvimento e desempenho da SI. Esta revisão, porém, não retornou nenhum estudo que relacionasse os dois temas discutidos neste trabalho: layout e SI.

Através da revisão bibliográfica e da RBS foi possível propor passos por uma análise teórica conceitual para planejamento do layout favorecendo a aplicação da SI. Esses passos foram então aplicadas em um estudo de caso para posterior análise e discussão dos resultados. Esses procedimentos descritos anteriormente estão estruturados na Figura 1 a seguir.

Para conclusão do estudo utilizou-se de uma aplicação com dados reais de empresas, que conforme Miguel (2010), com isso pode-se investigar um fenômeno atual num contexto onde tem-se a possibilidade de desenvolver novas teorias e aumentar o entendimento sobre os eventos. Nesta pesquisa a aplicação desenvolvida do procedimento é um ponto essencial para obter um exemplo teórico de uso para obter e analisar possíveis resultados.

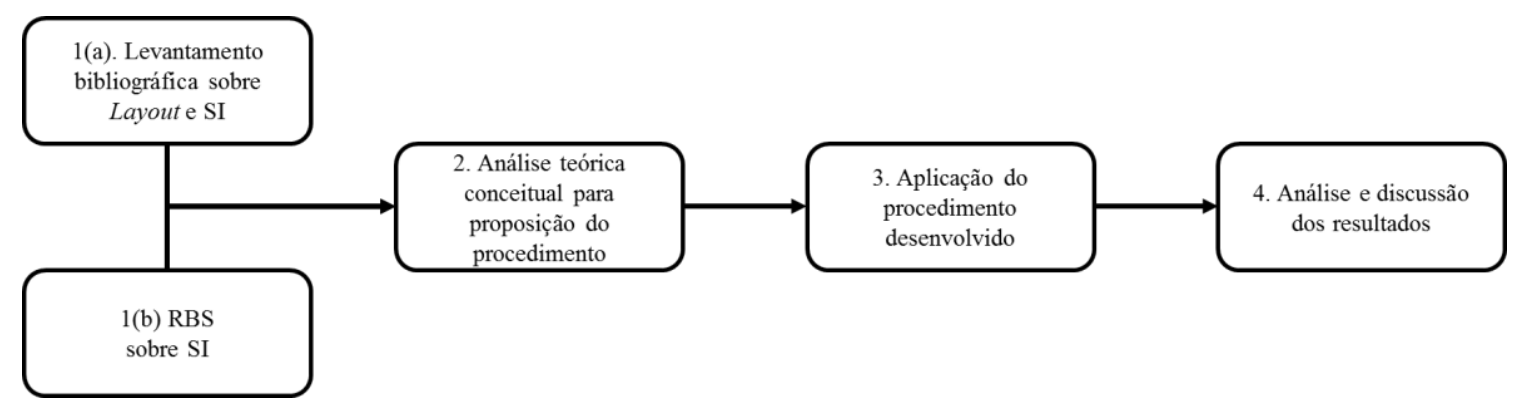

Figura 1 - Metodologia utilizada na pesquisa.

A primeira fase 1(a), chamada de levantamento bibliográfico sobre layout e SI, verificou este tema pertinente a esta pesquisa na literatura, buscando uma estrutura teórica de modelos que auxiliassem na construção dos passos. Procurou-se artigos que mostrassem modelos de planejamento e projeto de layout para sustentar a proposta e possibilitar a conclusão do objetivo 
desta pesquisa. Os modelos mais pertinentes e que tenham maior impacto na literatura foram selecionados para a conclusão desta fase e elaboração da pesquisa em si. O principal trabalho selecionado nesta etapa foi o de Muther (1973), e os auxiliares foram o de Camarotto e Menegon (1996), Apple (1977) e Gonçalves Filho (2001). Nesta mesma etapa definiu-se a SI e identificou-se os trabalhos mais importantes a respeito deste tema, para dar base a RBS a ser realizada na etapa seguinte, sendo estes os de Chertow (2000, 2004 e 2007).

Na 1(b) tem-se a RBS sobre SI, foi realizada uma revisão bibliográfica sistemática seguindo a metodologia de Biolchini et al. (2005). Considerada uma avaliação rigorosa e confiável de pesquisas dentro de um tema, ela funciona como um instrumento para mapear e gerar uma síntese dos trabalhos publicados.

Para isso desenvolveu-se um protocolo de revisão bibliográfica sistemática (Apêndice A), no qual consta a formulação da questão e a seleção dos estudos referentes a esta revisão.

O modelo considerado para a realização da RBS está dividido em três etapas: planejamento, execução e análise dos resultados. Na etapa de planejamento identifica-se a necessidade da revisão e desenvolve-se o protocolo, na execução realiza-se as atividades de busca, seleção e qualificação das pesquisas para posterior extração de informações consideradas relevantes e por fim, na fase de análise, atende-se o propósito da revisão e as informações importantes são apresentadas e utilizadas no estudo.

Foram selecionados os artigos que continham informações a respeito do tema SI, esses estão citados no capítulo 2 de revisão bibliográfica sobre ecologia industrial e no decorrer do trabalho. A busca por artigos que contemplassem os dois temas considerados nesta pesquisa, a SI e o planejamento de layout, seguindo os critérios definidos na fase de planejamento deste procedimento utilizado não obteve resultados.

O período considerado foi de vinte anos, com foco nos estudos mais recentes. Dentro desse período foram pesquisados artigos em duas bases de dados com acesso disponível, a SCOPUS e a Web of Knowledge. Foram encontrados mais de 700 artigos, porém estes foram filtrados através da leitura e análise do resumo, introdução e conclusão de cada um, além de eliminar os que apareciam em ambas as bases, além de que, nem todos os artigos estavam disponíveis para consulta e leitura.

No final restaram apenas 105 artigos, dos quais 73 foram utilizados nesta pesquisa, por serem considerados mais importantes no meio acadêmico de acordo com o número de citações e por contribuir com características da SI, benefícios obtidos com a aplicação dela e ferramentas que foram utilizadas juntamente com esta. 
Na fase 2 de análise teórica conceitual para proposição do procedimento e dos passos que o compõe. Primeiro analisou-se os trabalhos encontrados sobre layout e sobre SI e assim entendeu-se quais os fatores e características que deveriam conter no planejamento do layout para facilitar e desenvolver a SI e qual o modelo que melhor serviria como base a proposição dos passos. Depois foi desenvolvido o procedimento com os passos que colocavam características da SI nas fases dos modelos de planejamento do layout, principalmente de acordo com o modelo SLP do Muther (1973). São procedimentos baseados nos dois conceitos para favorecer a proximidade e disposição física das unidades participantes da SI dentro de um espaço definido. Os passos foram estruturados em um fluxograma para melhor organização e sequência quando utilizadas no planejamento.

O Quadro 1 contém as informações coletadas no tema SI e no tema de modelos de planejamento de layout, que juntas foram consideradas no desenvolvimento de cada passo deste procedimento.

Quadro 1 - Dados utilizados de cada tema para composição dos passos

\begin{tabular}{|c|c|c|}
\hline Simbiose Industrial & Modelos de layout & Passos \\
\hline $\begin{array}{l}\text { Levantamento dos resíduos ou } \\
\text { subprodutos, caracterização e } \\
\text { análise destes }\end{array}$ & $\begin{array}{l}\text { Fase de preparação de } \\
\text { Gonçalves Filho (2001); } \\
\text { Obtenção dos dados: produto, } \\
\text { quantidade, roteiro, serviços de } \\
\text { suporte e tempo, segundo } \\
\text { Muther (1973); Passo } 1 \text { do } \\
\text { modelo de Apple (1977) }\end{array}$ & $\begin{array}{l}\text { Passo 1: Obter os dados de } \\
\text { entrada }\end{array}$ \\
\hline $\begin{array}{l}\text { Realização do input/output } \\
\text { correspondentes }\end{array}$ & Análise dos dados de entrada & Passo 2: Realizar o Matching \\
\hline $\begin{array}{l}\text { Análise dos relacionamentos } \\
\text { criados pelo Passo } 2\end{array}$ & $\begin{array}{l}\text { Etapas } 1 \text { e } 2 \text { do modelo SLP de } \\
\text { Muther (1973); Passos } 4 \text { e } 5 \text { do } \\
\text { modelo de Apple (1977); Fase de } \\
\text { projeto de Gonçalves Filho } \\
(2001)\end{array}$ & $\begin{array}{l}\text { Passo 3: Analisar o fluxo de } \\
\text { materiais }\end{array}$ \\
\hline \multirow[t]{3}{*}{$\begin{array}{lrr}\begin{array}{l}\text { Desenvolvimento } \\
\text { relacionamentos }\end{array} & \text { criados } & \text { no } \\
\text { Passo 2 } & & \\
\end{array}$} & $\begin{array}{l}\text { Etapa } 3 \text { do modelo SLP de } \\
\text { Muther (1973); Passo } 10 \text { do } \\
\text { modelo de Apple (1977) }\end{array}$ & $\begin{array}{l}\text { Passo 4: Elaborar as inter- } \\
\text { relações das tecnologias }\end{array}$ \\
\hline & $\begin{array}{l}\text { Etapas 4, } 5 \text { e } 6 \text { do modelo SLP } \\
\text { de Muther (1973); Passo } 13 \text { do } \\
\text { modelo de Apple (1977) }\end{array}$ & $\begin{array}{l}\text { Passo 5: Elaborar as inter- } \\
\text { relações das tecnologias com } \\
\text { espaço }\end{array}$ \\
\hline & $\begin{array}{l}\text { Etapas } 7,8 \text { e } 9 \text { do modelo SLP } \\
\text { de Muther (1973) }\end{array}$ & $\begin{array}{l}\text { Passo 6: Selecionar a melhor } \\
\text { alternativa }\end{array}$ \\
\hline
\end{tabular}

A fase 3 é quando ocorre a aplicação teórica do uso do procedimento, baseado em dados coletados em empresas reais, porém que não participam de um parque e não fazem parte de SI. Coletou-se todos os resíduos gerados pelas unidades, os materiais que elas utilizam e as respectivas quantidades. Para ilustrar o local foi utilizado o espaço de um parque industrial situado no interior do estado de São Paulo, bem como seus terrenos e quadras. 
$\mathrm{Na}$ última fase ocorre a análise e discussão dos dados obtidos e dos resultados conseguidos através da aplicação dos passos desenvolvidos na fase 2 para o estudo de caso em questão. Esses resultados servem para mostrar a aplicabilidade dos passos e tirar conclusões para esta pesquisa e a possibilidade da realização de trabalhos futuros.

\subsection{Estrutura do trabalho}

A estrutura e organização desta dissertação é definida da seguinte forma:

- Capítulo 1 - Introdução: apresenta o tema a ser abordado nesta dissertação, objetivo, justificativa, oportunidade de pesquisa, caracterização e método do trabalho

- Capítulos 2 e 3 - Referencial teórico do trabalho: reportam a pesquisa bibliográfica e a RBS realizada neste trabalho e constituem o embasamento teórico dos estudos feitos, considerando os principais temas envolvidos no trabalho - Layout e EI com a SI.

- Capítulo 4 - Estruturação do procedimento e seus passos: desenvolvimento do procedimento para planejamento de layout com aspectos de SI, através dos passos que o compõe e levam ao resultado final.

- Capítulo 5 - Aplicação e discussão do procedimento: exemplo teórico dos passos.

- Capítulo 6 - Conclusão: Conclusões alcançadas com a realização do trabalho, entre outras considerações para seu total entendimento.

- Referências - Apresenta as obras consultadas para desenvolvimento da dissertação. 


\section{Capítulo 2. ECOLOGIA INDUSTRIAL}

Para Allenby (2000), EI é o estudo de sistemas industriais e econômicos e suas conexões com sistemas naturais fundamentais. Esta apresenta uma visão sistemática, abordando a interação entre operações de sistemas humanos e ambientais, buscando um desenvolvimento sustentável. Chertow (2004) complementa que ela estuda o fluxo de materiais e energia e seus efeitos no ambiente, e a influência de aspectos econômicos, políticos, regulatórios e sociais no fluxo, uso e transformação de recursos.

O sistema tradicional, onde cada empresa adquiria matéria prima, vendia produtos acabados e descartava resíduos altera-se para um sistema onde estes são tratados e reutilizados e as organizações operam de forma integrada, onde o consumo de energia e de material é melhorado, a geração de resíduo é minimizada e efluentes de um processo servem como matéria-prima para outro. O objetivo é ter um sistema com reaproveitamento ao máximo, numa visão de ciclo fechado (FROSH; GALLOPOULOS, 1989), abordagem que pode ser vista na Figura 2.

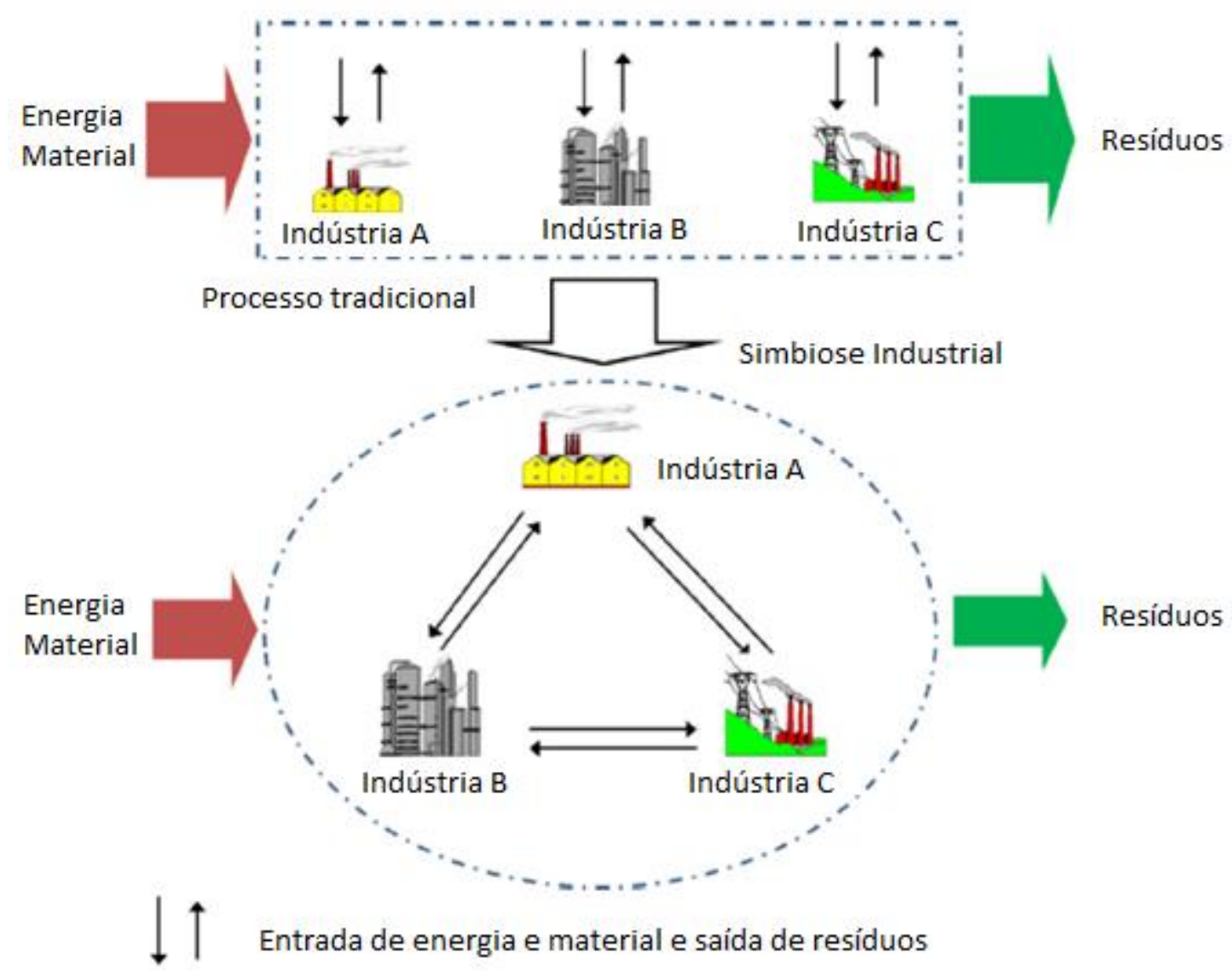

Figura 2 - Fluxos industriais, cíclico e linear. Fonte: Baseado em Frosh e Gallopoulos (1989). 
Para Pereira, Lima e Rutkowski (2007) a EI fala em alterar os processos lineares de produção para processos cíclicos, ter visão sistêmica, reorientação do processo industrial, estudo do fluxo e eficiência produtiva.

Segundo O'Rourke, Connelly e Koshland (1996) o sistema industrial deve ser similar ao natural e tornar-se fechado, aproveitando os resíduos e energias. Os principais objetivos são: Reduzir emissões e desperdícios; Aumentar a eficiência dos recursos; Fechamento dos ciclos dos materiais; Aumentar o uso de materiais e energia renováveis.

De acordo com Chertow (2000) a EI permite atribuir o foco em três níveis, na indústria, entre empresas e regional ou global, o que está ilustrado na Figura 3.

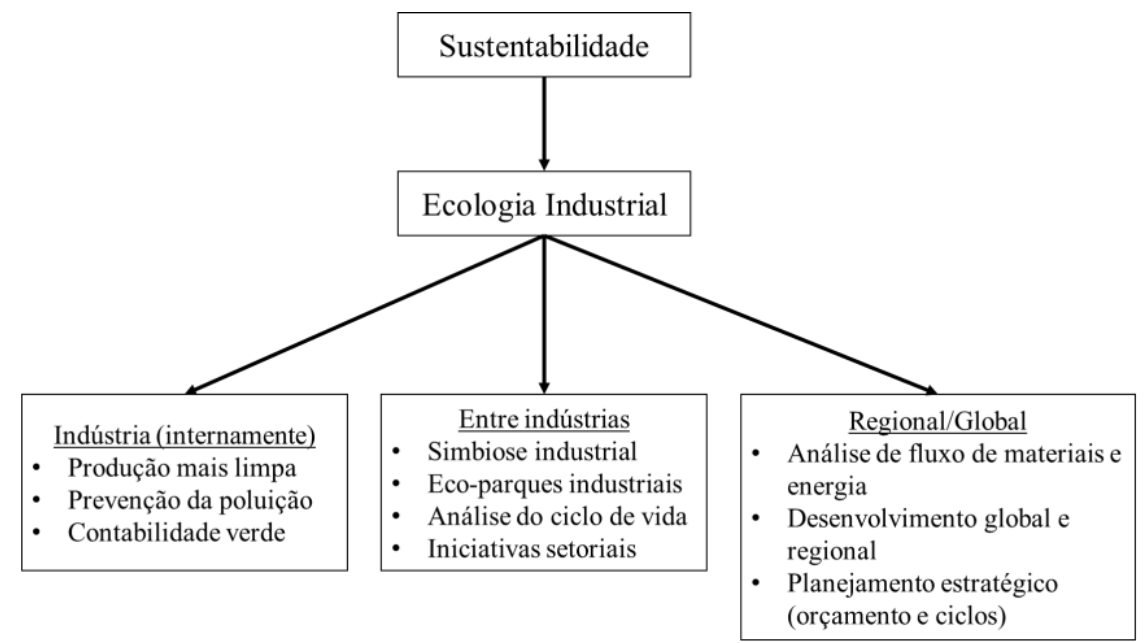

Figura 3 - Os três níveis da ecologia industrial.

Fonte: Traduzido de Chertow (2000).

Para tal, Chertow (2000) e Lowe (2001) sugerem que alguns instrumentos sejam utilizados para que seja possível o desenvolvimento da Ecologia Industrial, dentre os quais se destacam como fundamentais são a SI e Eco Parque Industrial pois segundo Felicio (2013) integram harmonicamente a visão de ciclo fechado num ecossistema industrial.

Lowe (2001) e Tibbs (1992) citam alguns princípios de EI:

- Conectar firmas individuais em ecossistemas industriais;

- Loops fechados através de reuso e reciclagem;

- Aumentar eficiência na utilização de materiais e energia;

- Minimizar geração de resíduos;

- Definir os resíduos potenciais para outras empresas;

- Balancear entradas e saídas para adequar a capacidade de um ecossistema natural;

- Evitar e minimizar a criação e transporte de materiais perigosos e tóxicos; 
- Projetar processos para reduzir o uso de energia;

- Fazer mais com menos;

- Alinhar a política com a perspectiva de evolução de longo prazo;

- Projetar o Sistema industrial com consciência das necessidades sociais e econômicas de comunidades locais;

- Otimizar o negócio local e o desenvolvimento de oportunidades de emprego;

Dentro do conceito de ecologia industrial foi encontrado o principal tema utilizado nesta pesquisa que é a SI e o conceito de EIP que pode influenciar no desenvolvimento dos passos para planejamento de layout com SI.

\subsection{Simbiose Industrial}

O aumento de geração de resíduos e escassez de recursos naturais levou ao desenvolvimento de estratégias para fechar o loop do fluxo de materiais, entre elas a SI ganha destaque pois retorna recursos e resíduos para o processo produtivo novamente (LYONS, 2007).

Parte da ecologia industrial que estuda os fluxos de um sistema com uma abordagem coletiva, buscando colaboração e possibilidades sinérgicas conseguidas por proximidades, para se conseguir vantagem competitiva e desenvolvimento sustentável (CHERTOW, 2004)

O termo simbiose vem do relacionamento biológico simbiótico existente na natureza onde dois ou mais seres vivos de espécies diferentes e não-relacionadas possuem uma associação benéfica na forma de troca de materiais, energia ou informações, onde a soma dos esforços coletivos supera a soma dos esforços individuais (CHERTOW, 2000; TAMIOTO, 2004). Um exemplo encontrado na natureza ocorre entre algas e fungos, onde os fungos mantinham e protegiam as células das algas produziam nutrientes para os fungos por meio da fotossíntese, formando-se assim um ciclo fechado.

Chertow (2000, p. 313) a define como "uma abordagem coletiva de indústrias separadas para obter vantagem competitiva envolvendo trocas físicas de materiais, energia, água, onde a colaboração e possibilidades sinérgicas obtidas pela proximidade geográfica são a chave para a simbiose industrial". Chertow (2004) complementa que a soma dos benefícios conseguidos coletivamente é maior do que os conquistados individualmente, com isso criando valores sociais que podem atingir toda a vizinhança. 
Lombardi e Laybourn (2012, p. 31) propõem uma outra definição baseada em Chertow (2000):

[...] SI engaja diversas organizações em uma rede para estimular eco inovação e uma cultura de mudança de longo prazo. Criando e compartilhando conhecimento através da rede, produz transações mutuamente rentáveis para novos fornecimentos dos inputs requeridos, destinações que agregam valor para saídas de não-produtos, e negócios melhores e processos técnicos.

SI possui como elementos de associação as empresas e suas operações, onde os resíduos gerados nos processos são aproveitados por outras empresas a fim de usar eficientemente os recursos, formando um ciclo fechado onde os desperdícios são aproveitados ao máximo em detrimento de um desenvolvimento econômico, sustentável e social auxiliando o meio ambiente (CHERTOW; ASHTON; ESPINOSA, 2008).

Ashton (2008) diz que as empresas podem compartilhar serviços, como transporte e coleta de resíduos, e compartilhar a gestão de certas utilidades, como no caso de energia e do tratamento de água. SI pode envolver ainda o compartilhamento de vapor, manufatura, logística e conhecimento (know-how) (JENSEN et al., 2011).

Chertow (2004) define uma taxonomia para tipos de trocas de materiais para considerar elementos espaciais e organizacionais, foram identificados 5 tipos:

1. Através de trocas de desperdícios: focado no estágio final da vida do produto, onde cria-se uma lista de materiais onde empresas dispõe seus produtos que não são mais necessários, porém outras organizações utilizam. Pode ser local, regional, nacional ou global.

2. Dentro de uma organização, instalação ou firma: ocorre dentro das fronteiras da própria organização, considerando o ciclo de vida dos produtos, processos e serviços, e a cadeia de suprimentos do produto em questão.

3. Entre firmas localizadas em um EIP definido: neste caso empresas podem trocar água, energia e materiais, além de informações e serviços. Os relacionamentos começam dentro do perímetro definido pelo parque porém pode-se estender para firmas externas, caso necessário.

4. Entre firmas locais não colocadas em um perímetro definido: empresas são próximas e apresentam parcerias, com trocas de materiais, água e energia, porém em uma proximidade geográfica não colocadas em um parque industrial. 
5. Entre firmas organizadas virtualmente por uma região: este tipo depende mais no conceito de SI, focando mais nas trocas do que na localização. Um exemplo principal está na agricultura ou reciclagem de automóveis.

Chertow (2007) para distinguir a SI de outras trocas define um critério mínimo chamado de "Heurística 3-2" onde no mínimo três empresas diferentes devem estar envolvidas em no mínimo duas trocas de recursos.

Estabelecido o critério definido por Chertow (2007), a SI possibilita ganhos econômicos e ambientais para o país e para as empresas que participam desta (JENSEN et al., 2011). Alfaro e Miller (2014) diz que ela aumenta o valor das marcas e consequentemente das empresas que a realizam além de reduzir impactos ambientais, que é algo tão requisitado pela sociedade nos dias atuais. Segundo Sokka et al. (2010) essa redução pode chegar a 20\% nos principais destes, com a redução da necessidade de comprar matérias primas virgens e energia, através de um consumo eficiente desses recursos.

Pakarinen et al. (2010) comentam que a redução de impactos ambientais comprovados pela SI são possíveis através das seguintes atividades: reciclagem de materiais, utilização de resíduos e subprodutos, menor uso de combustível, redução de poluentes químicos, redução da disposição de toxinas na água, minimização de emissões a água e ao ar, tratamento e reciclagem de resíduos, menos extração de matéria prima e menor nível de poluição, melhorando a saúde da população.

Dong et al. (2013) e Pearce (2008) dizem que a SI obteve ganhos econômicos nos EIPs analisados, salvando matéria prima virgem e reduzindo desperdícios no ar e resíduos sólidos dispostos na natureza, conseguindo assim reduzir a poluição e ter retorno econômico.

Chertow e Miyata (2011) dizem que uma rede simbiótica otimiza o fluxo dos recursos e minimiza a geração de resíduos, criando uma performance ambiental e econômica além do que quando essas empresas estivessem operando isoladas. No caso apresentado pelos autores houve redução da obtenção de matéria prima, melhora na cooperação e redução de impactos ambientais. Yuan e Shi (2009) diz ainda que um compartilhamento de infraestrutura ambiental como a SI, mais especificamente no caso de tratamento de água estudado por ele, melhora a vantagem competitiva das empresas, reduz custos, reforça a cooperação e integração, dando mais resultados do que se estas empresas funcionassem de forma singular.

Mirata e Entairah (2005), Zhu, Lowe e Barnes (2007), Sokka, Pakarinen e Melanen (2011), Dong et al. (2013), Won et al. (2006) e Van Beers, Bossilkov e Lund (2009) citam os seguintes benefícios conseguidos pela SI: redução de matéria prima e seus respectivos custos; eficiência no uso de recursos; redução de poluição e de gases responsáveis pelo efeito estufa; 
redução no custo com gerenciamento de resíduos; valor conseguido para resíduos e subprodutos; relacionamento com empresas externas; imagem green; novos produtos e mercado; benefícios sociais e ambiente mais limpo; seguro e natural; empresas trabalhando juntas; aumento de competitividade; suporte; poder de compra e estratégia conjunta; estabilidade das interações e diversidade de atores para haver maior complementariedade de necessidades; atividades e capacidades; e por fim, inovação entre empresas com SI.

Chertow (2007) cita ainda alguns outros benefícios encontrados por ela na adoção de práticas de SI: redução de custos gerais, aumento de receita e aumento da segurança a longo prazo dos recursos, bem como o aumento da eficiência e redução de emissões de gases poluentes. Mirata (2004) complementa com melhora nos relacionamentos com parceiros externos, facilidade para desenvolvimento de novos produtos, geração de emprego e ambiente de trabalho mais seguro e limpo, e ambientalmente responsável.

Ainda discutindo os benefícios identificados com a aplicação e prosseguimento da SI, Dong et al. (2014) confirmam através de um estudo que a emissão de carbono é reduzida com a SI, e esta utiliza eficientemente os recursos, reduzindo a necessidade de extração e refino de matérias primas virgens. Esta segundo Illsley, Jackson e Lynch (2007) e Costa e Ferrão (2010) promove e requer cooperação local e essencialmente entre os participantes e para Salmi (2007) contribui para a eco-eficiencia do sistema.

Para Golev, Corder e Giurco (2014) e Doménech e Davies (2011) a cooperação e a confiança são fatores de extrema importância para o desenvolvimento da SI e cruciais ou seu sucesso e eficiência.

Conforme Won et al. (2006) quanto mais membros participantes na SI, mais ligações podem ser estabelecidas e desenvolvidas, aumentando a diversidade de materiais e serviços, melhorando a flexibilidade e integração das empresas participantes.

Ashton e Bain (2012) falam da importância do aspecto social para o sucesso da SI, com mínima distancia mental, franqueza, confiança e comunicação entre os membros para importantes interações sociais.

Companhias envolvidas na SI precisam discutir preço, quantidade, frequência e qualidade das trocas em questão. A gerência é essencial para o desenvolvimento de todos os relacionamentos, seja este de materiais, de informação ou de energia (ASHTON; BAIN, 2012).

Simboli, Taddeo e Morgante (2014) diz que a SI inclui ferramentas e soluções para reduzir ineficiências e para promover eco-inovação de sistemas de produção inteiros, para isso ela possui como principais direcionadores: a localização geográfica, os requisitos técnicos, a 
presença de um sistema regulatório, a homogeneidade/heterogeneidade das empresas, e participação dos stakeholders.

Zhu, Lowe e Barnes (2007) diz que a essência da SI é tirar toda vantagem da utilização de sub-produtos, reduzindo produtos residuais e tratando-os efetivamente. Esta pode ocorrer em função de uma única empresa, que foi o caso estudado pelo autor, como ocorre no caso de usinas sucrooalcooleiras onde empresas menores se instalam próximas a esta e realizam a SI para obter ganhos e consequentemente se tornarem dependentes dos subprodutos e resíduos da empresa central. E também entre várias empresas, onde todas as participantes tem poder em igual relevância.

Conforme Chertow e Lombardi (2005) para que a SI ocorra é necessário que os atores envolvidos tenham principalmente e essencialmente confiança e comunicação, além de "empurrão" do governo, com incentivos ou leis que favoreçam o desempenho do sistema.

Pereira, Lima e Rutkowski (2007) afirmam que a SI é baseada em três pilares que são necessários para que esta ocorra, são as informações geográficas (localização), informações organizacionais e informações sobre processos.

Segundo Mirata (2004) há cinco fatores que influenciam no desempenho e no sucesso da SI, o fator técnico, incluindo tecnologias, logística, fluxos, materiais, o fator político, com leis, normas, regulações, taxas, o fator econômico e financeiro, considerando principalmente custos e retorno sobre o investimento, o fator informacional e por fim o fator organizacional e motivacional.

Chertow (2007) propõe três políticas para que a SI continue a evoluir no ambiente onde está inserida: trazer canais de atividades de cooperação que ainda estão escondidos; acompanhar os canais que estão se formando; identificar percursores para a simbiose entre os elementos.

Wang Feng e Chu (2013) alegam que para que a SI ocorra de forma eficaz esta deve ter seus custos menores que os lucros oriundos de cada relacionamento, levando em conta os custos com depreciação e com a implantação e manutenção do sistema apropriado para realizar cada troca. Won et al. (2006) fala que todos os membros devem sair ganhando, os equipamentos devem ser capazes de realizar os processos necessários que atendam as especificações de cada empresa e as características de cada troca.

Para atingir a SI Yang e Feng (2008) citam alguns fatores chaves, sendo eles: resolver problemas estruturais (obtendo estruturas produtivas racionais); implementação de uma estratégia de integração para ter vantagem com matéria-prima; suporte técnico; implementação de uma estratégia de diversificação de empresas membros para formar um complexo únicoindustrial forte. 
Chen et al. (2012) mostra alguns tipos básicos de interações que podem ocorrer em um sistema com SI: quando uma empresa é central e possui fortes relacionamentos, tornando o sistema dependente desta; quando a rede formada é baseada na igualdade e todas trocam recursos entre si, estando todas num mesmo nível de importância; Quando a SI ocorre em empresas que se tornam aninhadas as outras porém possuem empresa menores que trocam isoladamente com apenas uma participante; por fim quando a rede é totalmente organizada pela internet.

Através de análise da SI, Chertow, Ashton e Espinosa (2008) citam três tipos de relacionamentos observados por eles:

- Compartilhamento de utilidades ou infraestrutura: uso e gerenciamento comum de recursos por responsabilidade de um grupo (geralmente empresas).

- Serviços compartilhados: atividades de suporte a todas as empresas envolvidas que não fazem parte do escopo de cada uma e afetam o ambiente (limpeza, disposição de resíduos).

- Troca de materiais: uso de resíduos como MP, aumento da eficiência no uso de recursos, aumento do valor dos resíduos e subprodutos com redução de custos e busca de sistema circular.

Boons e Spekkink (2012) citam algumas variáveis para aumentar a conectividade entre as empresas participantes da SI, sendo elas: processo de aprendizagem e visão estratégica; diversidade de participantes; nível de confiança; empresas âncoras ou coordenadoras; contexto permitido em termos de políticas, regulações e outras instituições de incorporação; número e qualidade de relacionamentos; perspectivas compartilhadas em problemas e soluções; visão estratégica compartilhada; e o nível de atuação dos líderes.

Segundo Bansal e Mcknight (2009) a SI difere de uma supply chain tradicional mercadologicamente (ambas contem relacionamentos interorganizacionais baseadas no fluxo de produtos). SI promove integridade ambiental com uso produtivo de resíduos, integridade de recursos e aceleração de degradação biológica (com diminuição de toxinas e separação de componentes), igualdade social com relacionamento com a comunidade, cooperação, redução de poluição e prosperidade econômica com diminuição de custos.

Boons e Spekking (2012) listam três capacidades institucionais para SI:

- Capacidade relacional: uma rede de relacionamentos que serve para reduzir custos transacionais entre firmas através de confiança e entendimento mútuo. 
- Capacidade de conhecimento: habilidade de adquirir e usar informações que permitam que as firmas e outros atores moldem suas trocas para reduzir impactos ambientais.

- Capacidade de mobilização: habilidade dos atores dentro do parque industrial de ativar firmas relevantes e outras partes para desenvolver ligações simbióticas.

Chertow e Ehrenfeld (2012) afirmam que a SI é diferente de clusters normais pelos seguintes fatores:

- Identificação de redes simbióticas como um sistema adaptativo complexo onde auto-organização por agentes possui papel importante.

- A origem das externalidades ambientais que são criadas coletivamente, mesmo que os atores não estão atentos a elas, mas isso vem a conhecimento num processo de descoberta que torna a realização consciente.

- Reconhecimento de atores tem pontos bons e ruins, redes podem se desenvolver espontaneamente na presença de normas institucionais fortes e talvez com necessária assistência pública.

- A maneira pela qual normas incorporadas de trocas e outros elementos de cultura e estrutura co-evoluem para incluir meio ambiente como parte de um processo de institucionalização.

- A necessidade de facilitação e coordenação de um corpo mais ou menos formal para sustentar as normas como elas evoluem de uma auto-organização inicial. O objetivo das entidades de organização é encontrar oportunidades para colaboração e ação coletiva.

Paquin e Howard-Grenville (2012) comentam de dois tipos principais de simbiose, uma desenvolvida naturalmente entre os indivíduos e outra conduzida através de planejamento. Este atenta para o fato de que o primeiro tipo consegue atingir maior confiança entre as partes e possui uma evolução consideravelmente rápida, porém esta é mais difícil de se conseguir e por isso é pouco encontrada. O ideal é obter normas integradas, cultura propícia a trocas e confiança o quanto antes para cada relacionamento.

Zaohua, Bin e Guilong (2010) caracterizam a SI em dois tipos, autônoma e compreensiva. A autônoma ocorre quando os participantes são independentes, sua participação ocorre para obter benefícios e somente enquanto esses ocorrem. A compreensiva ocorre quando as empresas pertencem a um grupo maior e este participa da simbiose para otimizar recursos, como estratégia ou para atender uma norma. 
- O tipo autônomo corre o risco de perder suprimentos caso outras empresas participantes saiam ou parem a produção, pode vazar informações do negócio e um resíduo se mal tratado pode causar danos graves. Como característica este tipo deve ter empresas economicamente atrativas, deve haver uma relação fechada e de confiança entre os membros, e a distância entre eles deve ser consideravelmente pequena.

- O tipo compreensivo tem como característica que todos os participantes participam para o mesmo grupo, com isso os membros não decidem deixar os relacionamentos firmados e a colaboração depende da estratégia do grupo e não dos benefícios.

Usón, Valero e Agudelo (2012) citam vantagens para desenvolver a SI:

- Diminuir a pressão institucional: visando atender normas e requisitos ambientais.

- Acesso a recursos críticos: vantagem competitiva, procurar substitutos ou força para adquirir tal material, conhecimento para substituir ou obter nova estratégia. Reduz custos com movimentação e acondicionamento e consegue obter a possibilidade de integração com a empresa fornecedora.

- Poupar custos e eficiência: Matéria prima mais barata e melhora a taxa input/output.

- Aprendizagem interorganizacional: aprendizado com cooperação, com outras empresas, tecnologias, know-how e informações.

- Economia com subprodutos.

- Poder ou controle sobre outros recursos.

- Fatores para rede de SI

- Coordenação e parcerias

- Inquilinos ancora e campeões na formação

- Comunicação e confiança

- Responsabilidade ambiental

Chertow $(2000,2004)$ ao examinar modelos de SI identificou ferramentas e elementos que enfatizavam o fluxo cíclico e o reuso de materiais, são considerados mais importantes para esse estudo:

1. Energia e materiais incorporados: para cada produto faz-se necessário a utilização de recursos que precisaram de transporte, extração e provável 
manufatura, com o reuso de materiais esta energia e material deixam de ser gastos e não participam do ciclo produtivo do produto em questão.

2. Perspectiva do ciclo de vida: considera todas as fases para obtenção de um produto, desde o material virgem até sua disposição final, estudando todos os impactos presentes em todas as fases do bem. Esta perspectiva pode ser boa para identificar possibilidades simbióticas no sistema produtivo.

3. Efeito cascata: ocorre quando um recurso é usado várias vezes em diferentes aplicações, este tem sua qualidade reduzida a cada uso, somente é descartado quando necessitar de muita energia para poder realizar a função. Este auxilia a SI pois o recurso pode servir para troca, reduzindo custos com disposição ou tratamento.

4. Loop circular: envolve um fluxo cíclico incorporado ao ecossistema industrial do recurso, utilizando a ideia de reuso, reciclagem.

5. Rastreamento do fluxo de materiais: rastreia materiais, energia e água. Identifica e quantifica todas as entradas e saídas de cada empresa para mostrar possibilidades simbióticas entre os elementos do sistema em questão e utilizar eficientemente os recursos.

6. Input/output correspondentes: Identifica e relaciona inputs e outputs de várias entidades para liga-los e assim realizar trocas simbióticas entre empresas, compatíveis com a estratégia da empresa e das normas vigentes.

7. Stakeholders: estes devem coordenar ativamente as empresas participantes para que estas estabeleçam e mantenham a SI.

8. Orçamento de materiais: mapeia o fluxo de materiais e energia num dado sistema, considera três conceitos: reserva, onde há estocagem; fluxo, entrando e saindo da reserva por unidade de tempo; fontes e sumidouros, taxa de inputs e perdas de materiais específicos entrando ou deixando um sistema.

Para criar uma rede de SI, Behera et al. (2012) definem 3 passos importantes:

Passo 1: Explorar novos compartilhamentos. Com coleta de dados para encontrar novas sinergias e com comunicação efetiva entre todas as empresas envolvidas.

Passo 2: Estudo de viabilidade. Com um relatório final que apresente um modelo de negócio que considere as restrições dos clientes.

Passo 3: Comercialização. Com participação do stakeholders e coordenação dos benefícios obtidos entre os participantes. 
Sopha et al. (2010) aplicam o conceito de engenharia de sistemas para desenvolver uma estrutura para modelar a SI considerando cinco fatores importantes para a sustentabilidade deste modelo e dos relacionamentos a serem criados. São eles: fator tecnológico, onde as trocas devem ser viáveis em termos físicos, químicos e espaciais; fator econômico, o qual diz que as trocas devem ser economicamente viáveis e sem risco; fator político, onde deve-se respeitar as normas, leis e regulações ambientais e fiscais; fator informacional, diz que as pessoas certas devem ter as informações necessárias no tempo certo; fator organizacional, onde as trocas devem respeitar questões corporativas, confiança, interação, proximidade, localidade, poder de decisão, interações e aspectos sociais.

Para desenvolver a metodologia Sopha et al. (2010) basearam-se na Figura 4 que mostra como cada conceito contribuiu na elaboração da metodologia.

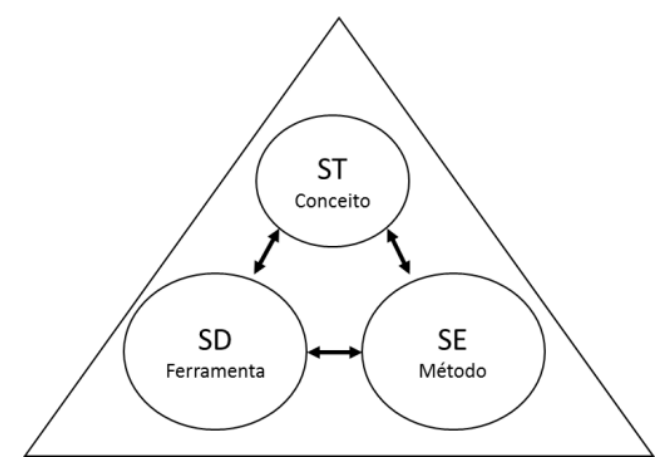

Figura 4 - Conceitos ligados na teoria de sistemas.

Fonte: Traduzido de Sopha et al. (2010).

Teoria de sistemas é utilizada no estágio conceitual, considera várias matérias a serem estudadas e interdisciplinaridade, tal como a integração de conceitos como ecologia industrial e SI. Engenharia de sistemas define, desenvolve e posiciona sistemas, neste caso é um procedimento para modelar a SI considerando um sistema interdisciplinar. Dinâmica do sistema é considerada uma ferramenta no estudo a qual analisa o comportamento e as interações dos feedbacks principalmente. Como visto na Figura os sistemas se interagem e são uma forma de definir problemas e desenvolver soluções.

O modelo proposto por Sopha et al. (2010) é mostrado na Figura 5, onde o processo é dividido em processo da engenharia de sistemas e os métodos correspondentes.

$\mathrm{Na}$ estrutura apresentada por Sopha et al. (2010) tem-se 6 etapas, divididas em duas partes, definição do problema e desenvolvimento da solução com três etapas cada. Os métodos são ligados as respectivas fases, sendo estes qualitativos. 
Etapa 1: Identificação da necessidade. Define-se o escopo do projeto, as questões de análise e os limites do sistema, identifica-se os elementos do sistema que influenciam no projeto e como métodos tem-se entrevistas, brainstorming e estudo de campo.

Etapa 2: Definição dos requisitos: aqui as necessidades são transformadas em requisitos, que podem ser questões investigativas, além de considerar que o modelo deve ser fisicamente capaz de representar o sistema realisticamente, informar os stakeholders, apto para incluir cenários e barreiras. Aqui utiliza-se estudo da literatura, survey e estudo de campo.

Etapa 3: Especificar performance. Define-se os indicadores para responder aos requisitos e qual a performance desejada. Analisa-se os indicadores, e determina-se as variáveis que influenciam o caso. Utiliza-se revisão da literatura, entrevistas, estudo de campo e survey.

Etapa 4: Análise. Obtêm-se quais os processos que direcionam a performance. Definese um modelo geral, com elementos, respectivos relacionamentos e um modelo conceitual. Os relacionamentos são analisados com auxílio da literatura ou de experts. O modelo é alcançado com entrevistas e discussões e o modelo ótimo é obtido. Usa-se workshop e revisão da literatura também.

Etapa 5: Projeto e melhorias. Formulação e formalização são realizadas, relações lógicas, matemáticas e teóricas entre variáveis são estabelecidas e o passo é conduzido até que os stakeholders concordem.

Etapa 6: Implementação. Testes são conduzidos e experimentos listam os procedimentos e parâmetros usados para atingir os objetivos.

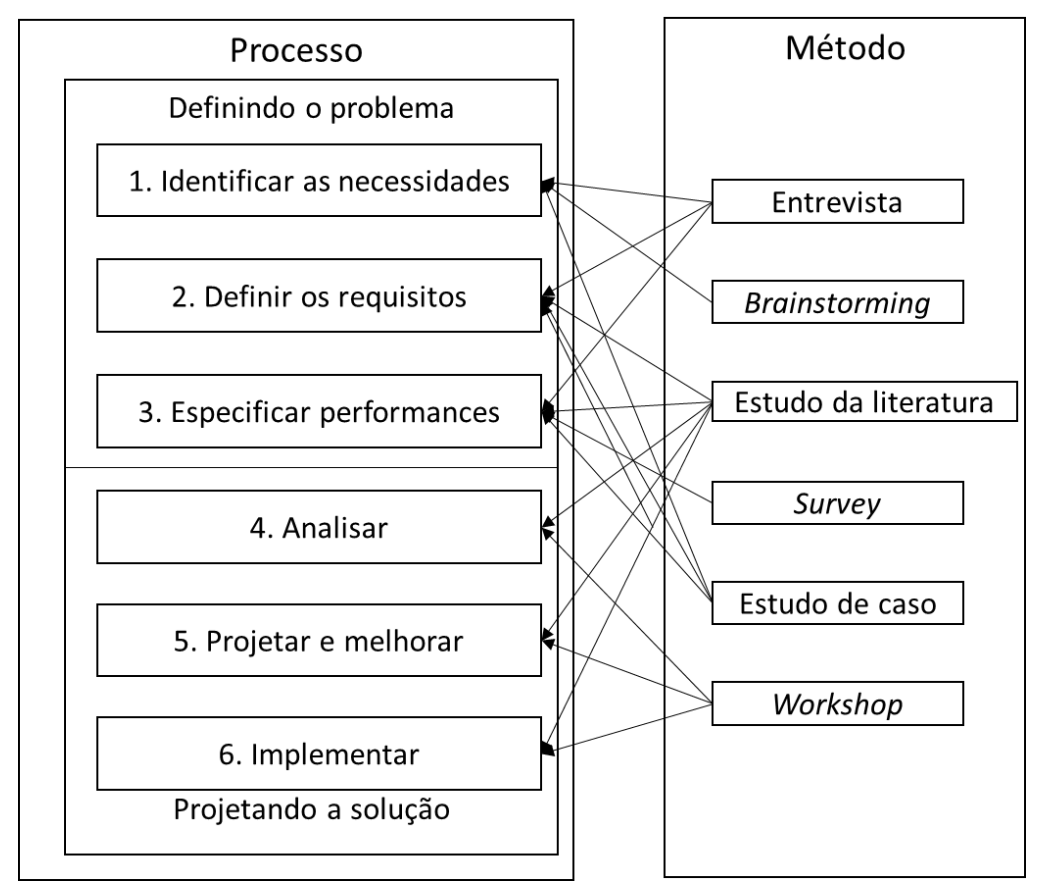

Figura 5 - Estrutura para modelar a SI baseado na teoria dos sistemas. Fonte: Traduzido de Sopha et al. (2010). 


\subsection{Eco-Industrial Parks (EIP)}

O President's Council on Sustainable Development - PCSD, no document Sustainable America: A New Consensus for Prosperity, Opportunity, and a Healthy Environment, de 1996, definiu EIP como um grupo de negócios integrados à comunidade para compartilhar eficientemente recursos (água, materiais, infraestrutura, energia, e informações), incrementar a prosperidade econômica e desenvolver o meio ambiente.

A United States Environmental Protection Agency - EPA coloca que:

“[...] EIP é uma comunidade de indústrias e negócios de serviços que objetivam aumentar o desempenho econômico e ambiental, por meio da gestão colaborativa do meio-ambiente e dos recursos. A comunidade de negócios, trabalhando em cooperação, procura produzir um benefício coletivo maior do que a soma dos benefícios individuais de cada empresa. Utilizando os princípios da ecologia industrial, a comunidade empresarial trabalha em conjunto para se tornar um ecossistema industrial."

Martin et al. (1996) coloca que o EIP leva a ganhos econômicos, ganhos em qualidade ambiental, e aprimoramento equitativa dos recursos humanos para o negócio e comunidade local, e que seus conceitos estão se espalhando pelo mundo como um modelo que considera as três dimensões da sustentabilidade, conquistando benefícios mútuos na comunidade, economia e meio ambiente.

O objetivo de um EIP é melhorar o desempenho econômico dos membros, minimizando seus impactos ambientais. Os componentes desta abordagem incluem o projeto verde da infraestrutura, parque e plantas (novos ou adaptados), produção mais limpa, prevenção da poluição, a eficiência energética e parcerias entre empresas (LOWE, 2001).

Lowe (2001) fala que para que para ser considerado um real EIP, este deve ser mais do que: Uma rede de troca de sub-produtos; Uma comunidade de reciclagem; Um conglomerado de empresas de tecnologia ambiental; Um conglomerado de empresas que fazem produtos "verdes"; Um parque industrial projetado em torno de um simples tema ambiental (energia solar, reuso de água); Um parque com infraestrutura ambientalmente amigável; Uma comunidade de negócios de uso variados (comercial, industrial e residencial).

Uma das diferenças ainda segundo Lowe (2001) entre o EIP e o distrito industrial é que o EIP utiliza os conceitos e as práticas do planejamento sustentável e da gestão ambiental cooperativa e o distrito industrial não. O EIP integra os princípios da EI, da SI, da gestão ambiental cooperativa, da prevenção da poluição, do planejamento, da arquitetura e das 
construções sustentáveis. As indústrias ao formarem parcerias aumentam sua vantagem competitiva.

Os benefícios são muitos segundo Lowe (2001), na escala industrial ocorre com a baixa nos custos de produção, aumento da eficiência energética e de reciclagem e reuso, eliminar a possibilidade de receber penalidades por questões ambientais e tronar-se competitivo com integração e cooperação. Em escala ambiental o EIP reduz a poluição, a produção de resíduos e a demanda por recursos naturais. Socialmente ao atingir um bom desempenho econômico, o EIP trará desenvolvimento a comunidade que está inserido, criará empregos e melhorará o ambiente ao redor. Conforme Cohen-Rosenthal, Mcgalliard e Bell (2001) um EIP ainda promove cooperação entre empresas, facilita trabalho de equipe, aumenta o valor dos outputs dos processos, recebe publicidade positiva e busca a eco-eficiência.

Um EIP também de acordo com Chertow (2000) é caracterizado segundo os cinco tipos descritos no tópico anterior deste trabalho, tendo atenção especial nos tipos 3, 4 e 5, os quais envolvem várias empresas em busca de objetivos de forma integrada e com cooperação.

De acordo com Liwarska-Bizukojc et al. (2009) informações básicas sobre os tipos de atividades das empresas devem ser levantadas para obter os locais onde a simbiose é possível, que ações devem ser tomadas para que ela trone-se possível e qual esforço e custo pra isso. Por fim quanto mais empresas diferentes o EIP tiver, maiores são as chances de criar relacionamentos simbióticos e obter um sistema sustentável.

Segundo Park et al. (2008) em seu estudo de caso realizado em Ulsan cinco pontos são necessários para tornar um parque industrial em EIP. São eles: reduzir custos e receitas entre negócios; política ambiental para melhorar o fluxo de recursos e transações para a SI; utilizar tecnologias disponíveis ou desenvolve-las para tornar a SI possível; Fazer relacionamentos com comunidades com atração de negócios e melhorar a qualidade de vida; fatores financeiros, temporais e humanos, tecnologias e benefícios ambientais são necessários para um EIP ser desenvolvido.

Por fim Heeres et al. (2004) alegam que um problema no desenvolvimento de um EIP está no estabelecimento de trocas simbióticas essenciais entre os membros, passando por cinco barreiras:

- Técnica, se a troca é tecnicamente possível;

- Econômica, se a troca é economicamente viável ou arriscada;

- Informacional, as pessoas certas devem ter as informações requisitas no tempo correto; 
- Organizacional, as trocas devem estar dentro da estrutura organizacional;

- Legal, respeitar leis e regulações.

Ainda segundo Heeres et al. (2004) as principais barreiras para um EIP estão em lidar com substancia tóxicas, trabalhar com resíduos com contaminantes que impedem o processo, coletar e transportar os resíduos, mapear o fluxo de energia e de materiais.

\subsection{EIP e SI}

Nascimento et al. (2006) dizem que para a implementação da SI, nas atividades de um EIP, as ações de planejamento devem contemplar análises econômicas (verificar o potencial de retorno do investimento para alocação de materiais e pessoas) análises técnicas (tecnologias disponíveis) análises ambientais (identificar os parâmetros ambientais desejados) e medidas de regulamentação (ambientais e fiscais).

Boons et al. (2011) classificam a SI como um processo que é facilitado em um ambiente propício para seus relacionamentos, suas trocas, interações e cooperações. Esta é então aplicada dentro de um local específico com distancias curtas entre elas e com isso tem sua máxima eficiência.

Os conceitos SI e EIP se complementam na medida em que o processo de SI é considerado uma das principais atividades desenvolvida num EIP (FELÍCIO, 2013). Chertow (2000) afirmou que os EIPs são uma parte da SI, destacando-a como característica fundamental. Agarwal e Strachan (2006) sugerem que a EIP seja um subconjunto de SI.

As vantagens da SI é essencial na formação dos EIP, pois funciona como atrativo para implantação do processo nesses ambientes. Benefícios como a redução na utilização de materiais virgens, redução da poluição, redução de custos com transporte de matérias-primas e de gerenciamento de resíduos, tratamento de água, maior participação da comunidade, marketing verde, sustentabilidade, aumento da eficiência energética, aumento da quantidade e tipos de saídas de processo com valor de mercado são reconhecidos por muitos autores como Chertow e Lombardi (2005), Geng et al. (2009), Lowe (2001) e Tudor et al. (2007).

\subsection{Considerações finais do capítulo}

A EI apresenta-se como um conceito muito importante para a redução de impactos ambientais e aproveitamento máximos dos recursos numa condição de ciclo fechado, onde empresas utilizam recursos até que sejam usados ao máximo potencial. 
Dentro da EI existe o conceito de SI que liga as empresas e realiza trocas simbióticas buscando ganhos financeiros e ambientais dentro de um parque. As empresas participantes obtem maior comunicação e integração com as outras empresas, conquistando vantagem competitiva e se adequando ao meio ambiente.

De acordo com os conceitos encontrados na literatura sobre SI entende-se que este processo é capaz de conquistar ganhos e trazer benefícios a um grupo de empresas, e que ao definirem este conceito como estratégia em comum para obter melhorias ambientais, possam conquistar a redução de custos e de resíduos.

A SI apresenta-se portanto como uma forte ferramenta para a construção de um parque industrial ambientalmente responsável e com ganhos na utilização de recursos e em integração e cooperação, desenvolvendo benefícios bem maiores para essas empresas participantes do que quando consideradas individualmente.

Na literatura pesquisada não foi encontrado nenhum trabalho que contemplasse questões de planejamento de layout para um parque que tivesse a SI considerada em seu desenvolvimento, ou ainda que favorecesse o desenvolvimento desta pela questão da proximidade geográfica.

A seguir estuda-se o conceito de layout, o qual traz benefícios em proximidade geográfica, considera os fluxos, neste caso sendo de resíduos, e os relacionamentos para obtenção de vantagem competitiva e eficiência. 


\section{Capítulo 3. LAYOUT - Modelos e avaliação}

O layout é definido por Dias (1993) como a integração do fluxo de materiais, da operação dos equipamentos de movimentação, combinados com características que conferem maior produtividade humana, processando dentro do padrão de economia e rendimento. $\mathrm{Ou}$ simplesmente é o arranjo de homens, máquinas e materiais. Muther e Wheeler (2000) argumentam que ele envolve basicamente as relações entre as diversas atividades ou funções, o tipo e a quantidade de espaço para cada função e o ajustamento destas nele.

O layout para Gonçalves Filho (2001) determina a disposição física dos equipamentos, máquinas, serviços auxiliares, área de tráfego e armazenagem e deve minimizar a movimentação de pessoas, materiais no chão de fábrica, diminuindo os custos e tornando a manufatura mais eficiente e produtiva. Este de acordo com Slack, Chambers e Johnston (2008) determina a maneira pela qual os produtos e pessoas fluem pelas operações.

O arranjo físico segundo Slack, Chambers e Johnston (2008) possui alguns objetivos que o torna consideravelmente bom, são eles: presença de segurança inerente em todos os processos, para clientes e funcionários; respeitar o fluxo dos recursos de forma a diminuir as distâncias percorridas; todo o fluxo deve ser claro de forma que os envolvidos possam entender as operações e seus caminhos; prover um ambiente agradável e confortável sempre que possível; facilitar a coordenação gerencial; garantir acesso a todos os recursos de transformação para limpeza e manutenção; uso adequado do espaço disponível; e flexibilidade de mudança a longo prazo.

Em relação ao planejamento das instalações de uma empresa ou de um conjunto delas, Tompkins et al. (2010) afirmam que este é dividido em projeto das instalações e localização das instalações. A localização se refere ao lugar com respeito aos clientes, fornecedores e outras instalações com que a empresa possui inter-relações, considerando todos os custos envolvidos nos relacionamentos, numa abordagem mais macro dos elementos, já o projeto considera o interior, a proporção micro do sistema.

Slack, Chambers e Johnston (2008) dizem que o projeto do layout inicia-se com a definição dos objetivos estratégicos da produção. Há 3 decisões importantes a serem tomadas neste processo, o tipo de processo o qual depende do volume e da variedade, dos objetivos anteriormente especificados e do processo produtivo, o tipo básico de arranjo físico e o projeto detalhado de arranjo físico com as posições físicas de todos os recursos, resultando no fluxo dos recursos de transformação. 
Para Tompkins et al. (2010) como características todas as instalações devem ser flexíveis, modulares, aprimoráveis, adaptáveis, operacionalidade seletiva, ambientalmente e energicamente amigável. Em relação a uma cadeia de suprimentos, esta deve ser totalmente integrada, confiável, manutenível e progressiva economicamente.

Os objetivos do planejamento de layout de acordo com os mesmos são: aumentar a satisfação do consumidor, aumentar o retorno sob o investimento, aumentar a rapidez, reduzir custos, integrar a cadeia de suprimentos e sua comunicação, dar suporte a visão da organização, utilizar recursos eficientemente, ser adaptável e fornecer manutenção, propor segurança ao trabalhador, ser ambientalmente responsável e assegurar sustentabilidade.

Para planejar e projetar um bom layout e assim atingir o objetivo deste trabalho, foram encontrados os seguintes modelos de planejamento e projeto de layout considerados pertinentes ao estudo e bom direcionadores para um novo modelo.

Os modelos que serão apresentados a seguir foram escolhidos por serem mais citados nos trabalhos pesquisados através do levantamento bibliográfico realizado. O modelo de Muther (1973) é o que foi mais utilizado nas pesquisas e o que traz melhores resultados em suas aplicações segundo Camarotto (1998), além disso, foca em intensidade de fluxos e seus relacionamentos. O modelo de Apple (1977) é antigo e também é vastamente usado nos trabalhos, sendo considerado bem geral e de fácil aplicação. O modelo de Camarotto e Menegon (1996) foi considerado por ter uma ideia de ambiente, templates e simulação, obtendo bons resultados nas pesquisas encontradas. O modelo de Gonçalves Filho (2001) é uma síntese dos anteriores, tendo forte influência do de Muther (1973), incorporando algumas ideias atuais, porém, mantendo a base dos antigos. Por fim o modelo de Tompkins et al. (2010) é o mais atual, contém as ideias de Slack, Chambers e Johnston (2008) e mostra que os modelos anteriores continuam tendo importância para a estruturação dos atuais.

\subsubsection{Modelo de Muther (1973)}

Multher (1973) apresenta um modelo de projeto de layout que ficou amplamente conhecido e utilizado até os dias atuais. Este é chamado de Systematic Layout Planning, aqui denominado de sistema SLP, sendo segundo o autor um método para conduzir qualquer realização de projeto de layout, através de uma estrutura composta por fases, com um conjunto de procedimentos e convenções que identificam, classificam e visualizam os elementos e áreas envolvidas no planejamento. 
A base para o planejamento de instalações para Muther (1973) consiste na coleta de informações e dimensionamento de cinco elementos para que seja possível obter soluções no layout, são eles o produto, a quantidade, o roteiro, os serviços de suporte e o tempo. Além disso três conceitos fundamentais também são base, sendo a inter-relação das atividades e departamentos, o espaço que considera as características e volume dos itens e o ajuste para obter o melhor arranjo.

A estrutura proposta por Muther (1973) pode ser vista na Figura 6.

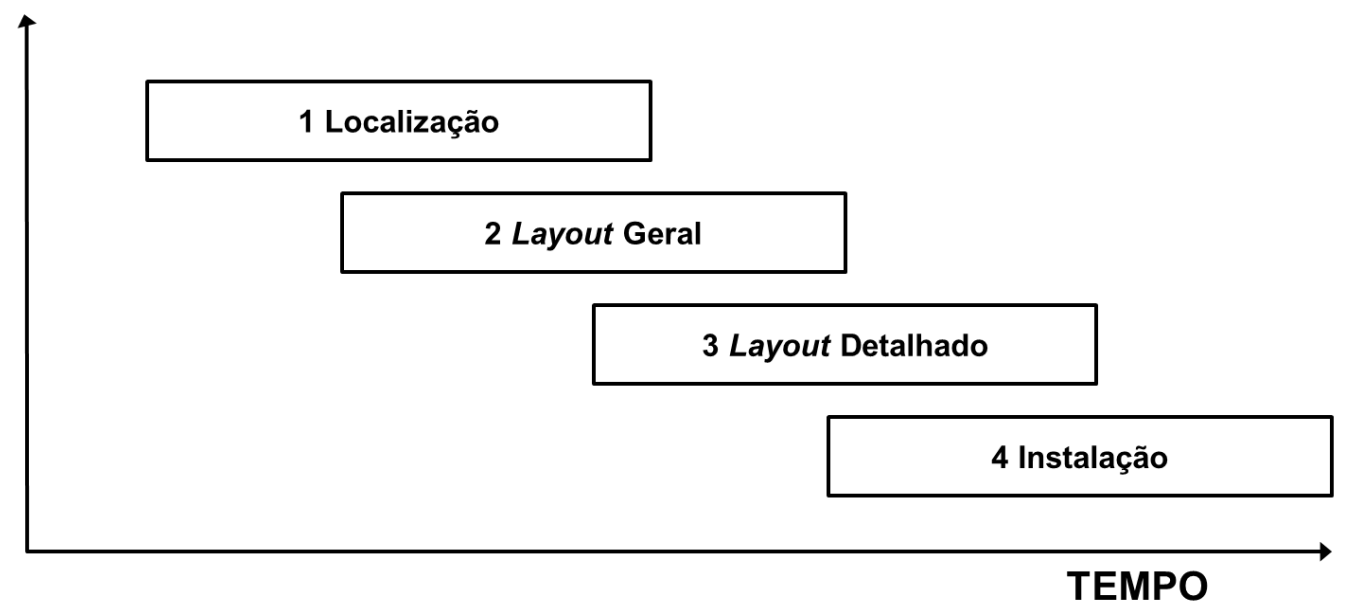

Figura 6 - Estrutura para projeto e planejamento de layout. Fonte: Muther (1973).

O planejamento é portanto dividido em quatro fases. A primeira fase é localização, onde determina-se as áreas e locais para o projeto, podendo ser os mesmos ou novos. A segunda fase é o layout global onde as áreas são alocadas de acordo com fluxos e inter-relações, podendo ser chamada de layout de blocos. A terceira fase consiste no layout detalhado, a qual envolve a localização de todos os elementos e recursos necessários ao sistema, bem como as características físicas de cada área. A quarta e última fase é a implantação onde define-se o planejamento da instalação, posteriormente obtém-se sua aprovação e por fim realiza-se as movimentações necessárias.

A partir da sequência apresentada composta por quatro fases tem-se um modelo Sistemático de planejamento de layout criado por Muther, o qual é mostrado na Figura 7. 


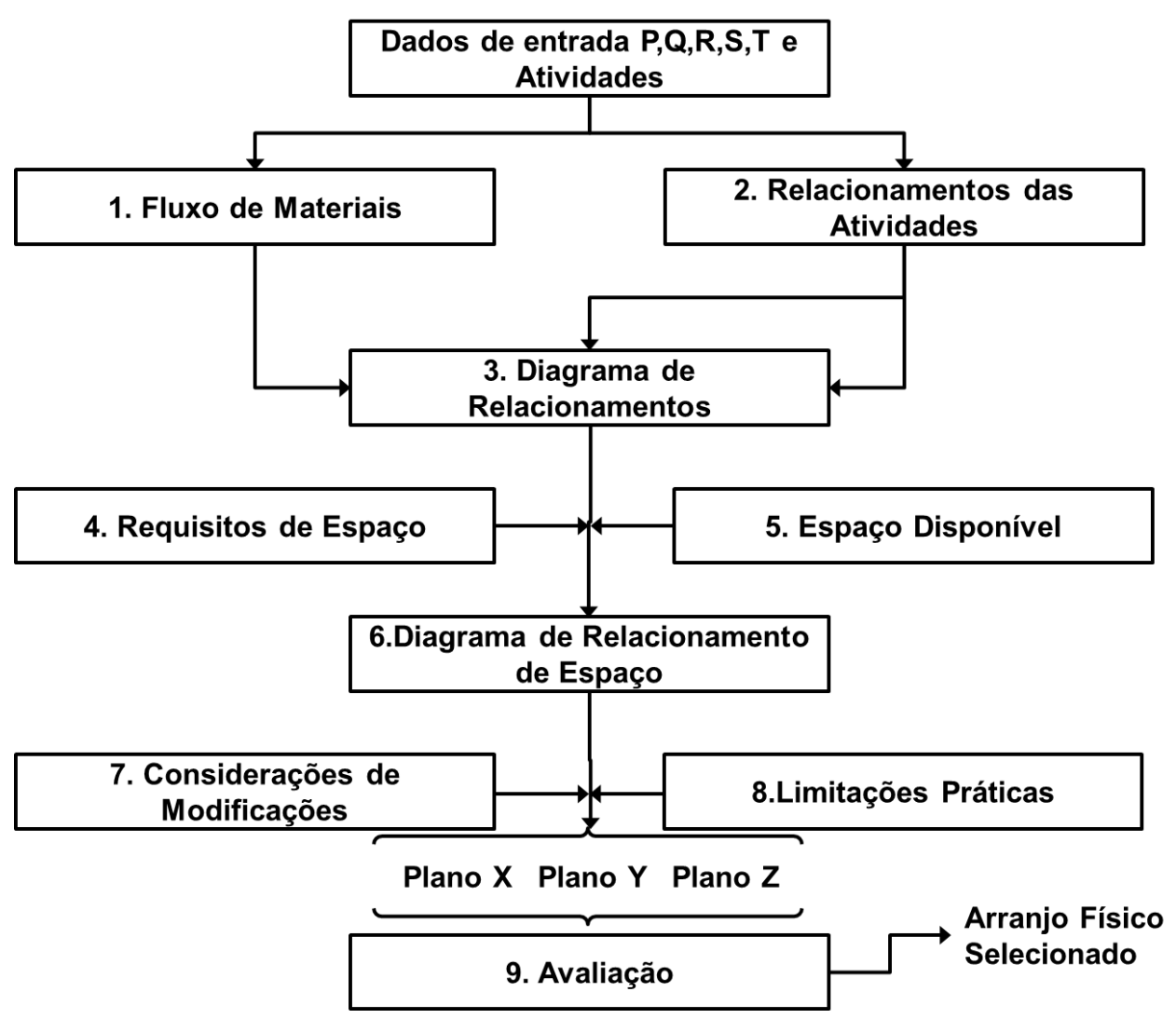

Figura 7 - Modelo SLP. Fonte: Muther (1973).

Dados de entrada: informações e dados sobre produto, quantidade, roteiro, serviços de suporte, tempo e de atividades.

Etapa 1 - fluxo de materiais: determinação da melhor sequência de movimentação pelas etapas do processo considerando intensidade e magnitude. Ferramentas como a carta de processo e o diagrama De-Para são utilizados nesta etapa.

Etapa 2 - relacionamento das atividades: relaciona as atividades de serviço umas às outras e integra o serviço de suporte ao fluxo de materiais. Para isso utiliza-se a carta de interligações preferenciais Figura 8.

Etapa 3 - Diagrama de relacionamentos: visualização dos dados, cálculos e análises feitas. Constrói-se o diagrama, começando com as inter-relações mais importantes até as de menor importância, o que pode ser visto na Figura 9 e Quadro 2. 


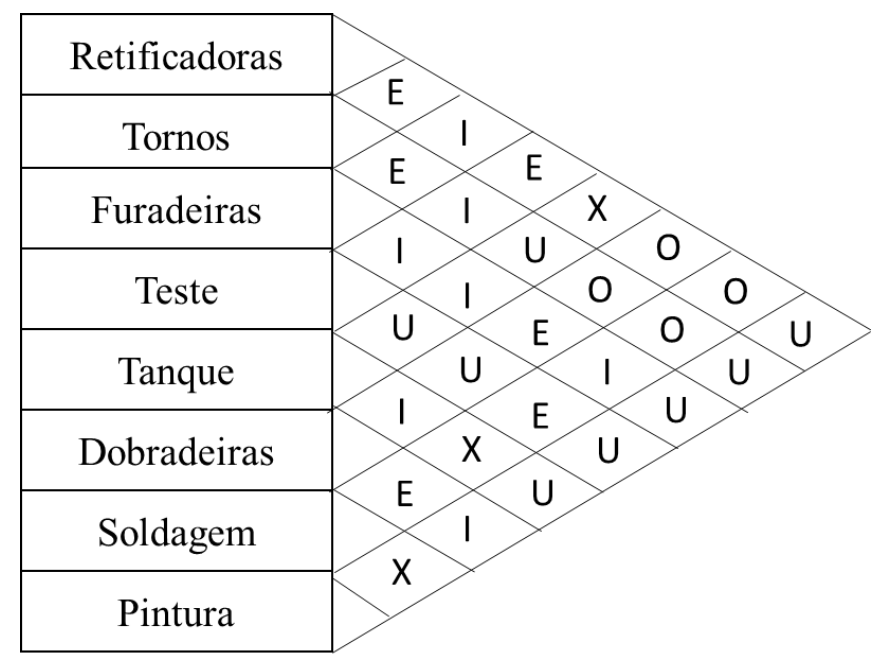

Significado das letras

A - Absolutamente importante

E-Especialmente importante

I - Importante

O-Ordinariamente importante

U - Não importante

$X$ - indesejável

Figura 8 - Carta de interligações.

Fonte: Muther (1973).

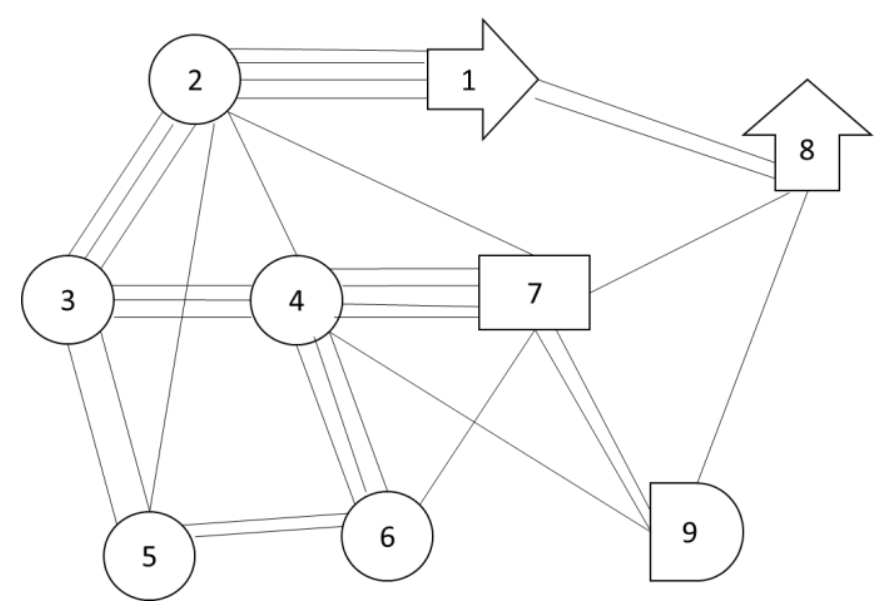

Figura 9 - Diagrama de relacionamentos.

Fonte: Muther (1973).

Quadro 2 - Explicação para o diagrama de relacionamento, (MUTHER, 1973)

\begin{tabular}{|c|c|c|c|}
\hline Letra & Valor & Número de linhas & Proximidade \\
\hline $\mathrm{A}$ & 4 & $/ / / /$ & Absolutamente necessário \\
\hline $\mathrm{E}$ & 3 & $/ /$ & Muito importante \\
\hline $\mathrm{I}$ & 2 & $/$ & Importante \\
\hline $\mathrm{O}$ & 1 & & Pouco importante \\
\hline $\mathrm{U}$ & 0 & $\bigwedge$ & Desprezível \\
\hline $\mathrm{X}$ & -1 & & Indesejável \\
\hline $\mathrm{XX}$ & $-2,-3,-4, ?$ & $\mathbb{4}$ & Extremamente indesejável \\
\hline
\end{tabular}

Etapa 4 e 5 - requisitos de espaço e espaço disponível: aqui levanta-se os espaços necessários para o novo layout, bem como a localização e relacionamento das áreas e locais, respeitando o espaço existente. 
Etapa 6 - Diagrama de relacionamento de espaço: representação dos departamentos e a inter-relação entre eles, considerando fluxos de materiais e as movimentações entre as diversas áreas.

Etapas 7 e 8 - Considerações de modificações e limitações práticas: aqui são levantadas as limitações existentes e o conjunto de considerações necessárias para cada layout de acordo com os objetivos definidos.

Seleção das alternativas: aqui apresenta-se as opções desenvolvidas, balanceia-se as vantagens e desvantagens de cada alternativa de layout, avalia-se os fatores e compara-se e justifica-se os custos.

Etapa 9 - Avaliação: consiste em avaliar a alternativa formulada e deve-se rever o plano com as pessoas envolvidas e preparar uma apresentação adequada, para assim conseguir a aprovação do projeto.

O planejamento da localização segundo Muther (1973) é composto de três elementos essenciais, o que se deseja, o que é disponível e o que é mais adequado. O projeto desta recai sobre quatro fases, estabelecer especificações, objetivos e restrições, analisar e selecionar a região e comunidade, analisar e selecionar o terreno específico e comprar ou alugar o terreno.

\subsubsection{Modelo de Apple (1977)}

Apple (1977) propõe um modelo de projeto de layout funcional, composto por 20 passos, não sendo necessário utilizar todos ou seguir a sequência corretamente:

1. Adquirir os dados básicos: vendas, quantidade a ser produzida, política de inventário, operações, métodos preliminares, layout existentes e limites por exemplo.

2. Analisar os dados básicos: determinar inter-relações possíveis, utilizar Assembly chart.

3. Projetar o processo produtivo para obtenção do produto final: determinar a rota de fabricação, as operações necessárias e assim identificar potenciais padrões.

4. Planejar o fluxo dos materiais: com os dados de frequência e rotas de fabricação elaborar os fluxos e considerar todos os fatos que influenciariam estes; em caso de vários componentes, considerar um fluxo máster (ou por famílias). 
5. Considerar o sistema de movimentação de materiais: fluxo dinâmico eficiente através da planta, integração entre todas as operações necessárias a um produto específico.

6. Calcular os equipamentos necessários: quantos equipamentos de cada tipo são necessários para fabricação dos produtos em quantidades pré-estabelecidas.

7. Planejar individualmente os postos de trabalho: detalhar as áreas, postos e processos, bem como a relação entre eles.

8. Selecionar equipamentos específicos para transporte de materiais: etapa importante para o correto e eficiente manuseio de materiais.

9. Coordenar os grupos de operações que possuem relações: planejar as interrelações entre postos de trabalho, centros de produção, departamentos ou processos.

10. Projetar o sistema de inter-relação das atividades: considerando nesta etapa as atividades de serviço, auxiliares e o fluxo de informação, além de admitir aspectos negativos e positivos nos relacionamentos.

11. Determinar requisitos de estocagem: estoque de matéria prima, produto acabado e bens em processo.

12. Planejar as atividades de serviço e de auxílio: considerar todo o sistema de manufatura.

13. Determinar requisitos de espaço: estipular o espaço total requerido para cada atividade.

14. Alocar as atividades no espaço local: realizar esta etapa de acordo com o relacionamento entre as atividades e encaixá-las na planta conforme restrições.

15. Considerar tipos diferentes de construções: estabelecer a melhor estrutura para o prédio caso este não tenha sido construído.

16. Construir o layout macro.

17. Avaliar, ajustar e checar o layout com pessoal apropriado.

18. Obter aprovação.

19. Instalar o layout.

20. Acompanhar a implementação do layout.

De acordo com Apple (1977) um layout bem planejado é um pré-requisito para uma produção econômica, com custos baixos, movimentação eficiente e produtividade elevada. $\mathrm{O}$ projeto de layout facilita o processo de produção, minimiza movimentações, traz flexibilidade, utiliza eficientemente os recursos produtivos e promove satisfação ao trabalhador. 


\subsubsection{Modelo de Camarotto e Menegon (1996)}

Este modelo contempla a simulação como base para análise do layout a ser desenvolvido e buscar flexibilidade, qualidade e a possibilidade de adaptar prováveis melhorias futuras. Segundo Menegon, Costa e Camarotto (1997) o projeto de layout industrial segue a mesma característica do projeto de produto, com restrições, especificações e necessidades dos futuros usuários. Segue a Figura 10 com o modelo referido.

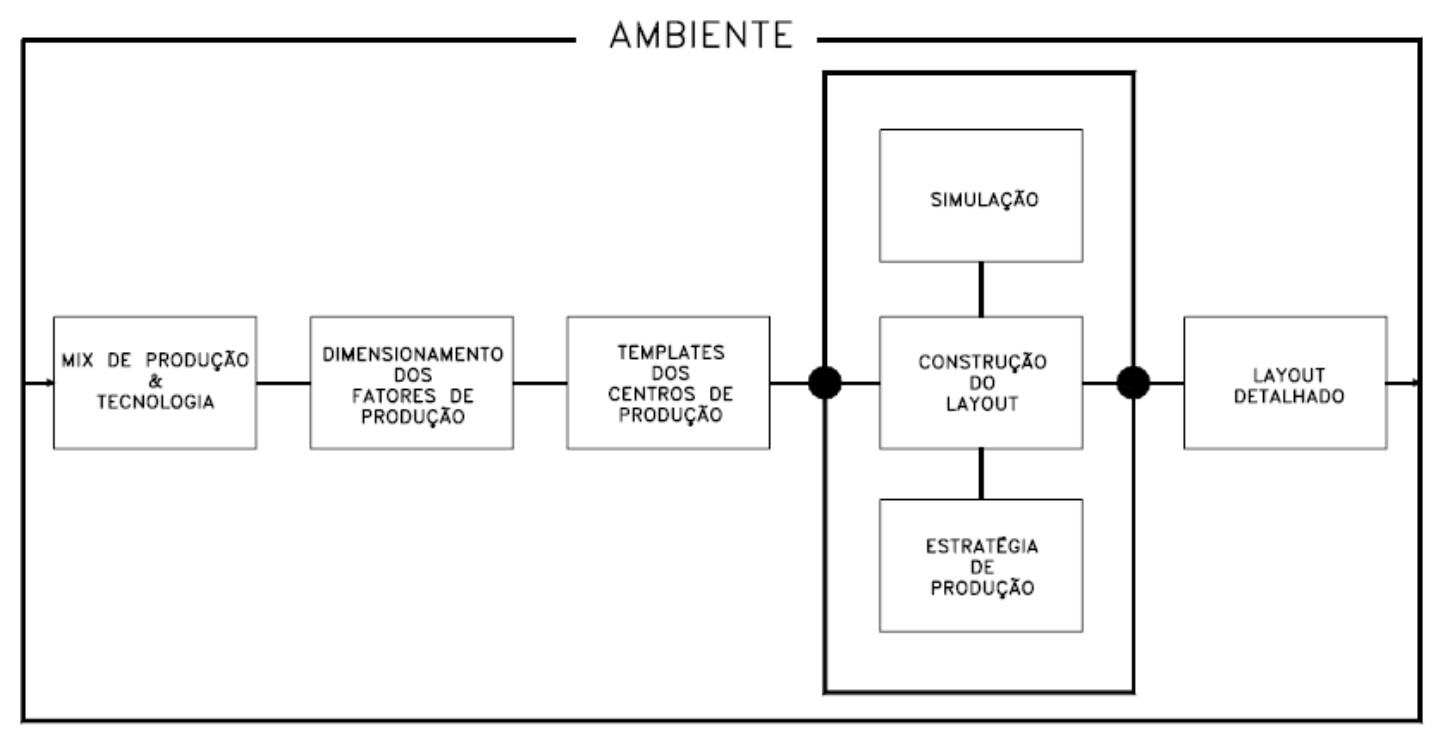

Figura 10 - Modelo de projeto de layout de Camarotto e Menegon. Fonte: Menegon, Costa e Camarotto (1997).

O ambiente é o conjunto de fatores que envolve e influencia o projeto de layout. Com isso deve-se conhecer os produtos a serem produzidos e o respectivo processo de obtenção destes, considerando todos os elementos que compõe o produto final. Na segunda etapa devese quantificar os fatores de produção diretos e indiretos. Na terceira fase deve-se conhecer a demanda dos centros de produção e do espaço para serviços, gestão e utilidades.

$\mathrm{Na}$ fase de construção do layout tem-se também a simulação e a definição da estratégia de produção, aqui ocorre a geração de alternativas, suas respectivas avaliações e a escolha. Cada estratégia privilegia uma alternativa de layout, considerando as áreas produtivas e não produtivas e seus respectivos graus de relacionamento, por fim ocorre a validação do projeto conforme a melhor alternativa com respeito aos objetivos e a estratégia adotada.

A última etapa de detalhamento do layout envolve a especificação de todos os elementos e da elaboração de um documento para correta implantação pelo pessoal qualificado. De acordo 
com Camarotto e Menegon (2006) a metodologia foi testada em inúmeros casos e conseguiu resultados consistentes.

\subsubsection{Modelo de Gonçalves Filho (2001)}

O projeto ou reprojeto de um layout de acordo com Gonçalves Filho (2001) pode ser considerado como o desenvolvimento de um produto cujo resultado final é o arranjo físico da facilidade. Ou seja, uma sequência de atividades que transforma informações coletadas no layout final de acordo com o objetivo, como pode ser visto na Figura 11.

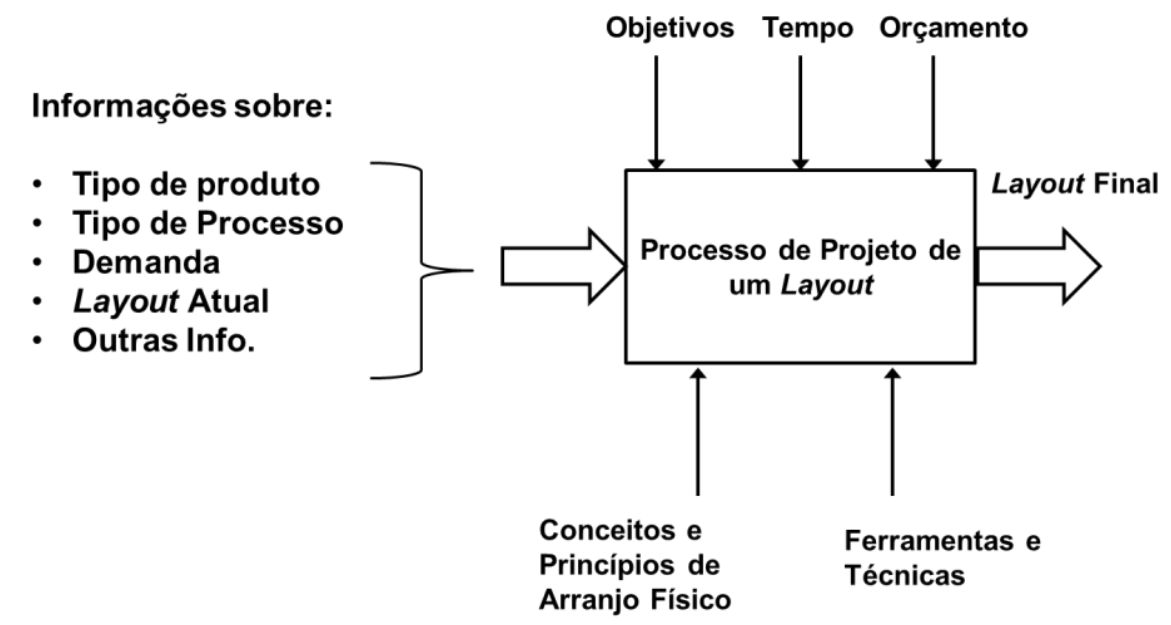

Figura 11 - Esquema de processo de projeto de layout. Fonte: Gonçalves Filho (2001).

$\mathrm{O}$ projeto baseia-se em conceitos e princípios de layout, apoia-se em técnicas e ferramentas para assim criar um produto que satisfaça os objetivos estratégicos da organização dentro de um prazo e orçamento estipulado.

Gonçalves filho desenvolveu um modelo detalhado para desenvolvimento de layout com cinco fases: preparação, pré-projeto, projeto, validação e implementação. O modelo pode ser visto na Figura 12. 


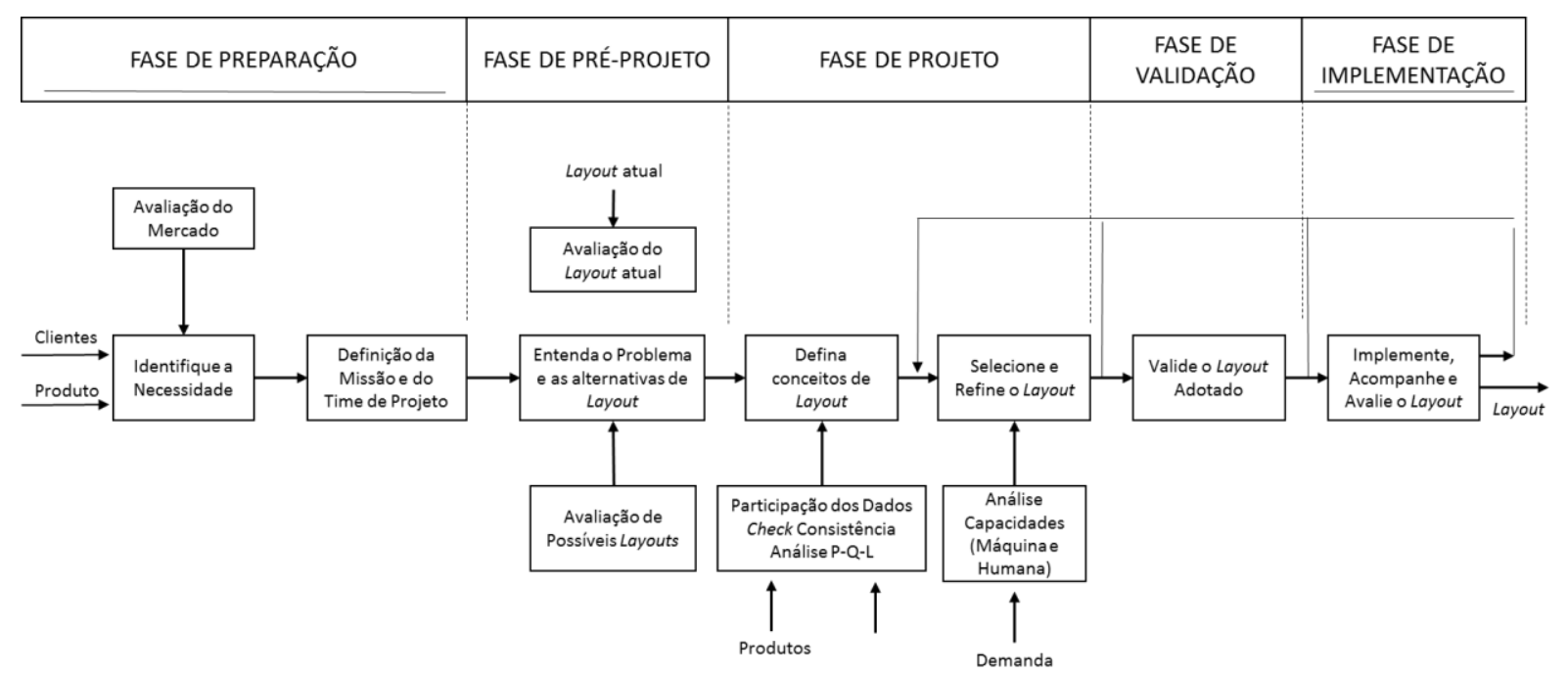

Figura 12 - Modelo de projeto de layout de Gonçalves filho. Fonte: Gonçalves Filho (2001).

Conforme Gonçalves Filho (2001) o layout deve ser bem planejado pois influencia diretamente na participação de mercado com custo e tempo, na qualidade do produto final e consequente satisfação do consumidor, no retorno do investimento, nas datas de entrega e na confiabilidade.

A fase de preparação compreende em identificar a necessidade de mudança que pode ser interna ou externa a organização, definir a missão, definir o time de projeto e planejar as atividades com responsabilidades e prazos.

A fase de pré-projeto consiste em conhecer as condições do chão de fábrica e os conceitos de layout que poderiam ser adaptados como melhorias, avaliar o layout atual com parâmetros e métricas que permitam uma comparação futura e estudar as possíveis alternativas a serem implementadas no arranjo físico. Para isso utiliza-se ferramentas como o Value Stream Mapping e o Diagrama de Causa e efeito, entrevistas e visitas.

A Figura 13 mostra a conexão entre os diferentes tipos de produtos e processos com os tipos de layout, para auxílio nos resultados do modelo em questão. 


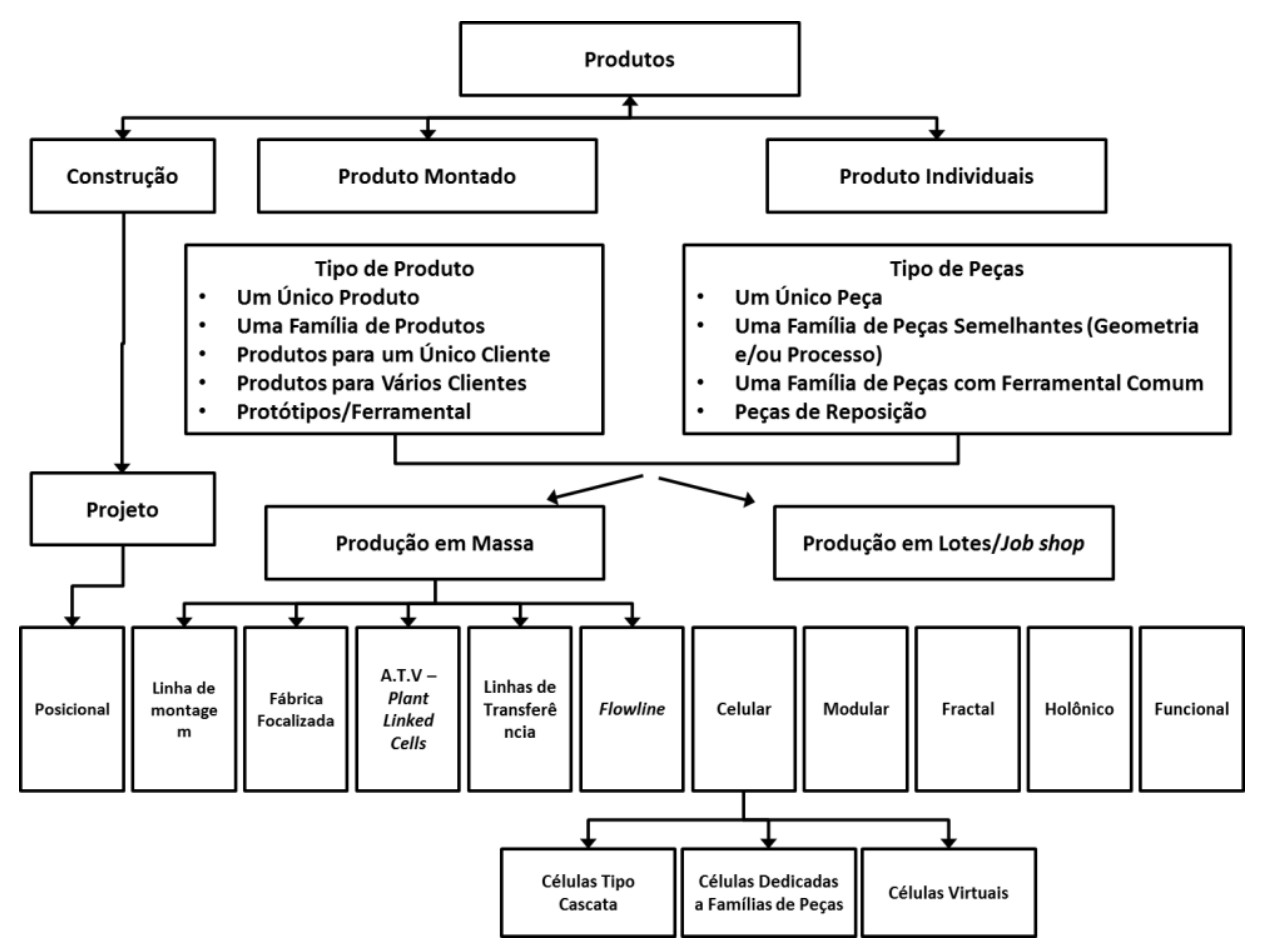

Figura 13 - Conexão entre produto, processo e tipos de layout. Fonte: Gonçalves Filho (2001).

$\mathrm{Na}$ fase de projeto define-se o layout que satisfaça os requisitos e objetivos estipulados anteriormente. Tem como atividades o projeto qualitativo do layout, com a obtenção de dados, checagem de consistência, partição dos dados e definição dos componentes e o projeto quantitativo com análise dos requisitos de carga para cada componente, definição do arranjo físico interno e global.

Como dados de entrada faz-se necessário as seguintes considerações:

O tipo de produto: o qual influencia em questões de dimensão, material, movimentação e acabamento, entre outras.

O processo de fabricação: deve-se conhecer todas as operações necessárias ou de suporte para uma análise de fluxo de produção.

A demanda: esta define a quantidade de produtos por um dado período de tempo, determinando a carga e trabalho e a quantidade de recursos.

A fábrica: esta deveria ser projetada em função do layout ideal, porém deve-se conhecer as paredes, colunas, tubulações, entre outras.

O pessoal: este envolve a qualidade das pessoas, treinamento e multifuncionalidade.

A fase de validação: consiste em visualizar o layout dentro de um espaço físico disponível e simula-lo para identificar as melhorias e os benefícios obtidos. 
A fase de implementação: onde o planejado torna-se realidade, ocorre a movimentação e disposição dos recursos, utiliza-se um software para controle do projeto, gráfico de GANTT ou técnica do caminho crítico. Finalmente auditorias devem ocorrer para garantir o correto funcionamento do layout proposto e implementado.

\subsubsection{Modelo de Tompkins et al. (2010)}

O modelo de Tompkins et al. (2010) faz-se importante pois é um modelo bem completo de processo de projeto de layout e engloba o modelo de Slack, Chambers e Johnston (2008). O modelo contempla três fases, na primeira delas envolve a definição dos objetivos do novo layout ou das melhorias no atual. A segunda fase acessa o estado atual, identificando as metas específicas, avaliando abordagens alternativas, definindo planos de melhorias e buscando suporte para as melhorias. A terceira fase consiste em implementar os planos e auditar os resultados. O Quadro 3 a seguir discutem o modelo de projeto de uma planta com o planejamento desta.

Quadro 3 - Fases e procedimentos do modelo de Tompkis et al. (2010).

\begin{tabular}{|c|c|c|}
\hline Fase & Processo de projeto de uma planta & Passos no planejamento da planta \\
\hline I & $\begin{array}{l}\text { Definir ou redefinir os objetivos } \\
\text { Especificar as atividades primárias e de } \\
\text { suporte }\end{array}$ & $\begin{array}{l}\text { 1a. Entender o modelo de sucesso da } \\
\text { organização } \\
\text { 1b. Entender as questões externas } \\
\text { 1c. Entender as questões internas } \\
\text { 2. Estabelecer critérios de projeto para o } \\
\text { planejamento da planta } \\
\text { 3. Obter um comprometimento } \\
\text { organizacional }\end{array}$ \\
\hline II & $\begin{array}{l}\text { Determinar o inter-relacionamento } \\
\text { Determinar requisitos de espaço } \\
\text { Gerar planos alternativos da planta } \\
\text { Avaliar os planos alternativos } \\
\text { Selecionar o plano da planta }\end{array}$ & $\begin{array}{l}\text { 4. Estabelecer times } \\
\text { 5. Avaliar o estado atual } \\
\text { 6. Identificar os objetivos específicos } \\
\text { 7. Identificar caminhos alternativos } \\
\text { 8. Avaliar caminhos alternativos } \\
\text { 9. Definir os planos de melhoria } \\
\text { 10. Obter suporte para os planos de } \\
\text { melhoria }\end{array}$ \\
\hline III & $\begin{array}{l}\text { Implementar o plano } \\
\text { Manter e adotar o plano da planta } \\
\text { Redefinir os objetivos da planta }\end{array}$ & $\begin{array}{l}\text { 11. Implementar os planos } \\
\text { 12. Verificar os resultados }\end{array}$ \\
\hline
\end{tabular}


O modelo não fixa que todos os layouts de todos os tipos de organizações sigam os procedimentos perfeitamente, sem realizar adaptações, porem um processo cíclico, como mostrado na Figura 15, deve ser seguido.

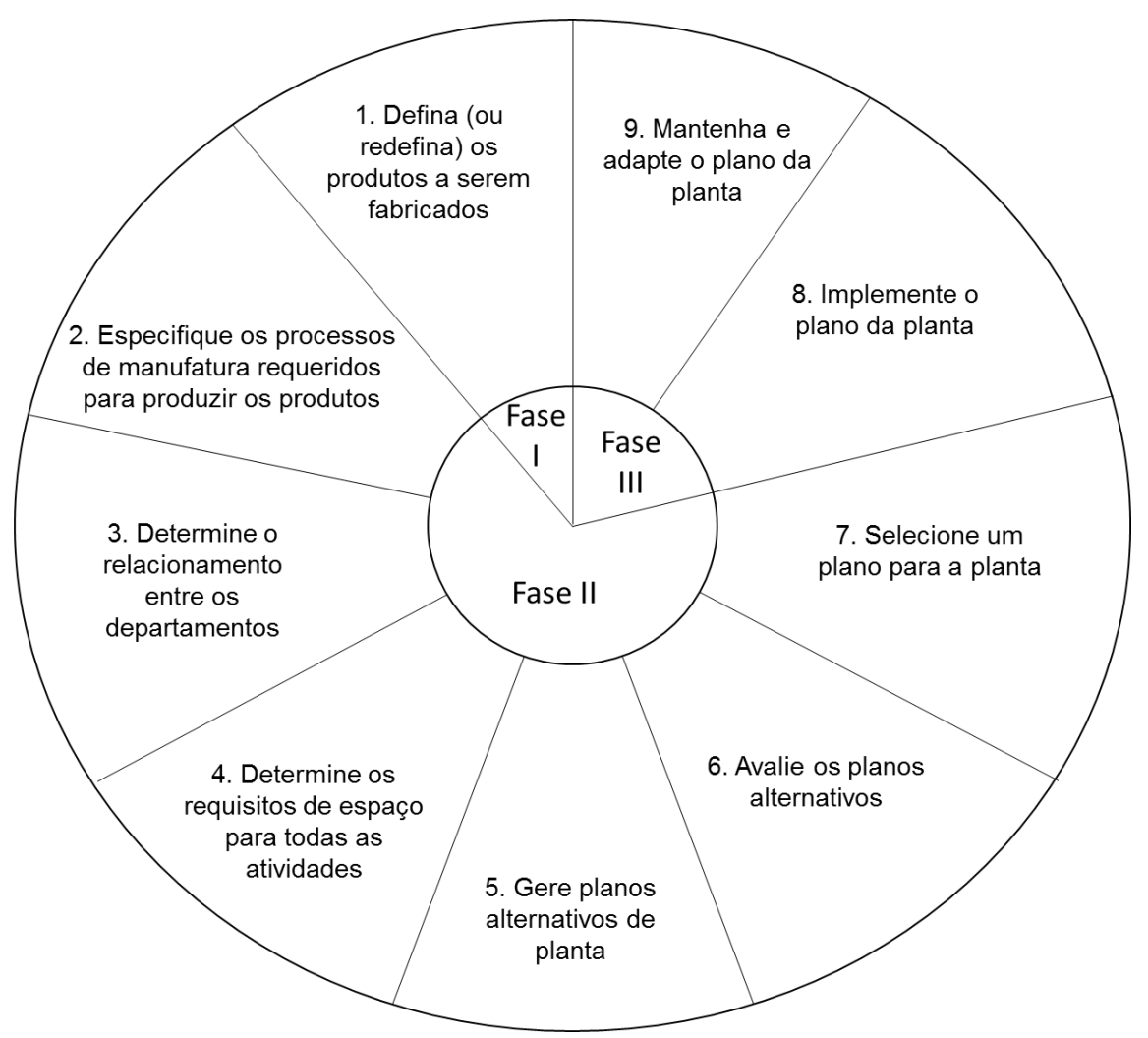

Figura 14 - Processo cíclico para projeto e implantação de layout. Fonte: Traduzido de Tompkins et al. (2010).

\subsection{Avaliação do layout}

A avaliação do layout tem como base a obtenção de soluções adequadas sobre algum tipo de critério objetivo, sendo quantitativo e/ou qualitativo de acordo com Torres (2007). Guerreiro (2005) diz que a análise quantitativa deve ser feita para encontrar um layout econômico e Tortorella (2006) cita como exemplos a flexibilidade, manutenabilidade e segurança, e a análise qualitativa considera influencias entre os diversos fatores de produção diretos e indiretos que não podem ser quantificados, Tortorella (2006) exemplifica o custo de transporte e a distância percorrida.

Muther (1976) apresentam algumas sistemáticas para avaliar um layout: comparação de custos, avaliação de produtividade e do espaço, comparação da linearidade de fluxo, análise de fatores quantitativos e qualitativos e pós e contras. Sempre considerando a estratégia e os objetivos da organização. 
Luzzi (2004) atenta para a definição de critérios para tomada de decisão, apresentando o fluxo de materiais, o custo de fabricação, o retorno de investimento e lead time produtivo, e critérios qualificadores como atendimento as normas, atendimento a demanda, feedback de qualidade e de trabalho em equipe e melhoria na satisfação dos funcionários, todos estes utilizados no seu trabalho. Tortorella (2006) utiliza como critérios, o fator humano, relacionamento entre os departamentos, flexibilidade para futura expansões, nível de re-layout, custo, aproveitamento de área e linearidade de fluxo.

Lin e Sharp (1999) apresentam um conjunto de critérios estruturados para avaliação de layout, o Quadro 4 mostra os 18 critérios classificados em três grandes grupos, custo, fluxo e ambiente. Segundo Lin e Sharp (1999) esses critérios são fáceis de usar e de coletar os dados

Quadro 4 - Critérios para avaliação de layout, traduzido de Lin e Sharp (1999).

\begin{tabular}{|c|c|c|}
\hline \multirow[t]{2}{*}{ Custo } & Não inventário & $\begin{array}{l}\text { Custo inicial: } \\
\text { - Terra } \\
\text { - Prédio } \\
\text { - Máquinários de produção } \\
\text { - Equipamentos de movimentação de materiais; } \\
\text { Custo anual de operação e manutenção: } \\
\text { - Trabalho } \\
\text { - Utilidade } \\
\text { - Manutenção } \\
\text { Futuro valor residual; }\end{array}$ \\
\hline & Inventário & $\begin{array}{l}\text { Custo de manutenção de estoque matéria prima; } \\
\text { Custo de manutenção de estoque WIP; } \\
\text { Custo de manutenção de estoque de produtos finais; }\end{array}$ \\
\hline \multirow{3}{*}{ Fluxo } & $\begin{array}{l}\text { Relacionamento de } \\
\text { espaço }\end{array}$ & $\begin{array}{l}\text { Clareza; } \\
\text { Suficiência de espaço e utilização; }\end{array}$ \\
\hline & Fluxo de material & $\begin{array}{l}\text { Corredor; } \\
\text { Densidade de volume e distância; }\end{array}$ \\
\hline & $\begin{array}{c}\text { Robustez e } \\
\text { flexibilidade }\end{array}$ & $\begin{array}{l}\text { Robustez da capacidade dos equipamentos; } \\
\text { Expansão dos prédios; }\end{array}$ \\
\hline \multirow[b]{2}{*}{ Ambiente } & Circundante & $\begin{array}{l}\text { Topografia e topologia; } \\
\text { Ambiente comunitário; }\end{array}$ \\
\hline & Qualidade do ambiente & $\begin{array}{l}\text { Segurança no trabalho; } \\
\text { Conforto; } \\
\text { Segurança das propriedades; } \\
\text { Acesso para manutenção; }\end{array}$ \\
\hline
\end{tabular}

Raman, Nagalingam e Lin (2009) desenvolveram um modelo de avaliação de layout que incorpora três fatores chaves de performance simultaneamente, sendo eles, flexibilidade, utilização da área produtiva e proximidade. Estes, conforme a Figura 16, foram definidos em vista de quatro objetivos de layout, minimização do custo de movimentação de materiais, melhoria de flexibilidade de arranjo e de operações, utilização efetiva da área disponível e minimização do tempo total de produção. 


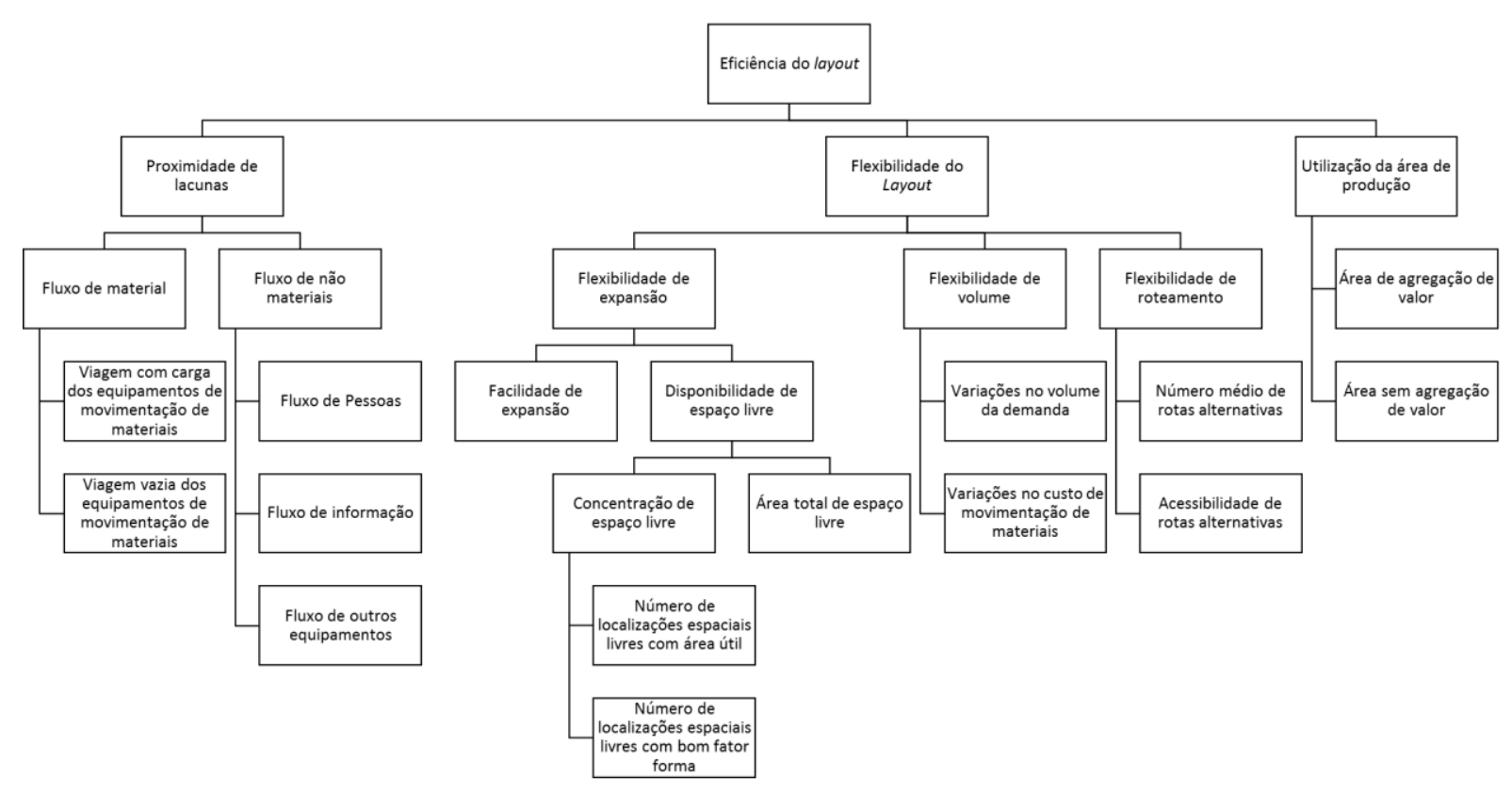

Figura 15 - Modelo de avaliação de layout.

Fonte: Traduzido de Raman, Nagalingam e Lin (2009).

\subsection{Considerações finais do capítulo}

O Capítulo 3 apresentou a revisão bibliográfica realizada para entender o conceito de layout, bem como compreender os diversos modelos existentes para projeto e implementação de layout considerados neste estudo pelos motivos explicados no início do tópico. Além de compreender os diferentes modelos, explica-se aqui os tipos de layout existentes na literatura e conclui-se com métricas para avaliação do layout.

O layout quando bem projetado apresenta-se como uma ótima oportunidade de reduzir ineficiências, transporte excessivo e movimentações desnecessárias, sendo assim importante para aumentar as trocas e relacionamentos entre empresas pois possibilita a interação e integração das empresas visando o correto estabelecimento dos fluxos de entrada e saída de forma simples e clara.

$\mathrm{Na}$ literatura pesquisada e nos modelos estudados e apresentados nesta revisão não foi identificado nenhum que contemplasse questões ambientais em seu planejamento, ou seja, que levasse em consideração as trocas de resíduos exercidas pelas empresas, a integração e compartilhamento de recursos visando a diminuição de impactos ambientais. Nem mesmo um procedimento que buscasse posicionar os recursos transformadores (que neste caso são as empresas) com prioridade para realização de trocas, cooperações e relacionamentos entre eles. 
Foram considerados neste estudo cinco modelos de planejamento de layout que realmente contribuem para o objetivo proposto de favorecer as trocas e a SI dentro de um parque industrial.

Com os modelos citados e o estudo realizado em SI elaborou-se o procedimento a seguir para atingir o objetivo proposto. 


\section{Capítulo 4. ESTRUTURAÇÃO DO PROCEDIMENTO E SEUS PASSOS}

O procedimento é composto por passos, as quais estão estruturadas em forma de um fluxograma, onde cada passo é explicado para correta compreensão e utilização desta. A sequência dos passos também possui importância para obtenção dos resultados desejados e cada uma delas deve ser concluída para que a próxima possa ser iniciada. A seguir tem-se os passos desenvolvidos nesta pesquisa.

\section{1. Ánalise dos modelos}

Inicialmente, faz-se necessário colocar os modelos de planejamento de layout e a característica importante de cada um deles para o desenvolvimento do procedimento e principalmente para o estabelecimento das passos:

- Modelo de Gonçalves Filho: modelo bastante abrangente, apresenta uma sistemática para identificação do melhor tipo de layout a cada situação. Importante para fornecer uma ideia geral do planejamento e seus aspectos em cada situação.

- Modelo de Muther: mais antigo e tradicional modelo de planejamento de layout, denominado de modelo SLP (Systematic Layout Planning). Este método é, sem dúvida, o mais conhecido e o mais utilizado por engenheiros projetistas de layout segundo Camarotto (1998). Devido à grande repercussão e utilização dele nos trabalhos acadêmicos que envolvem o tema, este desempenhou o papel de método base e de maior relevância para esta pesquisa.

- Modelo de Apple: Método geral e aplicável a qualquer tipo de sistema fabril. Os procedimentos traçados pelo autor consideram o processo de layout como um processo evolutivo, mas não restringe os métodos utilizados, permitindo certa variabilidade e confiabilidade dos dados trabalhados conforme Camarotto (1998). Este auxilia no desenvolvimento das etapas, bem como na organização e estruturação do procedimento.

- Modelo de Camarotto e Menegon: metodologia fundamentada no conceito de centro de produção, destaca a construção de templates como entrada para o processo de projeto do layout, sendo este definido em função da estratégia de produção e validado através da simulação. Com este procedimento tem-se a melhor adequação dos passos ao ambiente em questão, a análise importante do layout perante a estratégia adotada. 
- Método de Cury (dos elos): modelo simples que foca na movimentação nos setores, agrupando-os da melhor maneira possível, localiza os setores de forma a minimizar a movimentação. O método dos elos é utilizado como ferramenta em um dos passos.

Para Menegon, Costa e Camarotto (1997) os modelos de planejamento de layout estão inseridos em um ambiente que influencia diretamente no desenvolvimento do modelo, pois este visa atender os objetivos e estratégias adotadas naquele momento a curto, médio ou longo prazo. No modelo apresentado pelos autores todas as etapas estão dentro do ambiente, considerado o contexto e a estratégia para o planejamento do layout.

Neste caso, o contexto é a adequação da SI no planejamento do layout, buscando favorecer trocas, relacionamentos e assim obter o sucesso desta como estratégia para transformação de um ciclo produtivo linear em circular ou fechado, seguindo conceitos de EI e sustentabilidade.

\subsection{Adequação à SI}

Há portanto dois conceitos chaves para a adequação dos modelos, continuar a buscar eficiência produtiva, no que se refere a fluxos de materiais e informações para o processo de fabricação dos produtos de cada empresa e conciliar com o conceito de SI, onde existirão fluxos de subprodutos e resíduos, além de mais informações. Tudo deve coexistir dentro de um sistema onde tecnologias troquem esses fluxos a fim de reduzir custos e melhorar aspectos ambientais dos participantes.

No planejamento do layout faz-se necessário a introdução de conceitos de SI para melhor desenvolvimento, desempenho e consequente sucesso dela em todo e qualquer sistema que envolva interação entre três ou mais empresas como sugere Chertow (2007).

Os passos desenvolvidos estão voltados ao ambiente de SI, portanto estão focadas no desenvolvimento de relações simbióticas, priorizando a proximidade geográfica entre empresas que as realizem. Para considerar os fluxos produtivos normais e as relações provenientes dos produtos principais de cada empresa, deve-se utilizar o método clássico em conjunto com estes passos para melhor tomada de decisão.

O foco portanto está voltado a SI, entre suas trocas e relacionamentos, é neste fluxo que os passos desenvolvidos nesta seção têm sua razão de existir, objetivando auxiliar a tomada de decisão quando planejar com esta estratégia ambiental. Este é o contexto no qual situam-se os passos para o planejamento do layout para SI a ser elaborado. 
Para propor os passos para o planejamento de layout considerando aspectos de SI, os quatro modelos escolhidos foram comparados e utilizados na elaboração de cada passo, com a inclusão e modificações pertinentes ao conceito a ser colocado.

Trazendo para o cenário onde a SI é o foco, objetivo e estratégia principal do planejamento do layout, a primeira fase portanto tem que consistir na obtenção de dados das unidades produtivas. Neste caso, unidades produtivas são expandidas da definição atual para uma conversão de uma forma ou estado de material ou energia em outro, incluindo também o deslocamento geográfico e a estocagem (RAAFAT et al., 2013).

Neste estudo as unidades produtivas consideram entrada de recursos, serviços de suporte se necessários e saída, sendo o output principal desta função e subprodutos e/ou resíduos.

\subsection{Primeiro passo (D1): Obter os dados de entrada}

Todos os modelos começam com a busca e obtenção de dados, Apple (1977) em seu contexto geral fala em adquirir os dados básicos, o autor cita 14 itens a serem obtidos, sendo entre eles: demanda, volume, tempos e limites de espaço. Gonçalves filho (2001) estruturou uma fase de preparação, onde deve-se entender a necessidade e definir a estratégia e uma próxima fase chamada de fase de pré-projeto onde tem-se a atividade de avaliação do layout atual. Camarotto e Menegon (1996) estruturam a fase de mix de produção e tecnologia onde deve-se identificar todos os produtos envolvidos e a tecnologia para fabricá-los. Por fim e com maior importância, Muther (1973) começa a estruturar seu modelo com a obtenção dos dados de entrada (chamados por ele de Produto (P), Quantidade (Q), Roteiro (R), Serviços de suporte (S) e Tempo (T)), pois são eles que darão base para os demais passos.

Os primeiros dados que devem ser coletados são todos os inputs e outputs (inclui-se subprodutos e resíduos) dentre todas as tecnologias envolvidas no planejamento do layout geral.

A Figura 17 mostra a primeiro passo no centro e os dados que devem ser coletados e portanto a compõe, ao redor desta, dizendo também que todos os dados são importantes e necessários para futuras análises. 


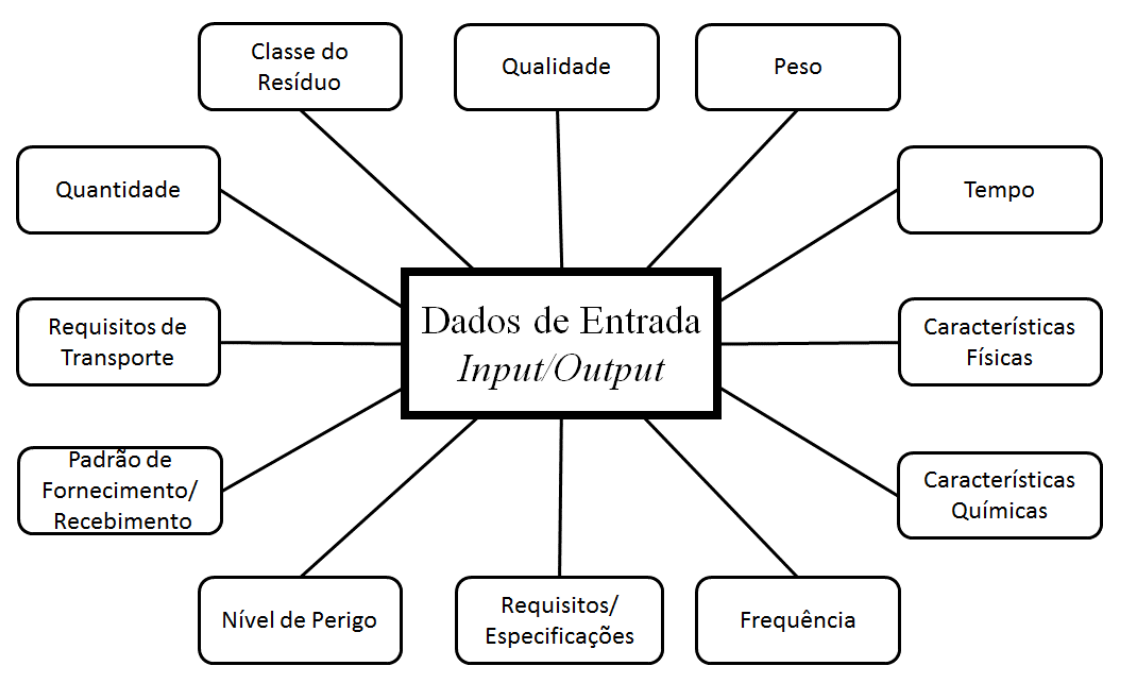

Figura 16 - Passo D1 e seus dados necessários.

Para desenvolver a SI é necessário obter informações a respeito de cada input/output para posteriores trocas e relacionamentos. Baseados em Felício (2013) e Raafat et al. (2013), Lowe (2001) e Trokanas, Cecelja (2013) tem-se os seguintes dados a serem conseguidos neste início:

- Classe do resíduo: Não perigosos - Inerte (Classe IIB), Não perigosos - Não inertes (Classe IIA) e Perigisos (Classe I); (pode ser consultado no anexo A);

- Qualidade: deve-se observar se o resíduo em questão pode ser utilizado novamente, se ele está apto a realizar sua função com eficácia. Caso este estiver fora da qualidade exigida pela unidade produtiva que irá utilizá-lo, deve explicar o porquê para que sejam tomadas providencias ou descarte. E deve-se analisar a qualidade requerida para que seja input.

- Quantidade: corresponde ao volume produzido de output por determinada unidade de tempo, e a quantidade demandada de input por unidade de tempo.

- Peso: peso de uma dada unidade, lote ou volume de cada resíduo ou subproduto para saber a carga e força necessária para move-la ou armazena-la, tanto dos inputs quanto dos outputs.

- Tempo: período de tempo em que o output ainda pode ser utilizado após o processamento até ser um input sem perder a qualidade e funcionalidade ou se este necessita de um período para voltar a condição inicial.

- Características físicas: características que definem o resíduo ou subproduto e o input requerido, estado físico, aspecto, temperatura e anormalidades se houver. 
- Características químicas: necessário principalmente em gases e líquidos para entender toxidade, entalpia, combustão, reatividade, instabilidade, inflamabilidade, caso for importante para a troca.

- Frequência: frequência com que o output é produzido por unidade de tempo, e com que o input é demandado (por mês, por dia, por hora, por minuto).

- Requisitos/especificações: aqui estão as necessidades e características específicas de cada resíduo ou subproduto, para que este mantenha integridade, qualidade e validade durante o período em que o output torna-se input, bem como se há necessidade de armazenagem específica.

- Nível de perigo: se os resíduos ou subprodutos são tóxicos, inflamáveis, radioativos, perigosos, de temperaturas altas, de temperaturas muito baixas, corrosivos, etc.

- Padrão de fornecimento/recebimento: padrão no qual o resíduo ou subproduto é fornecido e recebido pelas unidades produtivas, necessário para adequação do transporte e qualquer movimentação necessária.

- Requisitos de transporte: o que for necessário realizar no transporte entre as unidades produtivas para que o resíduo ou subproduto mantenha a qualidade, validade, integridade e tenha segurança tanto dele como das pessoas e materiais envolvidos.

Uma informação que deve ser coletada para melhorar o desenvolvimento da SI, inclusive no longo prazo com a sustentação dos relacionamentos é sobre o processo em si. Este deve estar atualizado e portanto ter a taxa de geração de resíduos mínima possível, caso o processo seja ultrapassado, este pode ser trocado e portanto teria a oferta de resíduos ou subprodutos reduzida, podendo afetar nas trocas simbióticas estabelecidas. Portanto, é muito importante realizar a verificação e análise do processo para identificar oportunidades de melhorias neste primeiro passo.

Os dados abordados por Muther (1973) como Roteiro de fabricação, Tempo de processamento e Serviços de suporte não são consideradas por esta pesquisa no planejamento do layout com aspectos de SI. O foco não está no processo em si, em como e com quanto tempo os inputs são transformados em outputs, mas sim na integração das trocas e relacionamentos na transformação das saídas em inputs simbióticos para posterior processamento. Portanto considera-se o tempo de processamento de cada unidade produtiva como zero. 
No apêndice B apresenta-se um exemplo de formulário para ser aplicado neste primeiro passo para obter os dados pertinentes a esta. Não é necessário preencher todos os campos, pois cada resíduo possui certas particularidades que se encaixam ou não em cada campo. Ao final deste é colocado um campo de observações para serem discutidas questões específicas de cada resíduo que não foram contempladas pelo formulário. Os dados que são imprescindíveis de serem coletados para o desenvolvimento dos passos e obtenção dos resultados são o tipo de material e a quantidade.

Além de obter os dados de entrada para dar prosseguimento ao planejamento, a SI requer que se tenha uma etapa onde esses resíduos são analisados e comparados para verificação de possíveis trocas (matching), o que é baseado no procedimento 2 de Apple (1977) que fala em análise dos dados obtidos a Figura 18 relaciona a etapa 1 com esta seguinte.

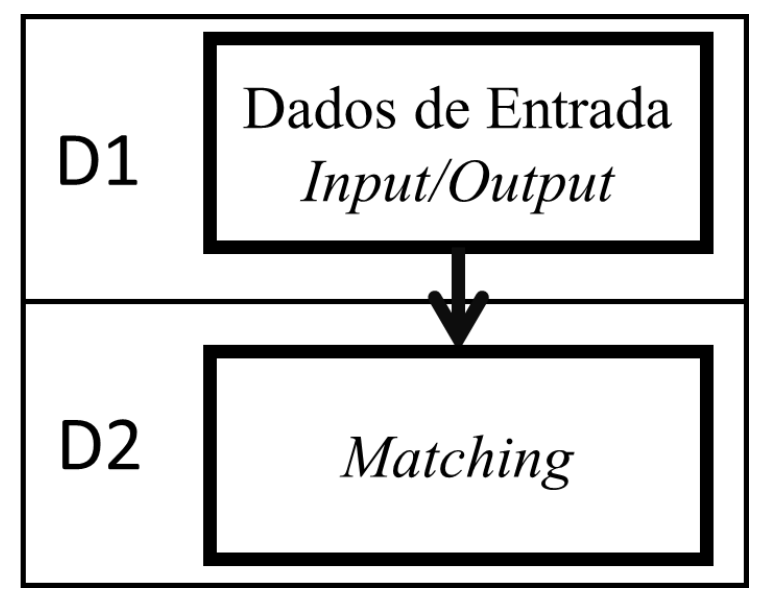

Figura 17 - Primeiro e segundo passos.

Portanto após conseguir todos os dados de entrada necessários, o próximo passo consiste em encontrar os inputs e outpus correspondentes para realizar o "match", ou seja, unir aqueles que são iguais e portanto transformar os outputs de um processo em inputs de outro. Desta forma neste momento encontra-se as possíveis trocas simbióticas no sistema em questão, de acordo com as características de cada empresa participante na SI.

\subsection{Segundo passo (D2): Realizar o Matching}

Nesta etapa primeiramente ocorre a combinação dos outputs que são iguais ou muito semelhantes em tipo (observa-se o nome do resíduo) para que se tornem inputs simbióticos. Todas as possibilidades devem ser apontadas para que seja feito uma escolha das melhores oportunidades de troca posteriormente. 
A Figura 19 a seguir ilustra a relação das atividades que compõe esta etapa, começando com os dados de entrada, a busca por semelhanças, a verificação dos demais dados com o auxílio do Quadro 5 para se ter um melhor entendimento do que deve ser analisado e por fim obtém-se a compatibilidade e os matchings possíveis.

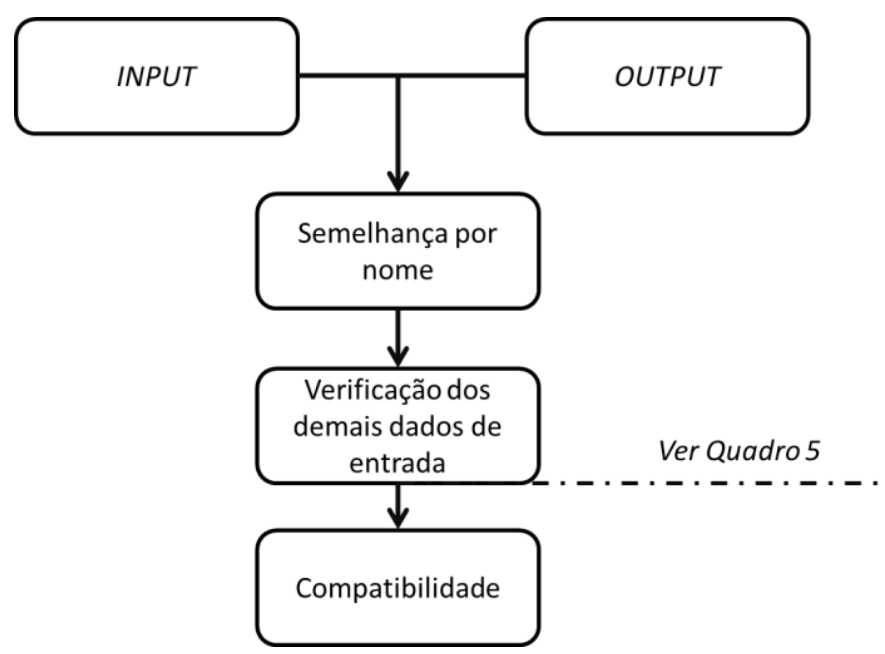

Figura 18 - Fluxograma do passo D2.

Encontrado os inputs e outputs correspondentes, estuda-se os demais dados de entrada para verificar questões de quantidade ofertada e demandada, validade, características, frequência de produção, requisitos gerais ou de transporte, padrões de fornecimento e recebimento e por fim se a qualidade fornecida é compatível com a desejada pela empresa cliente.

O Quadro 5 a seguir apresenta como deve ser realizada a verificação dos dados de entrada, são colocadas as informações requisitadas, o que deve ser verificado para cada uma delas, levando em consideração as necessidades futuras do procedimento, e ações que devem ser tomadas em cada caso, se alguma especificação for diferente de um resíduo para outro em uma provável troca.

Quadro 5 - Verificação e ações para cada dado de entrada.

\begin{tabular}{|c|c|c|}
\hline \multicolumn{3}{|c|}{ Verificação dos dados de entrada } \\
\hline Dados de entrada & Verificar & Ações \\
\hline Classe & $\begin{array}{l}\text { Se o input e output são da mesma } \\
\text { classe }\end{array}$ & $\begin{array}{l}\text { Caso estes não forem da mesma } \\
\text { classe, analisar a necessidade de } \\
\text { reprocesso ou tratamento }\end{array}$ \\
\hline Qualidade & $\begin{array}{l}\text { A qualidade do output fornecida e } \\
\text { a requerida pelo input }\end{array}$ & $\begin{array}{l}\text { Analisar para tratamento, } \\
\text { reprocesso ou descarte. }\end{array}$ \\
\hline & & \\
\hline & & \\
\hline
\end{tabular}




\begin{tabular}{|c|c|c|}
\hline Dados de entrada & Verificar & Ações \\
\hline Tempo & $\begin{array}{l}\text { O tempo em que o resíduo não } \\
\text { perde suas características }\end{array}$ & $\begin{array}{l}\text { A troca deve ser realizada } \\
\text { rapidamente caso o tempo for } \\
\text { curto, se necessitar de espera, } \\
\text { providenciar armazenagem. }\end{array}$ \\
\hline Características físicas e químicas & $\begin{array}{l}\text { A compatibilidade das } \\
\text { características }\end{array}$ & $\begin{array}{l}\text { Analisar para tratamento, } \\
\text { reprocesso, seleção, separação ou } \\
\text { descarte. }\end{array}$ \\
\hline Frequência & $\begin{array}{l}\text { A frequência de produção (diário, } \\
\text { semanal, anual) }\end{array}$ & $\begin{array}{l}\text { Analisar a oferta do resíduo com a } \\
\text { necessidade deste e quando elas } \\
\text { ocorrem para assim saber se é } \\
\text { preciso ter estoques ou não. } \\
\text { Adequar a estratégia das unidades } \\
\text { produtivas envolvidas. }\end{array}$ \\
\hline $\begin{array}{l}\text { Padrão de } \\
\text { fornecimento }\end{array}$ & $\begin{array}{l}\text { Como o output é fornecido e o } \\
\text { input é recebido pelas unidades } \\
\text { produtivas }\end{array}$ & $\begin{array}{l}\text { Analisar o transporte } \mathrm{e} \\
\text { movimentações necessárias, no } \\
\text { caso de incompatibilidade, trocar } \\
\text { as unidades produtivas. }\end{array}$ \\
\hline
\end{tabular}

\subsubsection{Considerações desta fase}

Em caso de duas ou mais trocas possíveis, deve-se escolher a mais interessante e vantajosa ao sistema conforme a estratégia (GONELA e ZHANG 2014).

Se não houver trocas relacionadas a um dado resíduo, deve-se seguir a estratégia e tomar decisão conforme os stakeholders e se nenhuma outra função for encontrada, realiza-se o descarte deste apropriadamente e legalmente.

Necessidade de retrabalho, reprocessamento, processamento diferenciado, tratamento ou separação torna-se importante na consideração de etapas por onde os resíduos passariam antes de serem inputs novamente e locais para realizar tais procedimentos no planejamento do layout. Para tanto deve-se entender exatamente o que precisa ser feito e como, para adequação do plano.

\subsection{Terceiro passo (D3): Analisar o fluxo de materiais}

Neste passo, Apple (1977) sugere o planejamento do padrão de fluxo dos materiais como próxima etapa, Camarotto e Menegon (1996) falam do templates dos centros de produção e Muther (1973) diz que deve-se pensar no fluxo de materiais sendo este a base da maioria dos 
arranjos físicos e estruturar as inter-relações e Gonçalves Filho (2001) sendo mais geral, comenta para que defina-se a organização geral do layout relacionando demanda e capacidade e os demais dados.

Desta maneira, este passo é o fluxo dos resíduos, mais especificamente o roteiro de cada um desses, juntamente com quantidade e/ou volume, desde a saída de uma unidade produtiva até funcionarem novamente como inputs em outra. Resíduos neste caso também representará os eventuais subprodutos de uma empresa que sirvam como matéria-prima para outra dentro do sistema analisado.

A Figura 20 ilustra as duas atividades que compõe esta etapa, sendo a ferramenta Carta De-Para e a Carta com unidades produtivas e resíduos que juntas conseguem analisar o fluxo de materiais para melhor planejamento do layout.

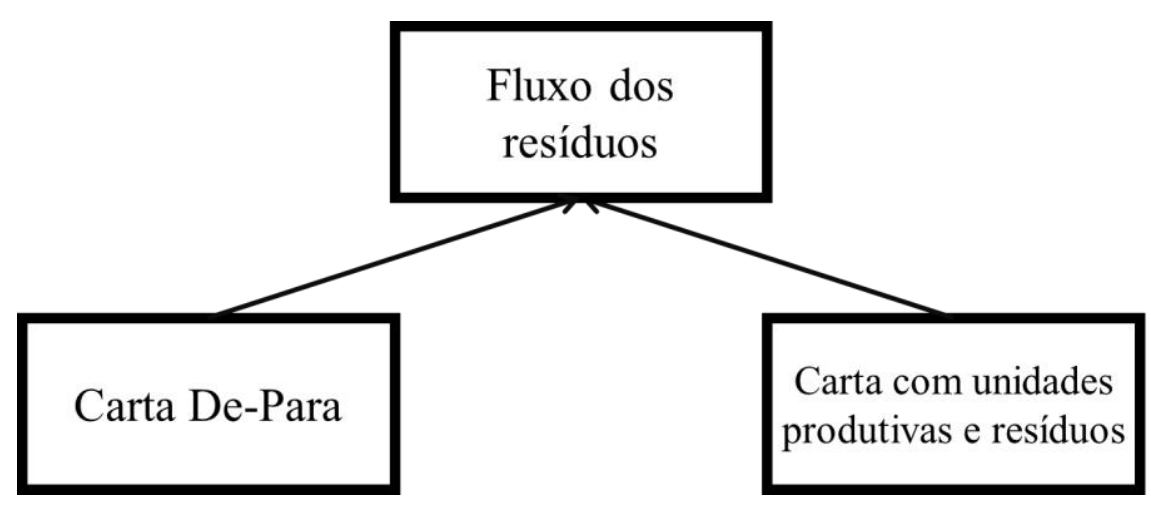

Figura 19 - Atividades que compõe a etapa de Fluxo dos resíduos.

Uma ferramenta a ser usada neste momento é a carta de processo onde basicamente segundo Muther (1973) são dados símbolos e estes são ligados por linhas segundo o roteiro específico, e cada símbolo é colocado no processo a qual este se relaciona, os processos são descritos na primeira coluna do quadro a ser elaborado e cada produto corresponde a uma coluna, como demonstrado na Figura 21.

\begin{tabular}{|l|c|c|c|c|c|c|c}
\hline $\begin{array}{l}\text { Peça/ } \\
\text { produto } \\
\text { Operação }\end{array}$ & A & B & C & D & E & F & \\
\hline Cortar & 1 & 1 & 1 & & 1 & 1 & \\
\hline Entalhar & 2 & 2 & 2 & 1 & & & \\
\hline Estirar & & 3 & & 4 & 2 & 3 & 3 \\
\hline Furar & 3 & & 3 & & 2 & 2 & \\
\hline Dobrar & 4 & 4 & & 3 & 4 & 4 & \\
\hline Aplainar & & 5 & 5 & 4 & 5 & &
\end{tabular}

Figura 20 - Carta de processos. Fonte: Adaptada de Muther (1973). 
Adaptando esta ferramenta segundo o contexto da SI, os processos são as unidades produtivas que fazem parte da SI e os produtos são os resíduos. Para cada resíduo é colocado uma circunferência com o número 1 representando a unidade produtiva em que este é output, uma circunferência com o número 2 representando a qual ele torna-se input simbiótico e assim sucessivamente caso este resíduo passe por mais de 2 unidades produtivas, até que o resíduo seja totalmente utilizado ou descartado, por fim liga-se os círculos com uma linha, como pode ser visto no Quadro 6.

Nesta ferramenta deve-se incluir locais de processamento dos resíduos, separação e tratamento caso for necessário na realização das trocas. No exemplo a ser utilizado por esta pesquisa utiliza-se os nomes de unidades produtivas para quatro empresas fictícias e o nome de centro de tratamento, este serve para identificar um processo intermediário no sistema que trata resíduos e para exemplificar que as unidades produtivas podem ser nomeadas para melhor entendimento.

Quadro 6 - Carta de unidades produtivas e resíduos.

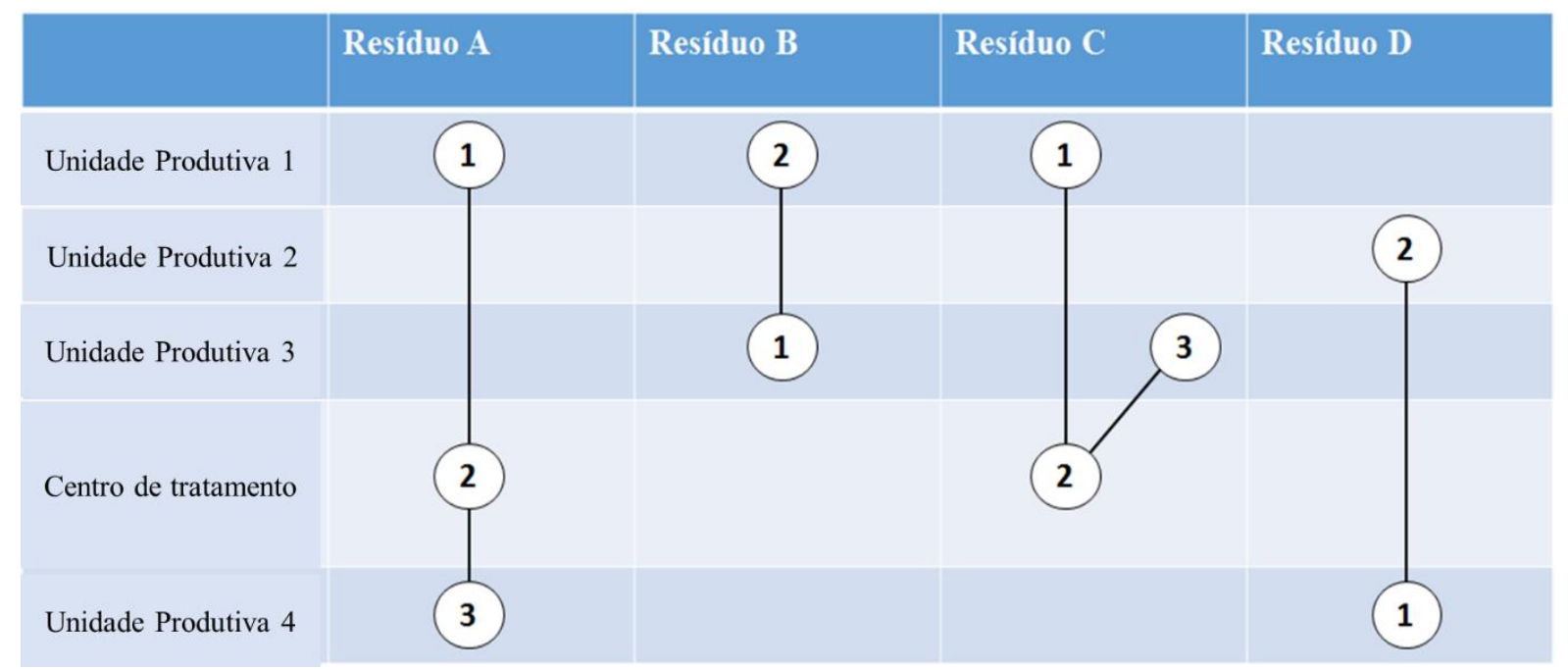

Outra ferramenta importante a ser utilizada neste momento para Muther (1973) é a Carta De-Para, exemplificada na Figura 22 abaixo, para construí-la lista-se as operações ou centros de trabalho na primeira linha e na primeira coluna, obedecendo a mesma sequência, para cada item é posto um valor (peso, volume, tamanho ou quantidade) na coluna apropriada que representa cada movimento deste. No final cada quadrícula é somada e tem-se o grau de fluxo para cada operação com as demais analisadas e ao somar as quadrículas correspondentes a um par de unidades produtivas, tem-se o fluxo total entre elas. No exemplo apresentado por Muther (1973), ele utiliza dois valores de referência em cada quadrícula, a quantidade de peças e a intensidade de fluxo (quantidade $\mathrm{x}$ tamanho $\mathrm{x}$ cuidado). 


\begin{tabular}{|c|c|c|c|c|}
\hline De Para & Embalagem & Recebimento/despacho & Armazém & Totais \\
\hline Embalagem & 0 & 400 & 0 & 400 \\
\hline Recebimento/despacho & 0 & 0 & 2000 & 2000 \\
\hline Armazém & 400 & 1600 & 0 & 2000 \\
\hline Totais & 400 & 2000 & 2000 & \\
\hline \multicolumn{5}{|l|}{ b. Total de fluxo entre } \\
\hline Pares de setores & Fluxo & $\begin{array}{c}\text { Prioridade } \\
\text { de proximidade }\end{array}$ & & \\
\hline Embalagem e recebimento/despacho & 400 & E & & \\
\hline Embalagem e armazém & 400 & E & & \\
\hline Armazém e recebimento/despacho & 3600 & A & & \\
\hline
\end{tabular}

Figura 21 - Exemplo de Carta De-Para.

Fonte: Adaptado de Muther (1973).

Para o contexto da SI, no lugar das operações coloca-se as unidades produtivas, nas quadrículas põe-se dois valores, o código para cada input simbiótico dado no formulário na etapa de dados de entrada Input/output e um número que represente a intensidade do fluxo do resíduo. Ver Quadro 7 com um exemplo com números e unidades produtivas fictícias.

Quadro 7 - Carta De-Para com unidades produtivas e resíduos.

\begin{tabular}{|l|c|c|c|c|c|}
\hline \multicolumn{1}{|c|}{ PARA } & $\begin{array}{l}\text { Unidade } \\
\text { Produtiva 1 }\end{array}$ & $\begin{array}{l}\text { Unidade } \\
\text { Produtiva 2 }\end{array}$ & $\begin{array}{l}\text { Unidade } \\
\text { Produtiva 3 }\end{array}$ & $\begin{array}{l}\text { Centro de } \\
\text { tratamento }\end{array}$ & $\begin{array}{l}\text { Unidade } \\
\text { Produtiva 4 }\end{array}$ \\
\hline $\begin{array}{l}\text { Unidade } \\
\text { Produtiva 1 }\end{array}$ & $\mathrm{X}$ & - & - & $\mathrm{A}, \mathrm{C} / 200$ & - \\
\hline $\begin{array}{l}\text { Unidade } \\
\text { Produtiva 2 }\end{array}$ & - & $\mathrm{x}$ & - & - & - \\
\hline $\begin{array}{l}\text { Unidade } \\
\text { Produtiva 3 }\end{array}$ & $\mathrm{B} / 200$ & - & $\mathrm{x}$ & - & - \\
\hline $\begin{array}{l}\text { Centro de } \\
\text { tratamento }\end{array}$ & - & - & $\mathrm{C} / 100$ & $\mathrm{x}$ & $\mathrm{A} / 100$ \\
\hline $\begin{array}{l}\text { Unidade } \\
\text { Produtiva 4 }\end{array}$ & - & $\mathrm{D} / 150$ & - & - & $\mathrm{X}$ \\
\hline
\end{tabular}

A intensidade de fluxo será calculada baseada principalmente na quantidade e em algumas variáveis que podem influenciar no planejamento do layout, baseado nos estudos de Muther(1973), Raafat (2013), Lowe (2001; 2007) e Trokanas, Cecelja e Raafat (2014).

A quantidade corresponde ao quanto daquele resíduo está sendo movimentado por um dado período de tempo, pode ser medido em volume, área ou unidade. 
Algumas variáveis encontradas nos trabalhos colocados anteriormente influenciam diretamente o planejamento do layout com aspectos de SI, porém estas não são facilmente mensuráveis e dependem de cada caso, das especificações e do sistema em si.

O volume do resíduo deve ser considerado em uma escala que analise se ele é muito grande ou grande e com isso demanda trabalho pra movimentação e necessita de proximidade geográfica até chegar num nível onde ele é pequeno e com isso fácil de movimentar.

O tempo é muito importante neste momento pois alguns resíduos podem perder características com o passar deste e portanto as unidades produtivas que os utilizarem necessitam estar próximas. Resíduos orgânicos geralmente possuem um certo período até que estes percam algumas características que podem ser essenciais para algumas funções.

As características são extremamente importantes para definir a forma de movimentação de um dado resíduo pois cada estado físico exige diferentes condições de transporte e formas para movimentação, transportar um sólido é mais fácil do que um líquido ou um gás. A temperatura influencia nos cuidados também, caso ela esteja maior ou menor do que a ambiente, esta trocará calor com o meio e portanto perderá suas características, necessitando assim de equipamentos especiais e será mais fácil se as unidades produtivas estiverem próximas. Quando estas são danosas ou ser humano, elas exigirão maior cuidado e isto deve ser levado em consideração na carta De-Para.

Por fim deve-se considerar para fins de custo baixo os requisitos de transporte, onde quanto mais equipamentos um resíduo exige em seu transporte, mais custoso ele se torna e menor deve ser a distância entre as unidades produtivas que o usam.

Cada variável citada anteriormente que influencia na intensidade de fluxo deve ser considerada no cálculo, porém elas dependem de caso a caso. Portanto deve-se entender a importância de cada uma de acordo com o sistema em questão e como cada uma será colocada na intensidade de fluxo fica a critério dos responsáveis pelo planejamento do layout para SI segundo os passos desta pesquisa. Cada estratégia adotada é diretamente afetada com maior ou menor intensidade por cada uma das variáveis citadas.

Após a obtenção do valor correspondente a intensidade de fluxo para cada unidade produtiva, deve-se ordenar as unidades produtivas de acordo com as intensidades de fluxo, conforme está apresentado na Quadro 8, somando o total DE e total PARA de cada unidade produtiva. 
Quadro 8 - Fluxos De e Para totais para cada unidade produtiva.

\begin{tabular}{|l|l|l|l|l|}
\hline $\begin{array}{c}\text { Ordem por } \\
\text { intensidade de } \\
\text { fluxo }\end{array}$ & Unidade produtiva & Total DE & Total PARA & Total \\
\hline 1 & 1 & 200 & 200 & 400 \\
\hline 1 & Centro de tratamento & 200 & 200 & 400 \\
\hline 2 & 3 & 200 & 100 & 300 \\
\hline 3 & 4 & 150 & 100 & 250 \\
\hline 4 & 2 & 0 & 150 & 150 \\
\hline
\end{tabular}

Com isso tem-se uma compreensão de quais unidades produtivas realizam mais relacionamentos e por isso precisam de mais atenção.

Após esse procedimento deve-se somar as quadrículas correspondentes ao par de unidades produtivas que realizam cada troca, considerando desta forma qualquer troca entre essas independentemente de qual é a cliente ou fornecedora e classificá-las conforme suas intensidades somadas em cinco grupos: A (absolutamente necessário), E (Especialmente importante), I (Importante), O (pouco importante) e U (desprezível). No Quadro 9 tem-se os pares, nomeados de trocas, as intensidades de fluxos somadas relativas a cada troca e sua classificação.

Quadro 9 - Intensidade de fluxo para cada par e classificação.

\begin{tabular}{|l|l|l|}
\hline Troca & Intensidade de fluxo & Classificação \\
\hline UP1 - Centro de tratamento & 200 & A \\
\hline UP3 - UP1 & 200 & A \\
\hline UP4 - UP2 & 150 & E \\
\hline Centro de tratamento - UP3 & 100 & I \\
\hline Centro de tratamento - UP4 & 100 & I \\
\hline
\end{tabular}

Todas as trocas são importantes, porém deve-se haver uma certa preferência a aquelas com maior intensidade de fluxo no planejamento do layout a fim de favorecer a eficiência da SI.

Os três passos desenvolvidos até esta parte da pesquisa estão representados na Figura 23. 


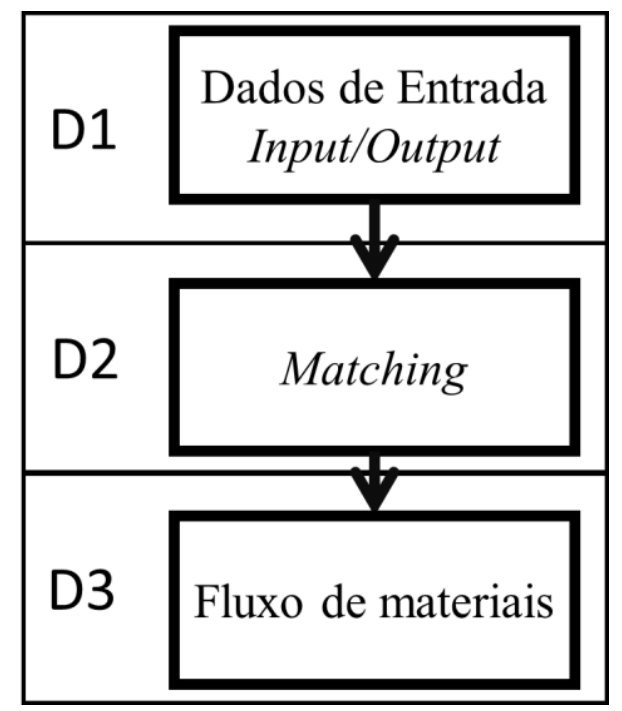

Figura 22 - Passos: D1, D2 e D3.

\subsection{Quarto passo (D4): Elaborar a inter-relações das unidades produtivas}

Apple (1977) em seu décimo procedimento cita a importância dos relacionamentos para a eficiência do layout, assim como Camarotto e Menegon (1996) na fase de templates dos centros de produção e construção do layout, além desses Muther (1973) coloca uma atividade em paralelo com o fluxo de materiais em seu modelo e a chama de inter-relações de atividades, sendo ela a terceira etapa do planejamento do Layout. Desta forma a quinto passo segue esta etapa, pois esta coloca todas as atividades e as classificam de acordo com as relações entre elas.

Neste passo, chamado de inter-relações das unidades produtivas, tem-se o desenvolvimento de duas importantes ferramentas tiradas de Muther (1973), a carta de interligações preferenciais e o diagrama de inter-relações das unidades produtivas, a classificação baseada no número de trocas simbióticas e a aplicação do método dos elos, conforme representado na Figura 24.

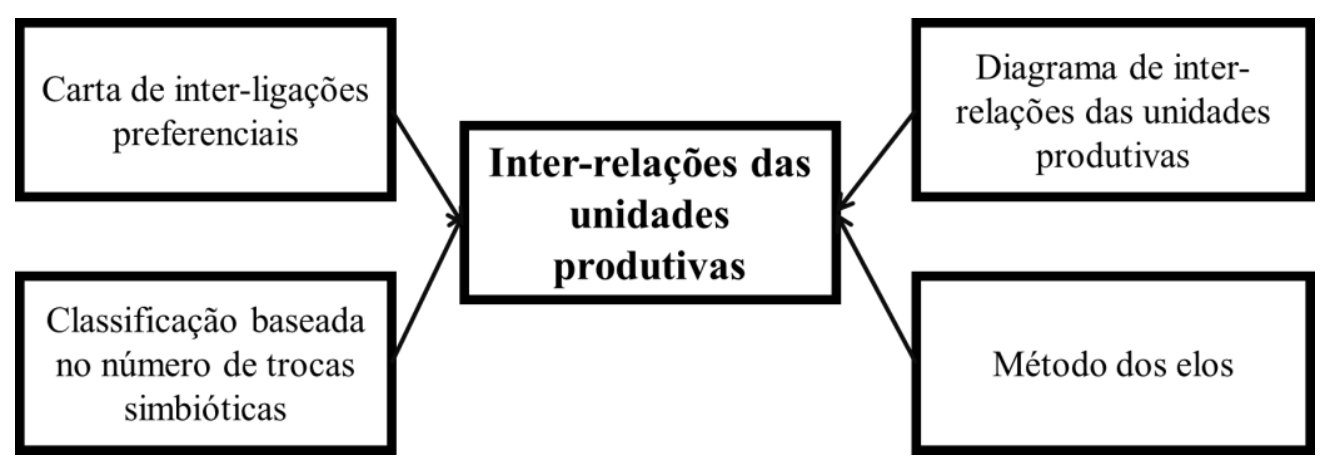

Figura 23 - Inter-relações das unidades produtivas e ferramentas que a compõe. 


\subsubsection{Classificação baseada no número de trocas simbióticas}

Nesta etapa tem-se a classificação dos resíduos conforme especificado anteriormente baseado apenas na intensidade de fluxo (a partir da carta De-Para) e na carta de interligações preferenciais onde o grau de proximidade é baseado em uma análise mais qualitativa do sistema. Faz-se necessário uma terceira análise que complemente essa classificação e o procedimento para posterior tomada de decisão, uma classificação baseada no número de interligações de cada unidade produtiva com as demais.

Todas as trocas devem ser contabilizadas, obtendo assim o número total delas que participam ativamente da SI.

Total de Trocas $=\sum n$ trocas realizadas entre todas as tecnologias

Em uma tabela são listadas todas as unidades produtivas na coluna à esquerda, em seguida são colocadas o número de trocas que cada unidade produtiva realiza, independentemente de suas parceiras, podendo esta realizar mais de uma troca com a mesma unidade produtiva. Total de trocas da unidade produtiva 1 (Tt1) é o somatório das trocas que esta unidade produtiva realiza.

$$
T t 1=\sum n \text { Trocas da tecnologia } 1
$$

Na coluna seguinte encontra-se o percentual de trocas que cada empresa desenvolve em relação ao sistema de SI, sendo o total de trocas por unidade produtiva dividido pelo total de trocas do sistema vezes 2 , pois as trocas são consideradas duas vezes.

$$
\% \text { de troca } n=\frac{\text { Ttn }}{\text { Total de Trocas } \times 2}
$$

Após este procedimento deve-se classificar as unidades produtivas em (A, E, I), para isso os percentuais são ordenados de forma decrescente, desconsidera-se as unidades produtivas com número de trocas igual a 0 , e por fim conta-se quantas unidades produtivas restaram e divide-se este número por quatro, correspondente as classes (A, E e I), este número determina quantas unidades produtivas pertencem a cada classe, os maiores percentuais são classe A, os seguintes E e assim sucessivamente. Caso o número não for inteiro, vale a interpretação de acordo com as demais classificações feitas anteriormente. O Quadro 10 apresenta em um exemplo as unidades produtivas e consequente classificação em relação a porcentagem de trocas realizadas perante o total. 
Quadro 10 - Unidades produtivas classificadas de acordo com a porcentagem de trocas.

\begin{tabular}{|l|l|l|l|}
\hline \multicolumn{3}{|c|}{ Classificação A, E, I, O e U conforme número de trocas } \\
\hline Total de trocas: 5 & $\begin{array}{l}\text { Total de trocas por } \\
\text { unidade produtiva }\end{array}$ & Classificação \\
\hline Unidades produtivas & 3 & 30 & A \\
\hline Centro de tratamento & 2 & 20 & E \\
\hline Unidades produtivas 1 & 2 & 20 & E \\
\hline Unidades produtivas 3 & 2 & 20 & I \\
\hline Unidades produtivas 4 & 2 & 10 & \\
\hline Unidades produtivas 2 & 1 & \\
\hline As demais unidades produtivas que não realizam trocas são consideradas como U
\end{tabular}

O par formado por duas unidades produtivas poderá apresentar duas classificações diferentes, será válida a de maior valor de importância.

\subsubsection{Carta de inter-ligações preferenciais}

A ferramenta a ser utilizada neste momento é a carta de interligações preferenciais que para Muther (1973) é uma matriz triangular onde representa-se o grau de proximidade e o tipo de inter-relação entre uma dada atividade e cada uma das outras. O objetivo é mostrar quais as atividades que devem ser localizadas próximas e quais não precisam ou não devem.

Nesta carta, apresentada na Figura 25 todas as atividades são listadas a esquerda (nas linhas $1,2,3, \ldots)$, quando as linhas se interceptam, estas formam um losango que mostra a interrelação das atividades referentes a essas duas linhas. Cada losango é dividido em duas partes, a parte superior leva a classificação da interligação de acordo com a carta De-Para e segundo a escala de valores (A, E, I, O, U, X) e na parte inferior coloca-se o número da razão desta classificação, podendo ser mais de uma. 


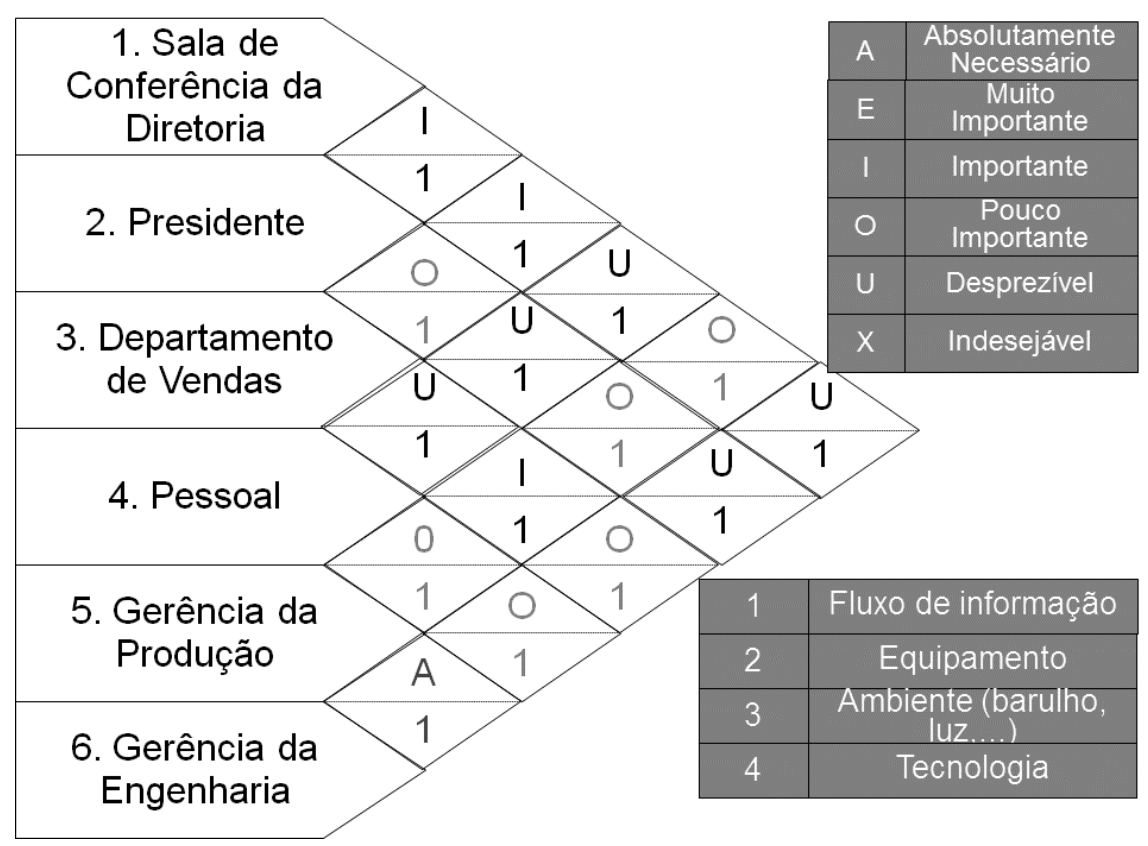

Figura 24 - Carta de interligações preferenciais.

Adaptando a ferramenta para o contexto desta pesquisa, tem-se a carta de interligações preferenciais entre todas as unidades produtivas. Seguindo a mesma estrutura da carta apresentada por Muther (1973), todas as unidades produtivas envolvidas na SI são listadas na coluna a esquerda. Para cada intersecção das linhas tem-se o losango dividido, aqui será utilizada a mesma classificação proposta pelo autor (A, E, I, O, U e X), esta demonstra o grau de proximidade importante para que a SI se desenvolva eficientemente, desta maneira identifica-se as unidades produtivas que devem ou precisam, as que podem ou as que não podem ficar próximas.

A classificação do grau de proximidade é subjetiva e qualitativa, portanto nesta etapa deve-se considerar todas as informações relevantes aos relacionamentos. Pode-se realizar um Brainstorming para identificar os dados de classe A, E e I, os que são pouco importantes e os que não influenciam nas relações entre as unidades produtivas.

Nesta etapa as opiniões podem divergir e a classificação pode não ser unanime, por isso deve-se focar no objetivo final da realização dos procedimentos, visando a obtenção do melhor layout final que potencialize a SI.

As principais razões para melhor classificação de acordo com o grau de proximidade das unidades produtivas são:

- Realiza troca;

- Compartilha serviços;

- Uso compartilhado de recursos; 
- Tem-se comunicação entre as partes;

- Troca que requer proximidade;

- Necessidade pessoal;

- Custo;

- Supervisão ou controle;

- Processo requer distância dos demais por motivos específicos;

- Transporte dos resíduos é complexo;

Por fim levantar quais relacionamentos são classe A, E, I, O, U e X. No fim desta etapa tem-se algo semelhante ao que está representado na Figura 26.

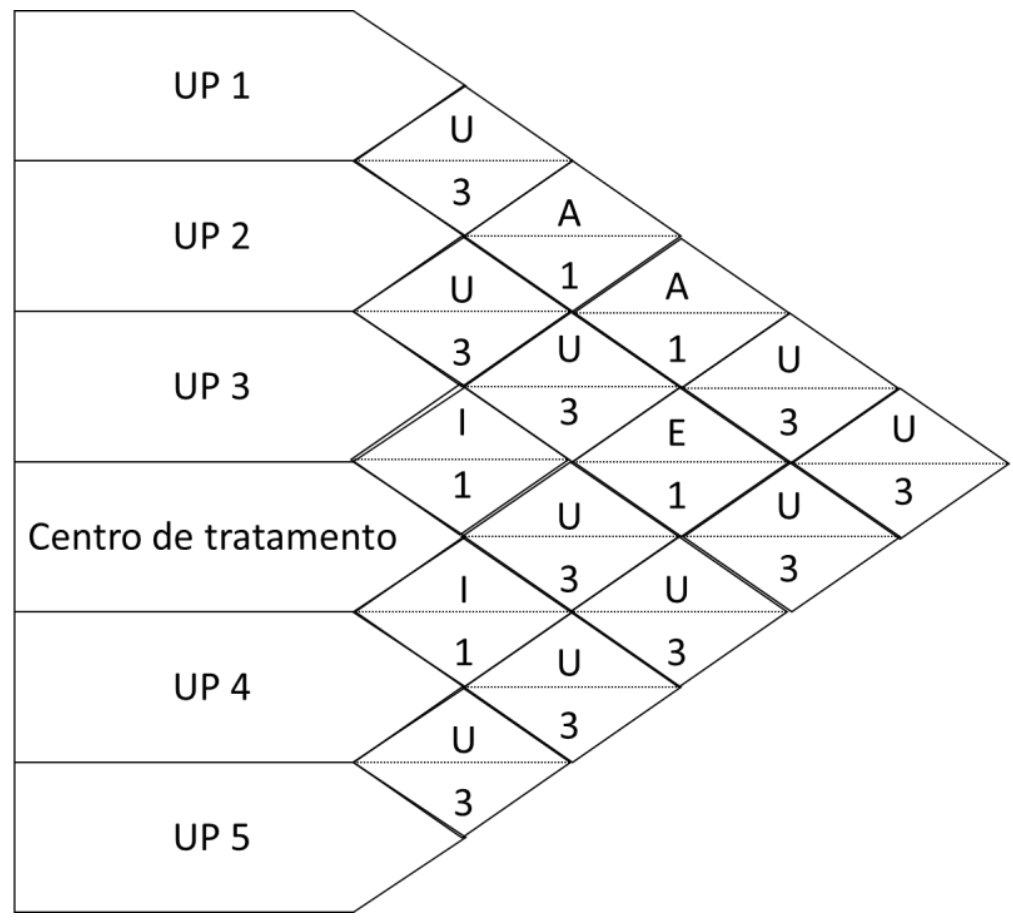

\begin{tabular}{|c|c|}
\hline A & $\begin{array}{c}\text { Absolutamente } \\
\text { Necessário }\end{array}$ \\
\hline E & Muito Importante \\
\hline I & Importante \\
\hline O & Pouco Importante \\
\hline U & Desprezível \\
\hline $\mathrm{X}$ & Indesejável \\
\hline
\end{tabular}

Figura 25 - Carta de interligações preferencias para unidades produtivas.

\subsubsection{Método dos elos}

Este método baseia-se na determinação de todas as inter-relações possíveis entre as várias unidades que compõe o arranjo físico de forma a se poder estabelecer um critério de prioridade de localização dessas unidades onde possuem preferências os setores com maior movimentação.

Ele estabelece os principais pares de postos de trabalho envolvidos no processamento dos produtos ou no andamento de documentos, identificando os elos ou postos mais solicitados 
para serem colocados em posições centrais, tornando mais fácil e racional o fluxo de trabalho. Para desenvolvimento deste método deve-se seguir os procedimentos definidos por Cury (2000):

1. Identificação e definição dos envolvidos e as respectivas quantidades médias, por processo de trabalho, no tempo médio estudado.

2. Definição da sequência dos postos de trabalho.

3. Com dados de 1 e 2 , elabora-se um quadro com 2 colunas, na primeira coluna coloca-se os postos de trabalho (operações) em ordem sequencial de fabricação $(1,2,3,4$ nas linhas), na segunda coluna forma-se os pares $(1,2 ; 3,4 ; \ldots)$ tudo isso para cada processo.

4. Elaborar o quadro das frequências para retratar quantas vezes cada elo ocorre no período considerado. Na primeira coluna é colocado cada elo encontrado, depois são feitas colunas para cada posto de trabalho (operação), nestas colunas são colocadas as quantidades estipuladas na etapa 1. Após colocar os dados cada linha respectiva ao elo é somada as quantidades médias para assim colocar na última coluna (a "total”) a somatória da linha.

5. Construção do quadro das solicitações, com o número destas para cada posto de trabalho. Enumeração em ordem crescente na horizontal e na ordem inversa na vertical, na célula que liga a coluna e linha (elo) coloca-se o número total obtido na etapa 4. Na última célula de cada coluna e linha, soma-se os valores presentes na coluna e na célula em questão, em se tratando da operação 7 soma-se sua coluna e linha, assim como no Quadro 11.

Quadro 11 - Exemplo da construção de um quadro dos elos.

\begin{tabular}{|c|c|c|c|c|}
\hline & A & $B$ & C & $\mathrm{D}$ \\
\hline$D$ & & 5 & 10 & 15 \\
\hline$C$ & & 10 & 20 & \\
\hline$B$ & 15 & 30 & & \\
\hline A & 15 & & & \\
\hline
\end{tabular}

Obtém-se como resultado os postos de trabalho (operações) mais solicitadas para ocuparem posições centrais no layout. Os processos de início devem ficar no começo e os de fimm no final (recebimento, expedição). 
Adaptando o método dos elos para o planejamento do layout com aspectos de SI, neste momento já foi identificado os pares, falta realizar o quadro dos elos. Para o desenvolvimento deste, no lugar dos postos de trabalho ou operações deve-se colocar as unidades produtivas e demais locais para tratamento, seleção, separação ou reprocesso e nas quadrículas as quantidades movimentadas como no Quadro 12, sem a preocupação de colocar na sequencia correta pois neste caso não se analisa a correta ordem dos elemntos participantes da SI em relação ao fluxo produtivo, mas sim ao fluxo dos resíduos.

Quadro 12 - Quadro dos elos para o exemplo utilizado no decorrer desta pesquisa.

\begin{tabular}{|c|c|c|c|c|c|}
\hline & UP1 & UP2 & UP3 & $\begin{array}{l}\text { Centro de } \\
\text { tratamento }\end{array}$ & UP4 \\
\hline UP4 & & 150 & & 100 & 250 \\
\hline $\begin{array}{l}\text { Centro de } \\
\text { tratamento }\end{array}$ & 200 & & 100 & 400 & \\
\hline UP3 & 200 & & 300 & & \\
\hline UP2 & & 150 & & & \\
\hline UP1 & 400 & & & & \\
\hline
\end{tabular}

Portanto segundo o método dos elos a Unidade produtiva 1 e o Centro de tratamento devem ocupar posições centrais no layout.

\subsubsection{Diagrama de interligações das unidades produtivas}

Esta ferramenta pertencente a fase quatro do procedimento baseia-se ainda na fase de construção do layout do modelo de Camarotto e Menegon (1996), nos procedimentos 11 a 16 do Apple (1977) e principalmente na fase três do modelo de Muther (1973).

Esta é o diagrama de fluxo e/ou inter-relações das unidades produtivas. Aqui tem-se a visualização dos dados e análises realizados até agora, será um primeiro esboço de localização. Esta ferramenta é simples e diagrama graficamente as inter-relações entre as atividades, cada departamento ou atividade é representado por um símbolo da carta de processo segundo o padrão ASME, com seu respectivo nome ou código dentro, e a intensidade do fluxo pelo número de linhas que ligam cada par de departamentos, um exemplo é representado na Figura 27. O número de linhas tem relação com a classificação feita na carta de interligações preferenciais: A corresponde a quatro linhas, $\mathrm{E}$ a três, I a duas, $\mathrm{O}$ a apenas uma, $\mathrm{U}$ a nenhuma e X a uma linha sinuosa. Pode-se colocar nesta ligação a intensidade de fluxo obtida na carta De-Para e uma seta para identificar a direção do fluxo. 
Para desenvolver a ferramenta em questão deve-se primeiro diagramar as inter-relações classificadas como A, bem como suas respectivas atividades ou departamentos, depois as do tipo E, posteriormente as do tipo I, depois $\mathrm{O}$ e por fim as do tipo U e X. O diagrama necessita ser rearranjado até que as interligações do tipo A estejam mais próximas, assim como as E e I, deixando as do tipo $\mathrm{O}$ com maior distância e as do tipo U e X mais longe. Este é uma base para o arranjo final.

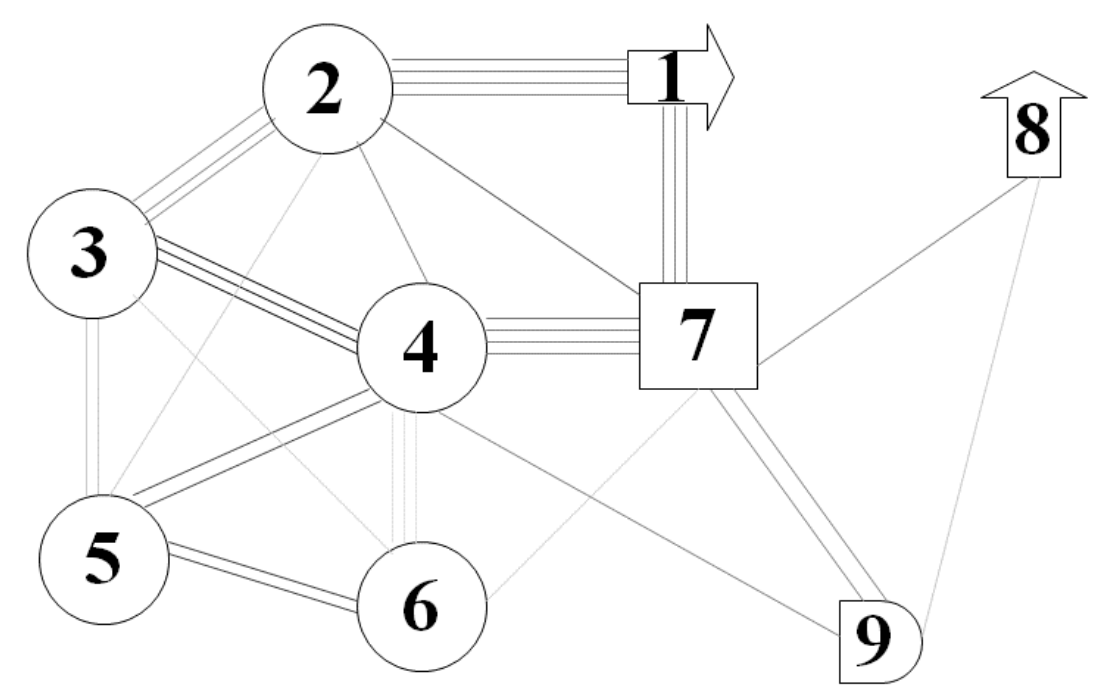

Figura 26 - Diagrama de inter-relações. Fonte: Adaptado de Muther (1973).

Para o diagrama de inter-relações no contexto da SI, este deve apresentar as unidades produtivas em retângulos com o nome ou código dado a cada uma anteriormente dentro deste, o número de linhas segue o mesmo princípio do que foi apresentado por Muther (1973), de acordo com a classificação da carta de interligações preferenciais já descritas neste trabalho. A intensidade de fluxo é colocada de acordo com a carta De-Para desenvolvida anteriormente e a direção de fluxo, corresponde a direção com a seta saindo da unidade produtiva onde o resíduo é output e apontando para a qual ele torna-se input simbiótico.

Para começar a desenvolver esta ferramenta deve-se primeiramente comparar a classificação obtida com a carta de interligações preferenciais com a classificação baseada no número de interligações descrita nesta pesquisa. Diagramar as unidades produtivas de acordo com o Quadro 13.

No Quadro 13 foram colocadas as trocas utilizadas como exemplo neste estudo na primeira coluna, e a respectiva classificação referente a carta de interligações preferenciais e 
ao número de interligações obtida nos exemplos de aplicação dessas ferramentas por esta pesquisa.

Quadro 13 - Ordem de diagramação de acordo com a classificação das trocas.

\begin{tabular}{|l|c|}
\hline $\begin{array}{c}\text { Ordem de } \\
\text { diagramação }\end{array}$ & $\begin{array}{c}\text { Classificação carta de interligações preferenciais / } \\
\text { Classificação baseada no número de interligações }\end{array}$ \\
\hline 1 & AA \\
\hline 2 & AE e EA \\
\hline 3 & AI e IA \\
\hline 4 & AO e OA \\
\hline 5 & AU e UA \\
\hline 6 & EI e IE \\
\hline 7 & EO e OE \\
\hline 8 & EU e UE \\
\hline 9 & IO e OI \\
\hline 10 & IU e UI \\
\hline 11 & OU e UO \\
\hline 12 & UU \\
\hline 13 & X (se houver) \\
\hline
\end{tabular}

Quadro 14 - Classificação das trocas pela carta de interligações preferenciais e pelo número de interligações.

\begin{tabular}{|l|c|c|}
\hline \multicolumn{1}{|c|}{ Troca } & $\begin{array}{c}\text { Classificação carta de } \\
\text { interligaçõ preferenciais }\end{array}$ & $\begin{array}{c}\text { Classificação baseada no número } \\
\text { de interligações }\end{array}$ \\
\hline UP1 - Centro de tratamento & A & A \\
\hline UP3 - UP1 & A & E \\
\hline UP4 - UP2 & E & A \\
\hline Centro de tratamento - UP3 & I & A \\
\hline Centro de tratamento - UP4 & I & - \\
\hline UP1 - UP2 & U & - \\
\hline UP2 - UP3 & U & - \\
\hline UP2 - Centro de tratamento & U & - \\
\hline UP1 - UP4 & U & - \\
\hline UP3 - UP4 & U & \\
\hline
\end{tabular}

A Figura 28 mostra as unidades produtivas de exemplo em retângulos ligadas por setas, na direção da saída para a entrada, com o número de setas baseado na intensidade de fluxo calculada anteriormente. 


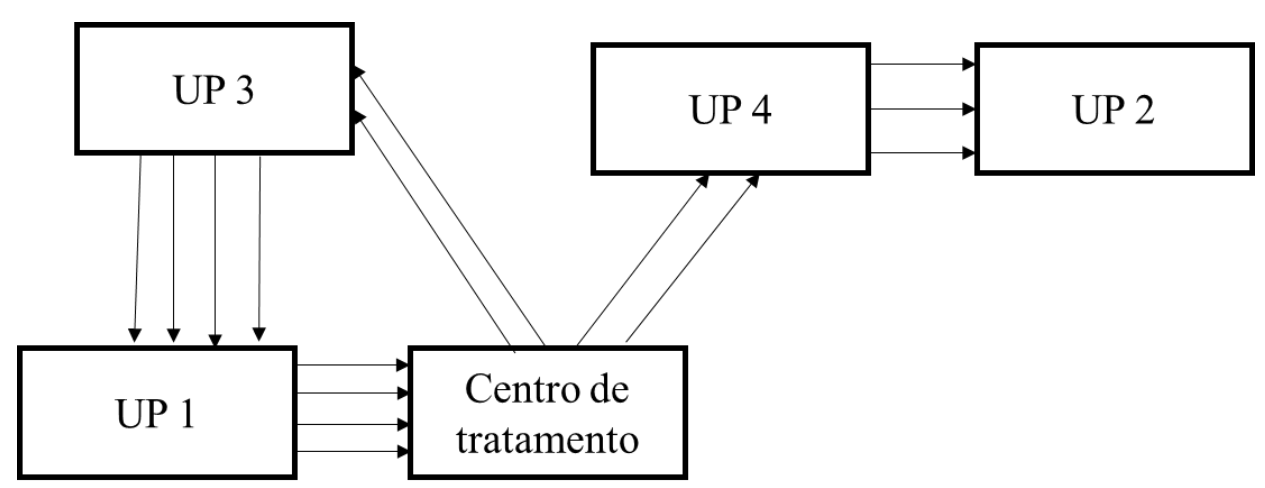

Figura 27 - Diagrama de interligações das unidades produtivas.

A Figura 29 representa uma possível opção de layout, estando sujeita a alterações devido a fatores de espaço e outras especificações e limitações. Esta concede preferência ao método dos elos, com a unidade produtiva 1 e o centro de tratamento no centro do layout.

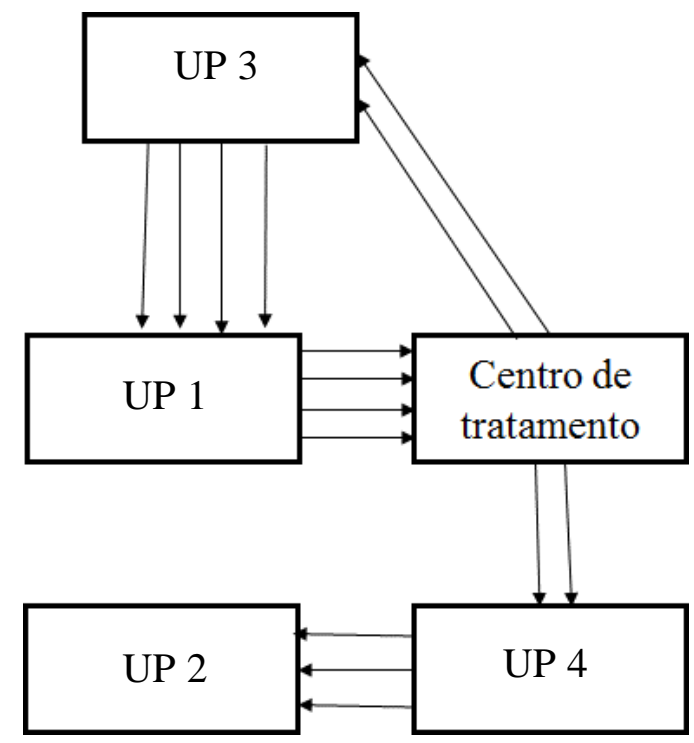

Figura 28 - Diagrama de interligações para o exemplo com o método dos elos.

Os quatro passos estão estruturados no fluxograma da Figura 30, mostrando principalmente a interação e sequencia destas. 


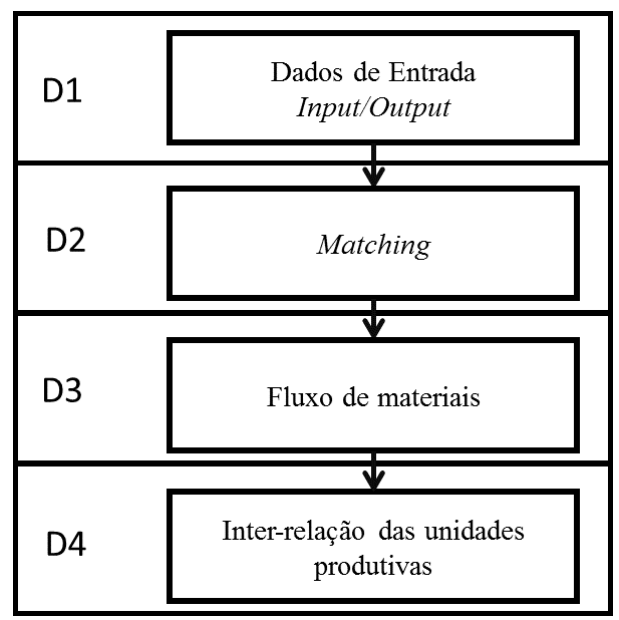

Figura 29 - Passos: D1, D2, D3 e D4.

\subsection{Quinto passo (D5): Elaborar a inter-relações das unidades produtivas com espaço}

Muther (1973) em seu modelo continua com os espaços necessários e espaço disponível, Camarotto e Menegon (1996) aborda esta questão na fase de templates dos centros de produção e construção do layout e Apple (1977) nos procedimentos 11 ao 14, nos quais ele aborda o tema requerimentos de espaço.

Esta fase é representada pela Figura 31 que mostra o quarto passo, que é a inter-relações das unidades produtivas, acrescida da informação de espaço disponível e requeridos pelas unidades produtivas formando a quinta etapa que é a de realizar as inter-relações das unidades produtivas com os dados de espaço necessários para construir as propostas de layout.

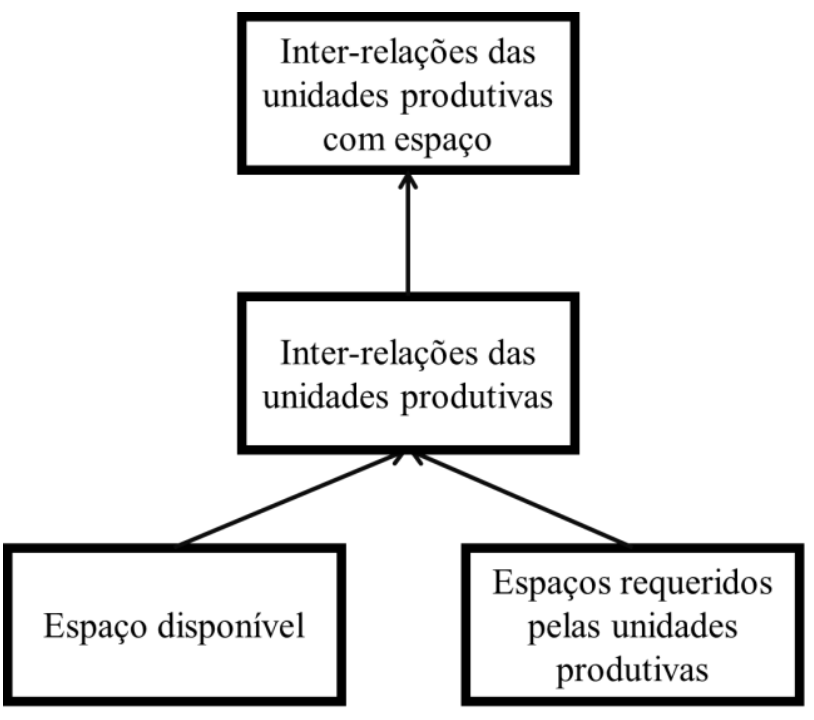

Figura 30 - Fluxograma do quinto passo. 
O quinto passo, baseada principalmente no modelo de Muther (1973), inclui a questão do espaço para assim realizar a construção do layout em si. Os departamentos ou atividades são desenhados em escala seguindo o diagrama de inter-relações desenvolvido anteriormente, estes são então manipulados para se conseguir a melhor configuração respeitando as áreas de suporte, serviço, as estradas e outras características, como está desenhado na Figura 32. Neste contexto de SI, esta etapa ocorre da mesma forma como apresentado pelo autor.

Cada unidade produtiva necessita ter seu espaço requerido medido neste passo, o procedimento de como obter essas medidas não será abordado nesta pesquisa, entende-se que a obtenção da planta com o layout é uma ajuda significativa no caso de comparação de departamentos ou áreas, no caso de processos faz-se importante a obtenção do inventário de máquinas e equipamentos, dos recursos e serviços a serem realizados para que o processo ocorra, para unidades produtivas sendo empresas é importante saber o local, os terrenos disponíveis e os limites deste para que as empresas possam ser instaladas de acordo com suas características para funcionamento eficiente.

Para obtenção do espaço requerido por uma empresa ou processo deve-se analisar e medir tal item de forma a entender os requisitos e características de cada um, para estipular a necessidade de espaço.

A melhor consideração neste passo está em estipular a mínima distância entre as unidades produtivas, a qual é baseada na planta, nos terrenos ou pelo processo a ser estudado e arranjado no layout com SI.

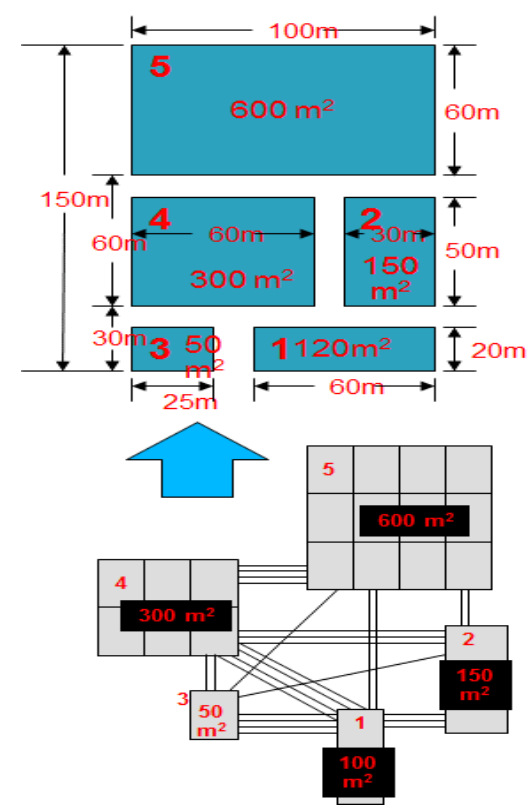

Figura 31 - Diagrama de inter-relação de espaço. Fonte: Adaptado de Muther (1973). 
A Figura 33 apresenta a proposta de layout a partir do método dos elos desenvolvida como exemplo para a aplicação destes passos, com a definição do espaço.

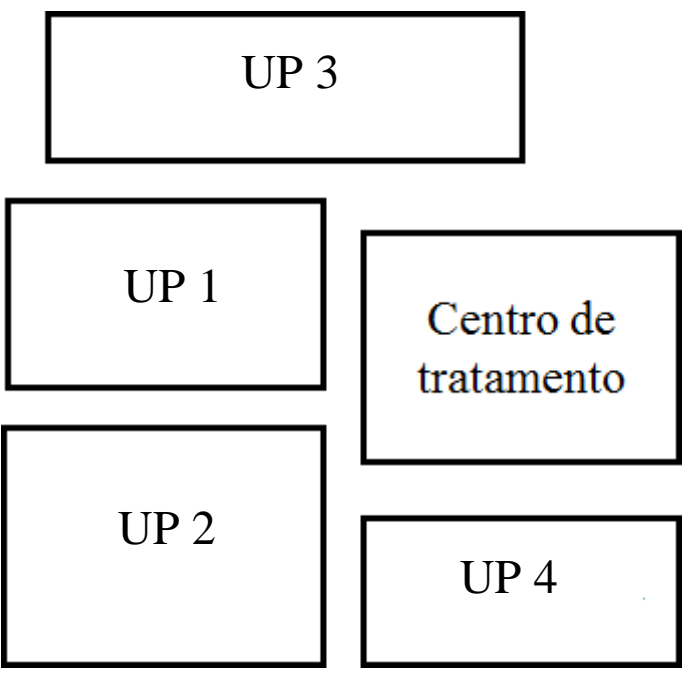

Figura 32 - Layout a partir do diagrama de inter-relação de espaço.

Com mais este passo desenvolvido, pode-se representar estes por um fluxograma da maneira como está demonstrado na Figura 34.

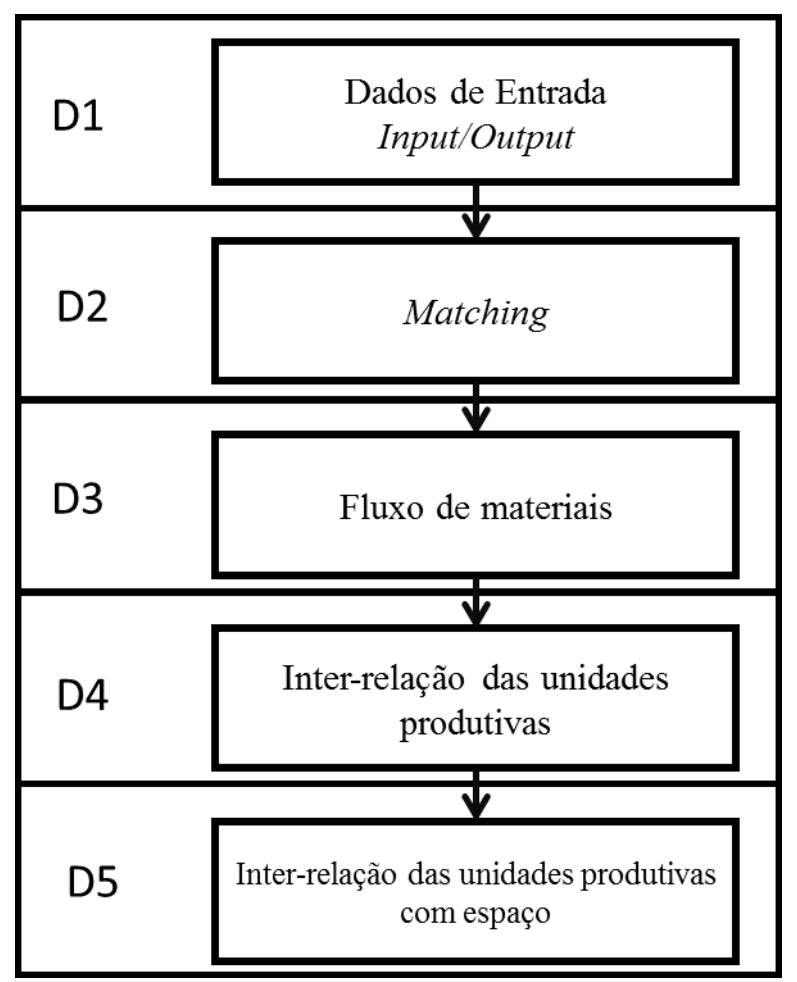

Figura 33 - Cinco passos: D1, D2, D3, D4 e D5. 


\subsection{Sexto passo: Selecionar a melhor alternativa}

No desenvolvimento dos passos pode-se obter mais de uma alternativa de layout, desta forma faz-se necessário a escolha da que melhor satisfaz a estratégia e reduz os custos. Elas devem ser analisadas e comparadas a fim de encontrar a que mais trará benefícios as unidades produtivas e aos stakeholders.

As vantagens e desvantagens de cada alternativa devem ser levantadas, assim como estipular um peso para cada uma delas, possibilitando uma análise mais quantitativa dos dados, facilitando a tomada de decisão. Para complementação de análise deve-se observar os pontos apresentados por Lin e Sharp (1999) e Raman, Nagalingam e Lin (2009).

Muther (1973) apresenta alguns fatores a serem considerados na análise da melhor alternativa: facilidade de ampliação; adaptabilidade e versatilidade; flexibilidade; eficiência do fluxo de materiais, do manuseio de materiais e da estocagem; utilização de espaço; eficiência da integração de serviços de apoio; higiene e segurança; condições de trabalho e satisfação; facilidade de supervisão e controle; relações externas; qualidade do produto e processo; problemas com manutenção; manutenabilidade; integração com a estrutura organizacional; utilização de equipamento; segurança da fábrica; satisfação da capacidade; planos de longo prazo.

A melhor alternativa pode estar relacionada a restrição de locais disponíveis para as empresas, a necessidade física de acordo com cada unidade produtiva, a preferência de localização mais próxima a trocas que possuem materiais mais perigosos ou de difícil movimentação ou ainda a escolha por uma alternativa que considere a empresa que mais troca informações no centro do local.

Esta etapa está diretamente ligada com a estratégia adotada no início do planejamento do layout, é importante que a alternativa a ser escolhida consiga melhorar a eficiência do sistema e favorecer a SI de acordo com o objetivo desta pesquisa, respeitando as restrições específicas de cada unidade produtiva, suas características e necessidades.

A partir deste ponto, com a melhor alternativa escolhida tem-se o resultado final pretendido com o desenvolvimento destes passos. Portanto o layout final para um momento em questão é finalmente construído. A Figura 35 a seguir, mostra os seis passos, considerando a sexta que é a seleção da melhor alternativa para casos de necessidade e o resultado que é o layout final para um dado momento $\mathrm{x}$. 


\subsection{Resultado: Layout final, para o momento $\mathrm{x}$ ?}

Ao desenvolver os passos para planejamento de layout com aspectos de SI proposto nesta pesquisa tem-se um resultado a partir das unidades produtivas e dados que estão sendo utilizados no momento $\mathrm{x}$, ou seja, no tempo em que o planejamento está sendo feito, a partir dos dados presentes aquela situação de referência. Portanto não está sendo considerado alguns fatores de longo prazo e nem a flexibilidade e dinamismo do sistema como um todo.

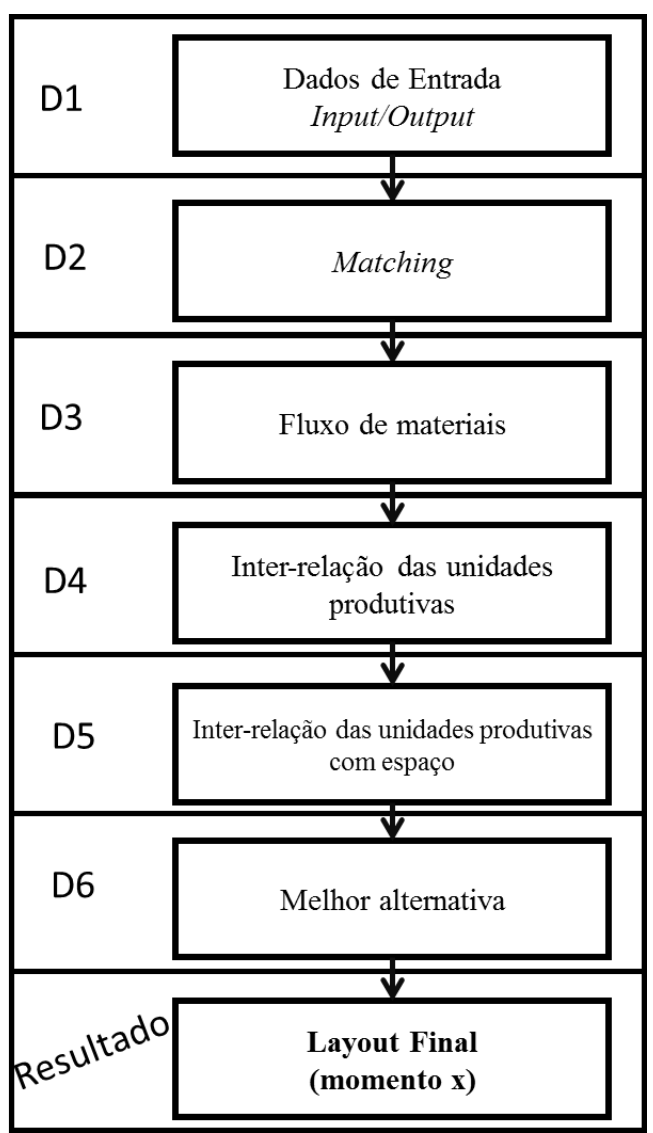

Figura 34 - Passos para o planejamento de layout com aspectos de SI.

Como esta pesquisa retrata a utilização de resíduos, estes podem sofrer alterações para cada mudança ocorrida nas unidades produtivas e também podem ser eliminados do processo, seja por melhoria, por troca de equipamento ou por alteração dos recursos a serem transformados.

Além dos problemas envolvendo os resíduos, há complicações que envolvem as próprias unidades produtivas envolvidas no cenário considerado pelo planejamento. As unidades produtivas podem sofrer alterações no processo produtivo, nos recursos, na linha de produção, no mix de produtos e até mesmo na gestão e elas estão suscetíveis a parada de 
produção, de operação, a falência, a mudança de estratégia, tornando o contexto do planejamento passível de alterações não previstas.

O momento utilizado funciona portanto como uma fotografia da situação atual e o resultado, ou seja, o layout final é desenvolvido conforme o contexto apresentado para execução dos passos. Os dados coletados e as unidades produtivas podem sofrer mudanças, tornando o layout não tão eficiente do que na situação considerada inicial.

\subsection{Considerações finais do procedimento}

Definiu-se portanto seis passos para o planejamento do layout com aspectos de SI. Cada passo possui atividades que devem ser realizadas para que cada uma seja concluída, essas atividades são compostas por tarefas de coleta de dados, elaboração de ferramentas e construção de alternativas de layout.

O exemplo utilizado usou de unidades produtivas e de um centro de tratamento fictícios. A nomeação das empresas e demais elementos do parque industrial pode ser feito através de unidades produtivas como foi realizado no exemplo, como também pode-se utilizar os nomes reais de cada elemento do sistema em questão, facilitando a organização e entendimento do planejamento e consequentemente do resultado final.

A Figura 36 ilustra os seis passos relacionados como uma escada para atingir o resultado, é necessário realizar da D1 até a D6 para chegar no resultado desejado. Todas elas possuem a figura do fluxograma mostrado anteriormente neste capítulo relacionado a cada uma delas para sua realização. Portanto o desenvolvimento de cada passo na sequencia apresentada gera o layout final desejado neste ambiente de SI.

A Figura 36 apresenta a noção de que os passos devem ser seguidas de forma sequencial, porém, deve-se compreender que elas podem não ocorrer exatamente como especificado nesta pesquisa. Alguns dados e algumas ferramentas podem não ser necessárias em alguns casos, e em outras situações a D2 pode já estar sendo realizada, entre outros casos que não serão colocados neste trabalho. 


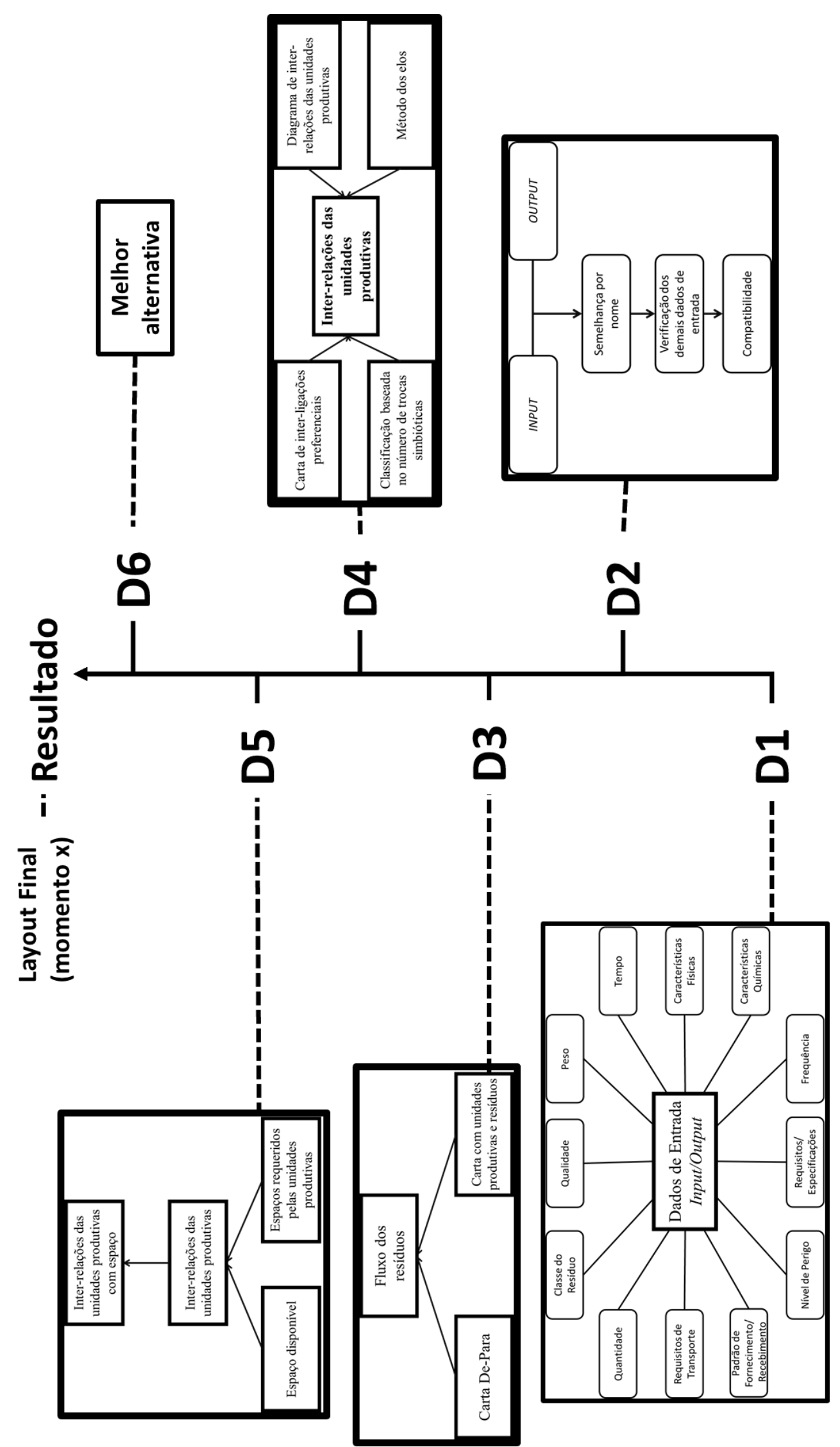

Figura 35 - Procedimento para planejamento de layout considerando a SI. 


\section{Capítulo 5. APLICAÇÃO E DISCUSSÃO DO PROCEDIMENTO}

Após a elaboração conceitual do procedimento foi necessário realizar um levantamento de dados entre empresas em um parque industrial para ilustrar sua aplicação. Para isso utilizouse de informações reais, porém as empresas ainda não estão operando no parque estudado.

Para realização desta aplicação foi escolhido um Parque Eco tecnológico real situado no interior do estado de São Paulo, que ainda está em fase de planejamento, porém este já possui seus terrenos vendidos a empresas, que logo estarão se instalando no parque.

Neste coletou-se os dados pertinentes a pesquisa para aplicação dos passos e obtenção do layout resultante. Foram obtidas informações relacionadas aos inputs e outputs de cada empresa participante nesta pesquisa, tendo como foco principal o tipo de resíduo e as quantidades geradas, bem como o espaço necessário a cada uma delas. Nem todas as empresas participantes no parque industrial forneceram as informações a tempo e por isso foram desconsideradas.

Considerando o parque industrial em questão, aplicou-se os passos desenvolvidos nesta pesquisa para obter o layout compatível com o objetivo proposto, porém não houve implantação real dos resultados na prática.

\subsection{Aplicação dos passos}

Neste ponto do trabalho os passos desenvolvidos no Capítulo 4 desta pesquisa são aplicadas no estudo de caso em questão.

\subsubsection{Passo D1: Obter os dados de entrada}

Para obtenção dos dados de entrada neste estudo de caso não foi possível aplicar o formulário desenvolvido no apêndice B. Somente os dados considerados essenciais para os passos foram coletados, os materiais de input e output e suas respectivas quantidades.

Para organização dos dados criou-se o Quadro 15 onde tem-se as unidades produtivas participantes da SI dentro do parque industrial, seus respectivos inputs e outputs com as quantidades geradas de cada um, referentes ao tempo de um mês de operação. Esses estão relacionados apenas aos resíduos e subprodutos.

Para estruturar melhor a aplicação neste trabalho, não foram colocados todos os inputs de cada unidade produtiva caso tivessem vários, desta forma foram coletados apenas aqueles que pudessem ter resíduos ou subprodutos como alternativa de uso, ao invés de matéria-prima 
virgem. Para os outputs foi utilizada a mesma regra de colocar apenas os que pudessem ser utilizados novamente por alguma outra empresa participante. Caso alguma empresa não possua dados nesta tabela foi por não apresentar informações consideradas relevantes à pesquisa. Os resíduos foram nomeados com códigos por serem considerados itens estratégicos das empresas.

Quadro 15 - Input e output das unidades produtivas.

\begin{tabular}{|c|c|c|c|c|}
\hline \multicolumn{5}{|c|}{ Coleta de dados de input e output dos elementos participantes da SI no parque } \\
\hline \multirow{2}{*}{$\begin{array}{l}\text { Unidades produtivas } \\
\text { (empresas, locais de } \\
\text { separação, tratamento, } \\
\text { reprocessamento) }\end{array}$} & \multicolumn{4}{|c|}{ Resíduos/Subprodutos } \\
\hline & Input & $\begin{array}{l}\text { Quant. } \\
\text { (ton.) }\end{array}$ & Output & $\begin{array}{l}\text { Quant. } \\
\text { (ton.) }\end{array}$ \\
\hline \multirow{3}{*}{ Unidade produtiva 1} & A3 & 115 & B2 & 70 \\
\hline & \multirow{2}{*}{ B } & \multirow{2}{*}{65} & L/D & 0,15 \\
\hline & & & $\mathrm{P}$ & 0,08 \\
\hline \multirow{2}{*}{ Unidades produtiva 2} & \multirow{2}{*}{ A2 } & \multirow{2}{*}{30} & $\mathrm{~A} 3$ & 7 \\
\hline & & & $\mathrm{O}$ & 1,4 \\
\hline \multirow{2}{*}{ Unidade produtiva 3} & \multirow{2}{*}{$\mathrm{A} 2$} & \multirow{2}{*}{380} & $\overline{\mathrm{A} 3}$ & 110 \\
\hline & & & $\mathrm{O}$ & 9,8 \\
\hline \multirow{2}{*}{ Unidade produtiva 4} & \multirow{2}{*}{$\mathrm{PA}$} & \multirow{2}{*}{18} & $\mathrm{C}$ & 3,6 \\
\hline & & & $\mathrm{O}$ & 0,8 \\
\hline \multirow{2}{*}{ Unidade produtiva 5} & \multirow{2}{*}{ M } & \multirow{2}{*}{152} & $\mathrm{~S}$ & 5 \\
\hline & & & PM & 18 \\
\hline \multirow{3}{*}{ Unidade produtiva 6} & $\bar{M}$ & 75 & $\mathrm{~S}$ & 8,8 \\
\hline & \multirow{2}{*}{$\mathrm{PM}$} & \multirow{2}{*}{12} & $\mathrm{~L}$ & 0,08 \\
\hline & & & $\mathrm{P}$ & 0,06 \\
\hline \multirow{4}{*}{ Unidade produtiva 7} & \multirow{4}{*}{ A } & \multirow{4}{*}{745} & $\mathrm{~A} 2$ & 100 \\
\hline & & & $\mathrm{L}$ & 1,3 \\
\hline & & & $\mathrm{P}$ & 0,09 \\
\hline & & & $\mathrm{O}$ & 3 \\
\hline \multirow{4}{*}{ Unidade produtiva 8} & \multirow{4}{*}{ A } & \multirow{4}{*}{930} & A2 & 235 \\
\hline & & & $\mathrm{L}$ & 1,5 \\
\hline & & & $\mathrm{P}$ & 1,2 \\
\hline & & & $\mathrm{O}$ & 4,3 \\
\hline \multirow{2}{*}{ Unidade produtiva 9} & ES & 30 & $\mathrm{P}$ & 1,5 \\
\hline & $\mathrm{C}$ & 20 & $\mathrm{~L}$ & 0,6 \\
\hline \multirow{2}{*}{ Unidade produtiva 10} & \multirow{2}{*}{ A } & \multirow{2}{*}{570} & $\mathrm{~A} 2$ & 90 \\
\hline & & & $\mathrm{E}$ & 3 \\
\hline
\end{tabular}




\subsubsection{Passo D2: Realizar o Matching}

Para realizar este passo elaborou-se o Quadro 16 a seguir, onde são colocados os outputs que servem como inputs para outras empresas. Neste exemplo em particular apenas pelo nome dos materiais foi possível realizar o matching, esses materiais podem ser utilizados novamente pois já são feitos na prática dessas empresas, o que facilitou o desenvolvimento deste estudo de caso.

Quadro 16 - Matchings das unidades produtivas.

\begin{tabular}{|c|c|c|c|c|c|}
\hline \multicolumn{3}{|c|}{ Output } & \multicolumn{3}{|c|}{ Input } \\
\hline $\begin{array}{c}\text { Unidade } \\
\text { produtiva }\end{array}$ & Material & Quantidade & Quantidade & Material & Tecnologia \\
\hline 2 & A3 & 7 & \multirow{2}{*}{115} & \multirow{2}{*}{ A3 } & \multirow{2}{*}{1} \\
\hline 3 & A3 & 110 & & & \\
\hline 7 & A2 & 100 & 30 & $\overline{\mathrm{A} 2}$ & 2 \\
\hline 7 & A2 & 70 & \multirow{3}{*}{380} & \multirow{3}{*}{ A2 } & \multirow{3}{*}{3} \\
\hline 8 & A2 & 235 & & & \\
\hline 10 & A2 & 90 & & & \\
\hline 5 & $\overline{\mathrm{PM}}$ & 18 & 12 & $\mathrm{PM}$ & 6 \\
\hline
\end{tabular}

No Quadro 16 pode-se verificar os outputs compatíveis com os inputs e no centro da tabela tem-se as quantidades, em caso de quantidades diferentes soma-se os outputs para cobrir o input ou tem-se sobras no caso de menor oferta do que necessidade pelo material. Foram encontradas sete matchings simbióticas, no caso do primeiro tem-se a unidade produtiva 1 que necessita de 115 toneladas de A3, duas unidades produtivas, a 2 e a 3 geram esta quantidade deste material. Neste caso a 2 possui uma sobra de 2 toneladas, ou num caso prático com uma análise melhor de custos, a 3 poderia ter a sobra de 2 toneladas.

Um segundo matching verificado foi entre a 2 e a 7, onde a necessidade de 2 é de apenas 30 toneladas e a oferta de 7 é de 100, com isso 7 pode também ser usada em outras trocas. Qualquer unidade produtiva entre a 7, 8 e 10 poderiam ter sido utilizadas, dependendo apenas de questões estratégicas e de custos.

O terceiro matching ocorre entre a 3 cuja necessidade de sucata de A2 é de 380 toneladas e as unidades produtivas 7, 8 e 10 que juntas fornecem 395 toneladas deste material, portanto uma delas tem sobra de 15 , ou esta sobra é rateada em 5 para cada uma delas. Neste estudo de caso foi-se descontado 5 toneladas em cada uma das três unidades produtivas envolvidas na geração do output em questão, para o decorrer da pesquisa. 
O último matching foi identificado entre a unidade produtiva 5 e 6 , onde 5 possui a geração de 18 toneladas de PM e a 6 necessita de apenas 12, criando uma sobra de 6 toneladas para a empresa 5 descartar ou trocar com outra empresa.

\subsubsection{Passo D3: Analisar o fluxo de materiais}

Neste passo aplica-se duas ferramentas para analisar o fluxo de materiais, a carta com unidades produtivas e resíduos e a carta De-Para. A primeira ferramenta utilizada foi a carta de unidades produtivas e resíduos.

O Quadro 17 mostra o resultado desta ferramenta, onde tem-se as dez unidades produtivas utilizadas neste estudo de caso e os três tipos de resíduos encontrados.

Quadro 17 - Carta com unidades produtivas e resíduos

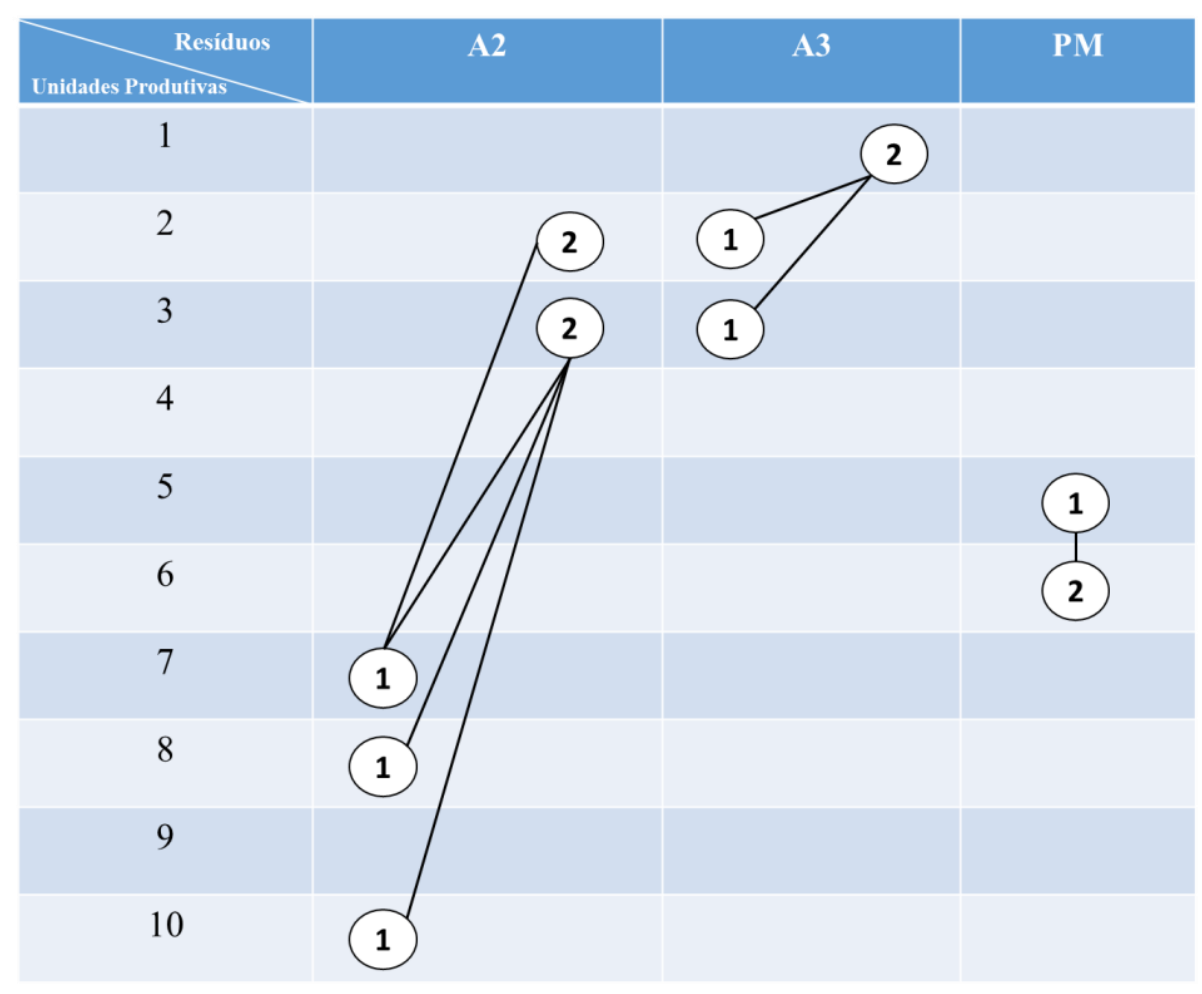

De acordo com o Quadro 17 identifica-se os relacionamentos que devem ser considerados no planejamento do layout, de forma que estes fiquem próximos no arranjo do parque industrial. Tem-se os relacionamentos entre as unidades produtivas 10, 8 e 7 com a 3, entre a 7 e a 3 para o resíduo de A2. Para o resíduo sucata de A3 tem-se o relacionamento entre as unidades produtivas 2 e $3 \mathrm{com}$ a 1 e por fim tem-se um relacionamento entre a 5 e a 6 para $o$ resíduo de PM. 
A segunda ferramenta a ser utilizada neste passo é a carta De-Para onde colocou-se as quantidades movimentadas (em toneladas) entre as unidades produtivas nos relacionamentos e o código correspondente ao resíduo que está sendo movimentado, conforme o Quadro 18.

Quadro 18 - Carta De-Para para as unidades produtivas.

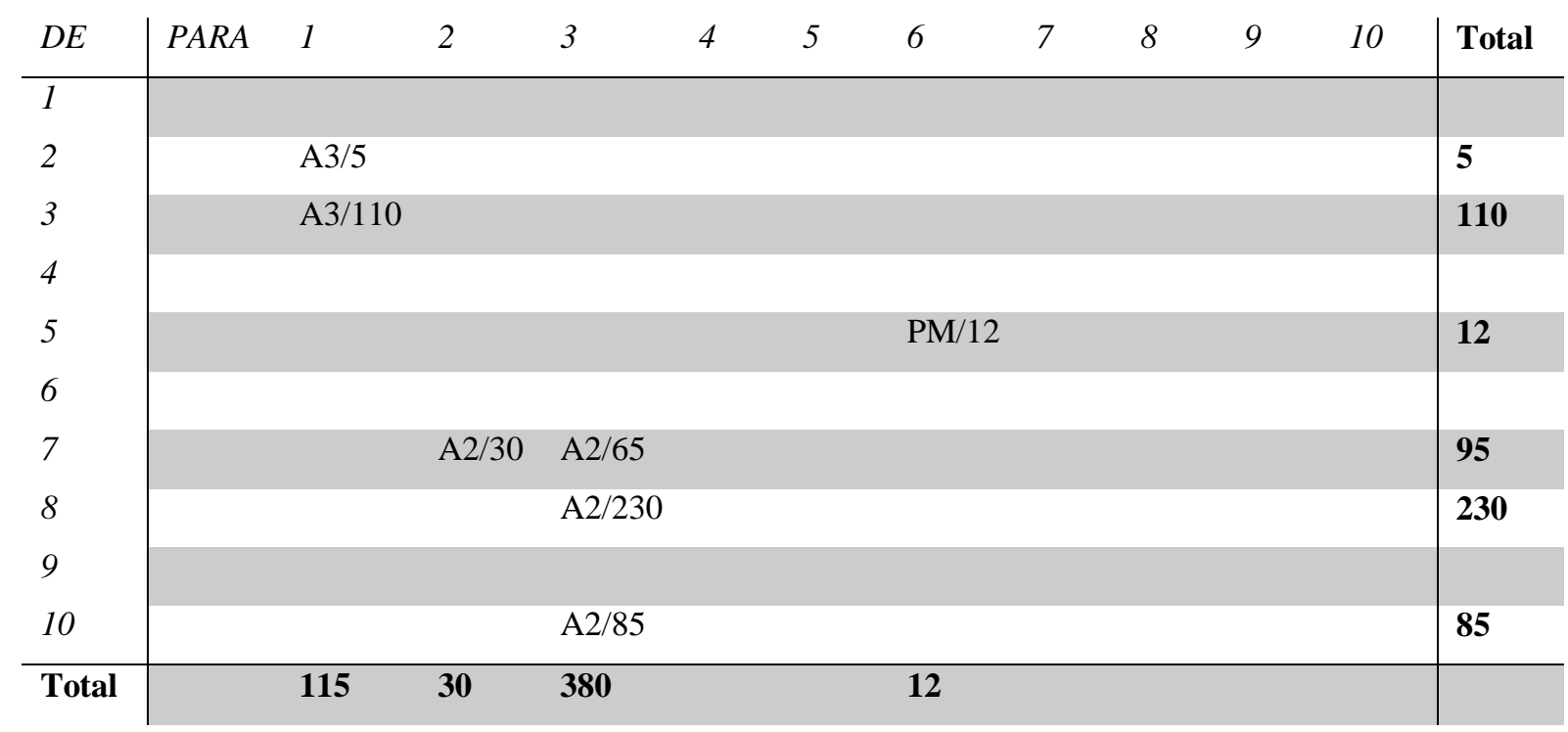

Após a elaboração da carta De-Para realiza-se o Quadro 19 a seguir para identificar as unidades produtivas que movimentam a maior quantidade de material (em toneladas).

Quadro 19 - Classificação das unidades produtivas por intensidade de fluxo

\begin{tabular}{|c|c|c|c|c|}
\hline $\begin{array}{c}\text { Unidades } \\
\text { produtivas }\end{array}$ & Total DE & Total PARA & Total & $\begin{array}{c}\text { Classificação por } \\
\text { intensidade de } \\
\text { fluxo }\end{array}$ \\
\hline $\mathbf{1}$ & 0 & 115 & 115 & 3 \\
\hline $\mathbf{2}$ & 5 & 30 & 35 & 6 \\
\hline $\mathbf{3}$ & 380 & 110 & 490 & 1 \\
\hline $\mathbf{5}$ & 12 & 0 & 12 & 7 \\
\hline $\mathbf{6}$ & 0 & 12 & 12 & 7 \\
\hline $\mathbf{7}$ & 95 & 0 & 95 & 4 \\
\hline $\mathbf{8}$ & 230 & 0 & 230 & 2 \\
\hline $\mathbf{1 0}$ & 85 & 0 & 85 & 5 \\
\hline
\end{tabular}

Portanto o Quadro 19 mostra que a unidade produtiva que possui maior intensidade de fluxo é a 3, seguido pela 8 e a 1, com isso entende-se que estas possuem uma importância maior no planejamento do layout do parque e por isso devem ter mais atenção no desenvolvimento dos passos seguintes.

Seguindo a D3 identificou-se a intensidade de fluxo de cada relacionamento criado no matching ao realizar a D2 e classificou-se as trocas de acordo com a intensidade de fluxo de cada uma delas em A, E e I, como mostrado no Quadro 20. 
Quadro 20 - Classificação das trocas segundo a intensidade de fluxo.

\begin{tabular}{|c|c|c|}
\hline Troca & Intensidade de fluxo & Classificação \\
\hline 1 e 2 & 5 & I \\
\hline 1 e 3 & 110 & A \\
\hline 2 e 7 & 30 & $\mathrm{I}$ \\
\hline 3 e 7 & 65 & $\mathrm{E}$ \\
\hline 3 e 8 & 230 & A \\
\hline 3 e 10 & 85 & $\mathrm{E}$ \\
\hline 5 e 6 & 12 & I \\
\hline
\end{tabular}

\subsubsection{Passo D4: Elaborar as inter-relações das unidades produtivas}

Neste passo tem-se a aplicação de quatro ferramentas consideradas importantes para conseguir elaborar as inter-relações das unidades produtivas, a carta de inter-ligações preferenciais, o diagrama de inter-relações das unidades produtivas, a classificação baseada no número de trocas simbióticas e o método dos elos.

A primeira ferramenta a ser utilizada é a classificação baseada no número de trocas simbióticas. Para esta elaborou-se o Quadro 21 a seguir, onde a porcentagem de troca é baseada no cálculo segundo as equações apresentadas anteriormente na seção 4.5.1.

Quadro 21 - Classificação das unidades produtivas por número de trocas

\begin{tabular}{|c|c|c|c|}
\hline \multicolumn{5}{|c|}{ Classificação A, E, I, O e U conforme número de trocas } \\
\hline Total de trocas: 7 & $\begin{array}{c}\text { Total de trocas por } \\
\text { unidade produtiva }\end{array}$ & \% de troca & Classificação \\
\hline Unidades produtivas & 2 & 14,3 & E \\
\hline 1 & 2 & 14,3 & A \\
\hline 2 & 4 & 29 & I \\
\hline 3 & 1 & 7 & E \\
\hline 5 & 1 & 14,3 & I \\
\hline 6 & 2 & 7 & I \\
\hline 7 & 1 & 7 & \\
\hline 8 & 1 & & \\
\hline 10 & \multicolumn{2}{|c|}{} \\
\hline
\end{tabular}

A partir do Quadro 21 pode-se compreender que a unidade produtiva 3 possui o maior número de trocas isoladamente e por isso merece maior importância, seguida pelas unidades produtivas 1,2 e 7. 
A segunda ferramenta a ser utilizada é baseada no método dos elos. Esta confirma a classificação por intensidade de fluxo obtida com a aplicação da carta De-Para, como pode ser visto no Quadro 22.

Quadro 22 - Quadro segundo o método dos elos

\begin{tabular}{|c|c|c|c|c|c|c|c|c|c|c|}
\hline & 10 & 9 & 8 & 7 & 6 & 5 & 4 & 3 & 2 & 1 \\
\hline 1 & & & & & & & & 110 & 5 & 115 \\
\hline 2 & & & & 30 & & & & & 35 & \\
\hline 3 & 85 & & 230 & 65 & & & & 490 & & \\
\hline 4 & & & & & & & $\mathbf{0}$ & & & \\
\hline 5 & & & & & 12 & 12 & & & & \\
\hline 6 & & & & & 12 & & & & & \\
\hline 7 & & & & 95 & & & & & & \\
\hline 8 & & & 230 & & & & & & & \\
\hline 9 & & $\mathbf{0}$ & & & & & & & & \\
\hline 10 & 85 & & & & & & & & & \\
\hline
\end{tabular}

De acordo com o método dos elos as unidades produtivas que merecem maior consideração no planejamento do layout são a 3, 8 e 1, essas devem ser consideradas como elo central no arranjo físico para maior eficiência do sistema.

A terceira ferramenta a ser elaborada segundo este passo é a carta de interligações preferenciais. Para a classificação A, E, I, O, U e X foi-se utilizado a classificação obtida segundo a intensidade de fluxo de cada troca na D3, como apresentado na Figura 37. 


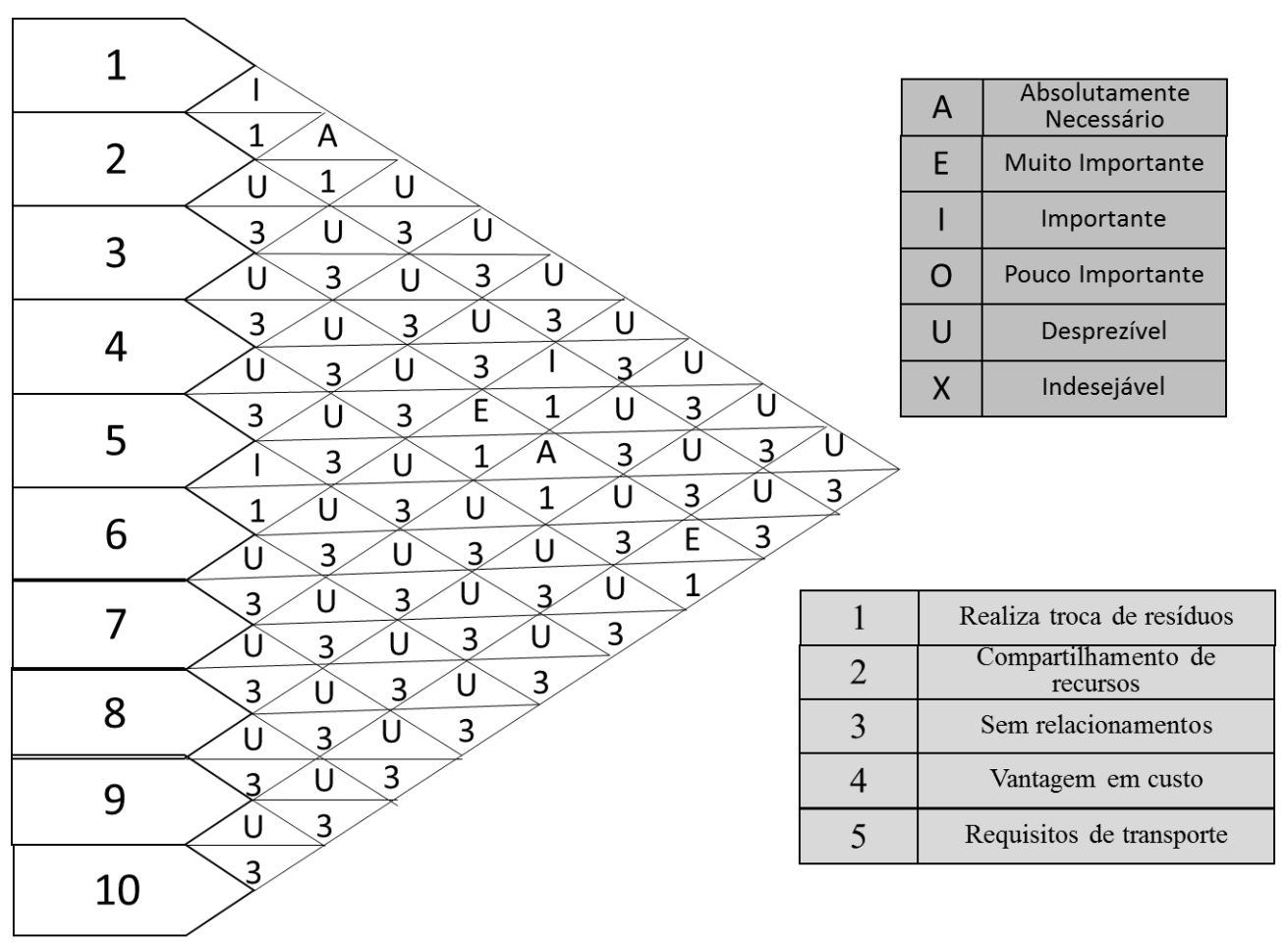

Figura 36 - Carta de interligações preferenciais segundo a D3 desta aplicação.

Esta ferramenta é mais qualitativa do que as demais e importante caso questões desta natureza influenciem no layout do parque industrial com SI. Neste estudo de caso não foi possível conseguir dados qualitativos em relação as empresas participantes, os materiais e as trocas entre eles. Assim o resultado obtido não influenciou no desenvolvimento do restante dos passos e no decorrer desta pesquisa, não evidenciando restrições, limitações ou necessidades especiais que exigissem proximidade ou distância.

A última ferramenta utilizada na D4 é o diagrama de interligações das unidades produtivas. O Quadro 23 apresenta as duas classificações obtidas até este momento, a baseada na carta de interligações preferenciais e na D3 e na baseada no número de interligações.

Quadro 23 - As classificações das trocas.

\begin{tabular}{|c|c|c|}
\hline Troca & $\begin{array}{l}\text { Classificação carta de interligações } \\
\text { preferenciais }\end{array}$ & $\begin{array}{l}\text { Classificação baseada no número } \\
\text { de interligações }\end{array}$ \\
\hline 1 e 2 & I & E \\
\hline 1 e 3 & A & E \\
\hline 2 e 7 & I & A \\
\hline 3 e 7 & E & A \\
\hline 3 e 8 & A & A \\
\hline 3 e 10 & E & I \\
\hline 5 e 6 & I & \\
\hline
\end{tabular}


Segundo esta tabela deve-se favorecer a troca 1 e 3 e a 3 e 8 . As demais unidades produtivas que não realizam trocas são consideradas como U, ou seja, desprezível para esse estudo de caso e neste momento, porém podem se tornar relevantes ao longo prazo ou caso comecem a realizar trocas.

Seguindo no desenvolvimento do passo D4 tem-se o diagrama de inter-relações das unidades produtivas. Este diagrama-se conforme explicado na seção 4.5.4, onde as unidades produtivas 3,8 e 1 necessitam de preferência e portanto devem ser colocadas no diagrama primeiro e as demais cercam estas, conforme os relacionamentos e intensidades de fluxo, o que pode ser visto na Figura 38.

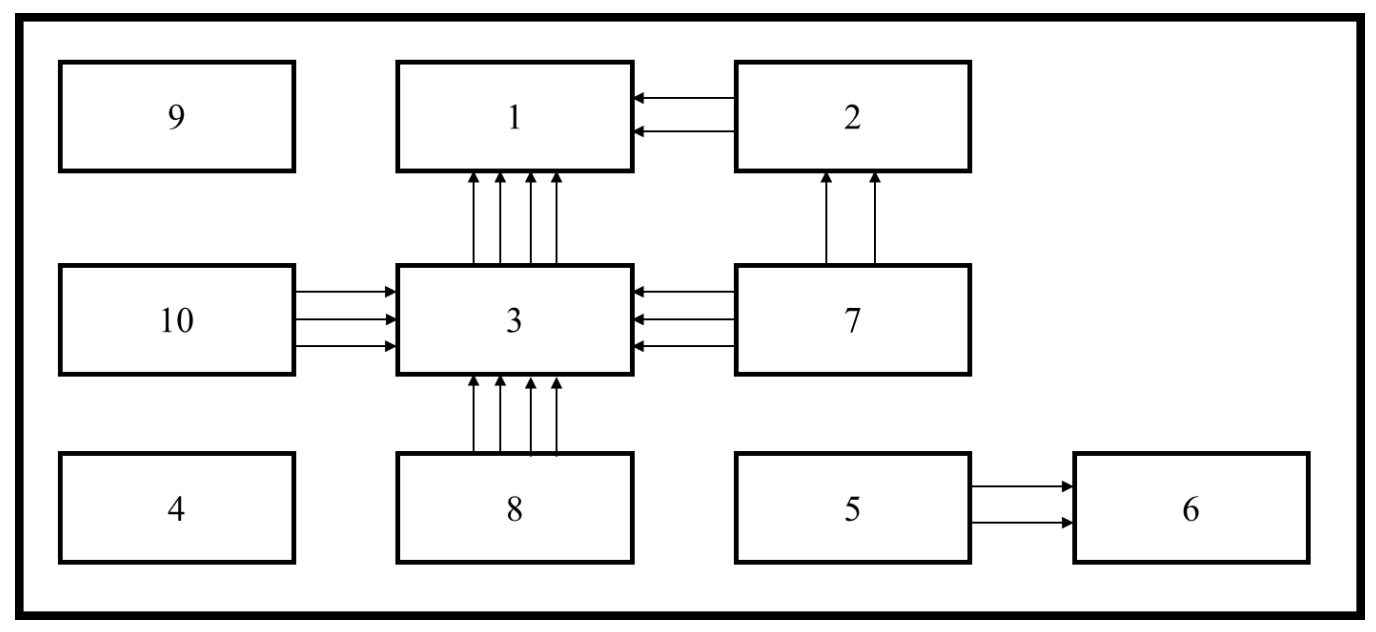

Figura 37 - Diagrama de inter-relações das unidades produtivas desta aplicação.

No diagrama apresentado colocou-se uma delimitação de espaço hipotética, e arranjouse as unidades produtivas nela, da forma como pede a ferramenta. Pode-se notar a importância da unidade produtiva 3 para o sistema e as demais que se relacionam com ela, a 7, 8, 10 e 1 . Mais alternativas podem ser geradas porém não há informações relevantes que influenciem nesta alternativa, exigindo novas.

Assim termina a D4, exigindo agora que obtenha-se informações de espaço como na D5 a seguir.

\subsubsection{Passo D5: Elaborar a inter-relações das unidades produtivas com espaço}

Para desenvolvimento da D5 necessita-se dos requisitos de espaço de cada unidade produtiva, que estão apresentados na Tabela 1 abaixo. 
Tabela 1 - Espaço requerido por cada unidade produtiva.

\begin{tabular}{|l|l|}
\hline Unidade produtiva & Espaço requerido $\left(\mathrm{m}^{2}\right)$ \\
\hline 1 & 5.600 \\
\hline 2 & 2.000 \\
\hline 3 & 7.400 \\
\hline 4 & 1.500 \\
\hline 5 & 6.000 \\
\hline 6 & 4.000 \\
\hline 7 & 9.000 \\
\hline 8 & 12.000 \\
\hline 9 & 6.000 \\
\hline 10 & 7.500 \\
\hline
\end{tabular}

A partir destes valores de espaço de cada unidade produtiva, incrementa-se o diagrama de inter-relações construído na D4. A Figura 39 ilustra o novo diagrama com os dados de espaço, fornecendo assim uma noção melhor da disposição de cada unidade produtiva no layout.

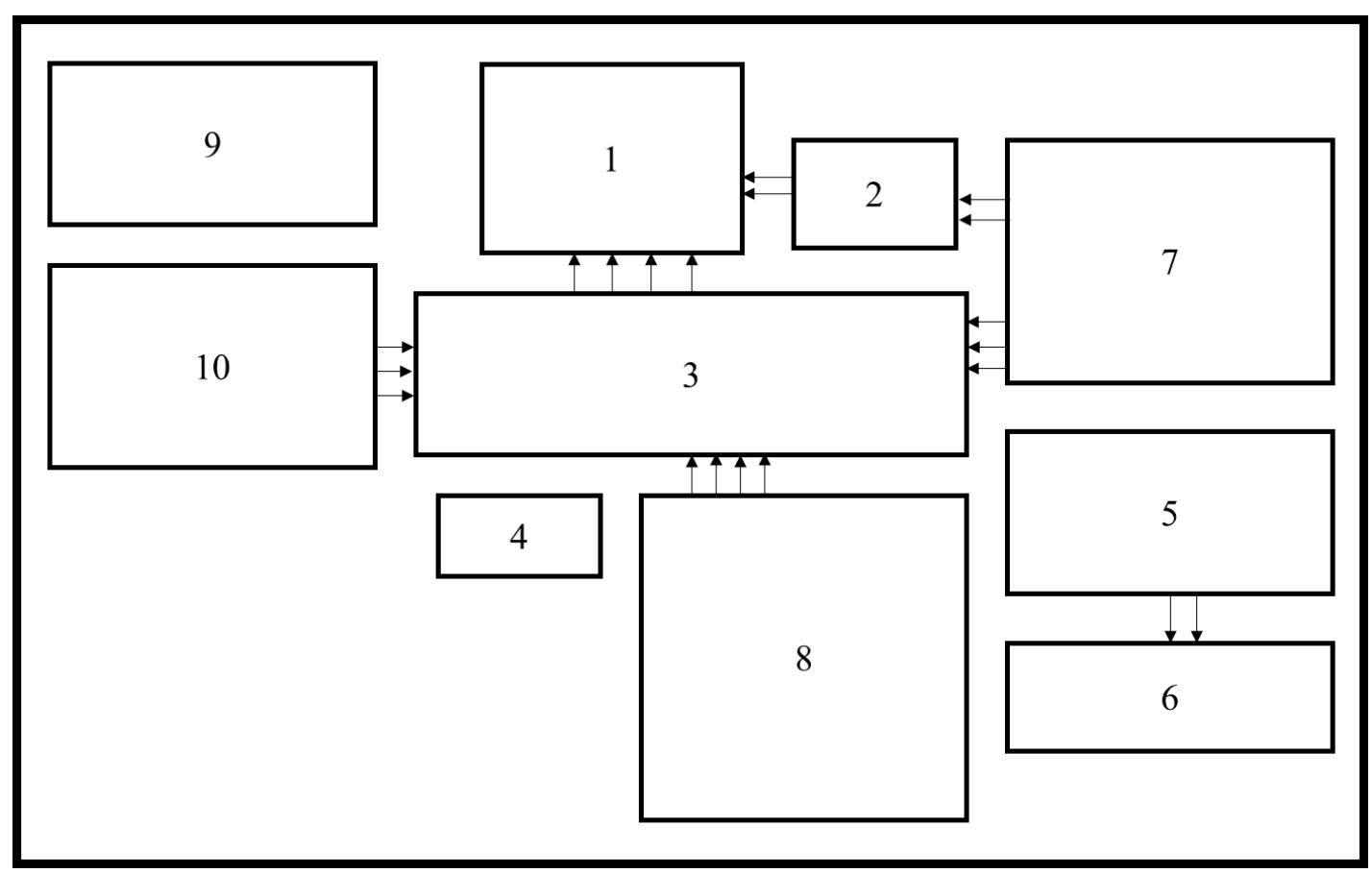

Figura 38 - Diagrama de inter-relação das unidades produtivas com espaço desta aplicação.

O espaço disponível no parque industrial deste estudo de caso é mostrado na Figura 40, onde os terrenos possuem apenas dois tamanhos, aqueles situados nos blocos com o número um medem $2.100 \mathrm{~m}^{2}$ e aqueles nos blocos dois medem $2.800 \mathrm{~m}^{2}$. 


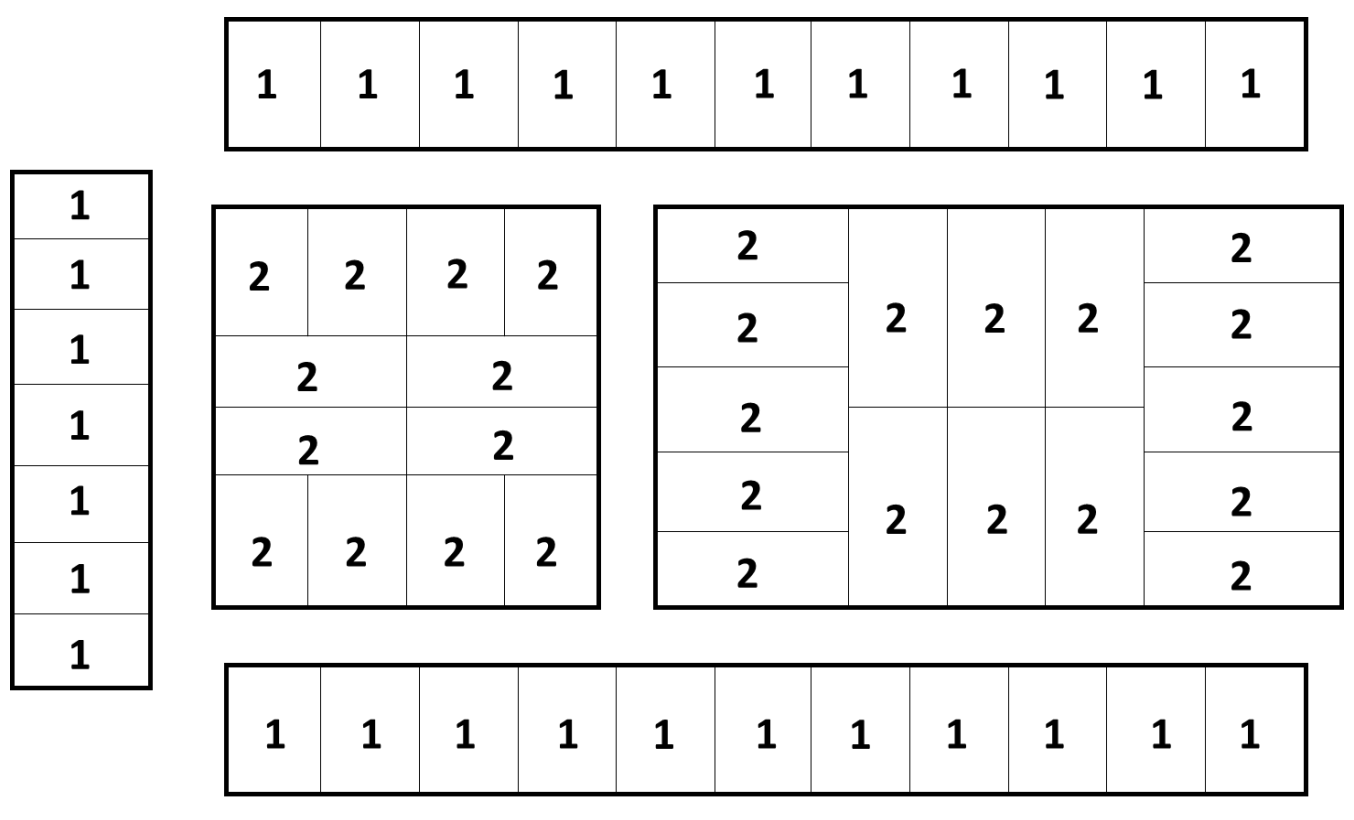

Legenda:

1 - Terrenos de $2.100 \mathrm{~m}^{2} \quad 2$ - Terrenos de $2.800 \mathrm{~m}^{2}$

Figura 39 - Terrenos do parque industrial.

Por fim adequa-se as unidades produtivas de acordo com os espaços requeridos de cada uma nos terrenos apresentados na Figura 41.
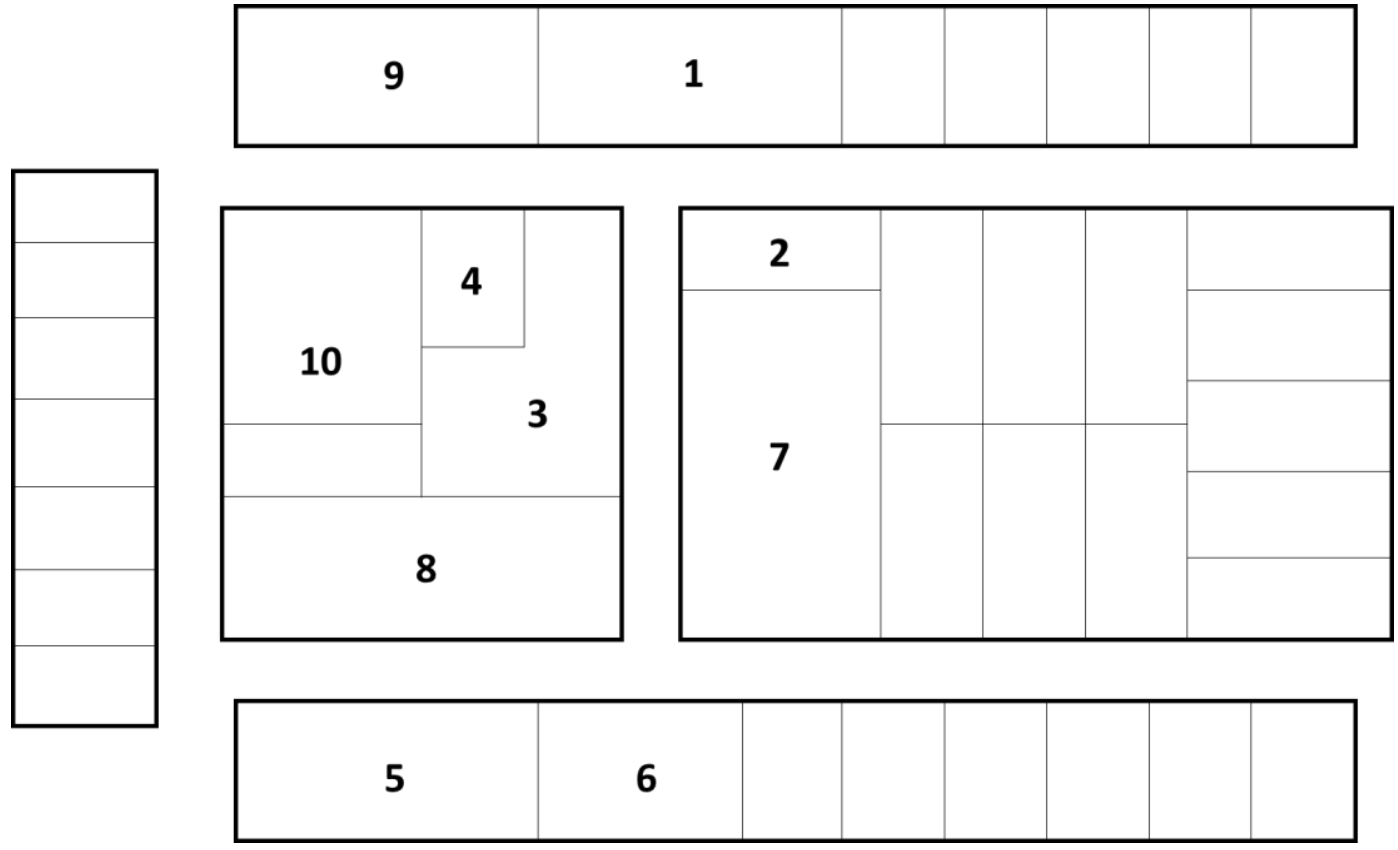

Figura 40 - Disposição final das empresas dentro do parque.

Como resultado final tem-se a disposição da Figura 41, colocados de acordo com a D4 e os requisitos de espaço. Nota-se a compactação das unidades produtivas e a proximidade desejada para as que realizam trocas neste momento. 


\subsubsection{Passo D6: Selecionar a melhor alternativa}

Neste estudo de caso elaborou-se apenas uma única alternativa de layout, baseado apenas nos resultados obtidos com a intensidade de fluxo de cada relacionamento. As trocas consideradas mais importantes estão próximas, bem como as de média importância ao redor destas, e nos terrenos mais distantes do centro tem-se as empresas que não realizam trocas.

$\mathrm{O}$ foco desta pesquisa portanto foi a intensidade de fluxo dos relacionamentos, este baseado em quantidade movimentada por mês e no número de trocas. Para a geração de mais alternativas é necessário a obtenção de mais informações, podendo estas serem restrições, limitações ou necessidades internas ou externas. Portanto como não se conseguiu mais dados considerados necessários para realização de novas alternativas, essa pesquisa limitou-se a apenas uma.

Outro ponto que influencia neste passo é a estratégia adotada, sendo esta na maioria dos casos baseada em custos baixos, mas também pode exigir flexibilidade alta ou redução da necessidade de transporte, por exemplo.

Como cada caso é diferente, pois as unidades produtivas são outras, as trocas diferem e o parque também se altera, deve-se analisar as alternativas, caso elas surjam, de acordo com a estratégia e com foco no objetivo final de favorecer a SI dentro do parque industrial.

\subsubsection{Resultado final}

O layout final que favoreça a SI é o apresentado anteriormente pela Figura 41. Faz-se importante ressaltar que este resultado é compatível com os dados obtidos e as condições apresentadas, seguindo apenas este contexto e não considerando questões burocráticas, solo, proximidade de entrada ou saída do parque, iluminação, água ou qualquer outra questão que interfira na eficiência do resultado.

O resultado é relativo a este momento do sistema, com esses elementos, onde as unidades produtivas não estão instaladas e possuem atualmente o tamanho fornecido e a produção estipulada aqui.

\subsection{Discussão dos resultados}

O resultado obtido com a aplicação dos passos arranja as unidades produtivas de forma a favorecer as possíveis trocas simbióticas que foram identificadas na D2, com a realização do 
matching. Este procedimento desenvolvido identifica as trocas, classifica estas de acordo com a intensidade de fluxo de cada uma, verifica se existe informações qualitativas que possam interferir na definição do layout, através de restrições ou limitações e considera os requisitos de espaço de cada unidade produtiva e do local onde estas serão situadas.

Desta forma as trocas e os possíveis relacionamentos são favorecidos, melhorando consequentemente a SI no sistema. A utilização máxima de resíduos passa a ser o foco do parque industrial, onde o arranjo físico facilita sua ocorrência, diminuindo a geração de materiais que são jogados no meio ambiente e a extração de recursos naturais.

A sequência dos passos que compõe o procedimento fornece uma estrutura que leva ao planejamento do layout para a SI de forma consideravelmente simples e rápida. Cada passo é dependente do anterior e possui ferramentas que se bem elaboradas mostram e melhoram o entendimento do sistema, com foco principalmente no fluxo de resíduos.

O primeiro passo é importante para entender os materiais que entram e saem de cada empresa, são eles que irão possibilitar a realização de trocas e serão essenciais para o correto posicionamento do layout final no parque. Nesta etapa compreende-se o que existe dentro do sistema e deve ser considerado como resíduo, as quantidades geradas são coletadas para se ter a dimensão do volume de material que se tem no parque e que está disponível as empresas. Outras questões mais qualitativas também são consideradas nesta etapa e influenciarão no quarto passo, tais como a qualidade dos resíduos, a temperatura, entre outras características físico-químicas.

O segundo passo analisa esses dados e realiza combinações para a ocorrência da SI no sistema. Esta etapa é onde ocorre o ponto chave do procedimento, é onde as trocas são estabelecidas e com isso todas os demais passos são desenvolvidos. O objetivo central desta fase está em utilizar todos resíduos novamente no sistema, em algumas ocasiões isso é possível de forma direta, onde o resíduo é utilizado novamente sem necessidade de retrabalho, porém em alguns casos será preciso realizar etapas intermediárias para tornar o output de empresa satisfatório para ser input de outra. A intenção é realizar todos os matchings possíveis e tornar o sistema mais eficiente em questão de uso de recursos.

O terceiro passo é responsável por obter informações sobre o fluxo dos materiais, neste caso dos resíduos e subprodutos. Nesta fase entende-se as trocas obtidas na etapa anterior, estas são quantificadas com um valor de intensidade de fluxo, o qual é baseado principalmente na quantidade de material transportado de uma empresa a outra. As questões qualitativas, como características de movimentação, restrições ou qualidade devem ser consideradas para aumentar 
a intensidade do fluxo. Com este valor é necessário classificar as trocas em função do maior para o menor valor, identificando as trocas que merecem maior atenção e menor distância.

O quarto passo diz respeito a inter-relação das unidades produtivas, esta é dividida em quatro atividades que facilitam a compreensão do relacionamento entre as empresas. É necessário entender também quais unidades produtivas apresentam maior número de trocas, estas são portanto consideradas como prioritárias na elaboração do layout. Para conseguir um esboço do layout sem a noção de espaço, faz-se necessário a realização de uma análise qualitativa do sistema, para identificar possíveis restrições, especificações e limitações que possam requerer que as unidades produtivas fiquem próximas ou distantes. Para terminar esta fase o método dos elos é realizado para confirmar as trocas que devem ser colocadas no centro do layout e ter preferência no arranjo.

O quinto passo faz-se necessária para inclusão de espaço no esboço do layout desenvolvido na etapa anterior. Aqui coleta-se e considera-se os requisitos de espaço de cada unidade produtiva, do tamanho total do parque e inclusive dos terrenos, se estes já estiverem divididos.

O sexto passo completa o procedimento através da análise das possíveis alternativas de layout. Essa análise limita-se as informações obtidas, principalmente no que diz respeito ao custo de cada alternativa e na redução do tempo necessário para a troca simbiótica, e a estratégia adotada pelo sistema, onde esta pode optar por flexibilidade, rapidez, menor custo, adaptabilidade entre outras características.

Por fim o resultado final obtido é um layout compatível com as informações coletadas e analisadas do sistema, favorecendo as trocas e consequentemente a SI. Deve-se atentar para o fato de que este layout é baseado na situação atual de análise, porém o sistema é dinâmico de forma que produtos são trocados, empresas estão sujeitas a falência ou mudança de endereço e linhas produtivas estão em constante adaptação e melhoria, levando a eliminação ou alteração de resíduos.

O processo de realização do procedimento faz com que as empresas que compõe o sistema compreendam os materiais que entram e saem de todas as pertencentes ao parque, bem como a respectiva quantidade de cada um, facilitando a organização e a comunicação interiormente a este.

\subsubsection{Benefícios}

Com a aplicação deste procedimento um benefício verificado é a proximidade geográfica das unidades produtivas que realizam trocas, isto possibilita que as empresas tenham 
um maior controle de seu estoque de resíduos, pois a empresa consumidora está bem perto, facilitando a movimentação dos materiais e até um possível fornecimento Just in time.

Outro ponto positivo é a redução de transporte desnecessário, como as empresas estão próximas e as trocas com maiores intensidades de fluxo são favorecidas e estão lado a lado, o transporte é reduzido e consequentemente os impactos ambientes causados por este, como poluição do ar por exemplo, e os custos diretamente e indiretamente ligados a este.

A comunicação é facilitada pois as empresas que se relacionam estarão localizadas próximo umas das outras, desta forma as informações podem ser passadas com rapidez e de maneira mais simples.

Com o favorecimento das trocas vem a integração dos elementos do parque, as empresas se interagem com maior facilidade e passam a compreender de todos os resíduos gerados no parque e suas quantidades. Com essa informação pode-se gerenciar melhor o reuso e a reciclagem de materiais e auxiliar no desenvolvimento de novas trocas simbióticas.

O maior benefício é a redução de custos, que vem a partir da redução de transporte, de movimentação e de controle desses resíduos.

O procedimento possibilita a compreensão do sistema, das empresas que o compõe e da relação entre elas. Este mapeia os relacionamentos, liga as possíveis trocas, prioriza-as e arranja o parque em função da SI. Esta consegue reduzir a emissão de poluição por reduzir a quantidade de transporte, melhora a comunicação e integração das empresas, que no procedimento são tratadas como unidade produtiva, e reduz o volume de material posto na natureza como lixo.

\subsubsection{Análise da aplicação}

A aplicação dos passos foi bem realizada e estruturada, a sequência apresentada leva ao resultado esperado, sendo que as informações que são obtidas em cada passo servem como dados de entrada para aquela que a sucede.

Nesta pesquisa os dados foram coletados apenas para realizar uma aplicação do procedimento, onde dez empresas forneceram alguns dados requisitados por este trabalho, focando apenas nos dados principais, sendo os materiais de entrada e saída, bem como a quantidade de cada um. Essas empresas não pertencem a um parque, estão apenas situadas na mesma cidade no interior do estado de São Paulo. Os dados de espaço foram obtidos em um parque industrial da mesma cidade que possibilitasse a aplicação do procedimento.

Os dados foram conflitados como se estas empresas estivessem situadas em um parque e realmente utilizassem os resíduos alheios. Para esta pesquisa foram analisadas empresas do 
setor metal-mecânico e duas moveleiras. Do parque foram considerados apenas o espaço total e o tamanho de cada terreno, para assim posicionar as empresas nas quadras e terrenos que favoreçam o arranjo final.

Neste caso existem seis empresas que já utilizam materiais que sobram de outras empresas, basicamente três empresas fornecem a mais duas que posteriormente fornecem a mais uma. Desta forma a aplicação do procedimento ficou mais simples e possibilitou mostrar melhor o resultado pretendido.

A aplicação do procedimento serve para entender o desenvolvimento, sequência e estrutura dos passos, bem como nos resultados que são obtidos em cada uma delas e no resultado final possível de ser obtido.

Alguns dados não foram possíveis de serem obtidos, dados mais qualitativos não foram coletados por falta de informação das empresas e de tempo disponível para isso. Dados importantes.

\subsubsection{Proposta para processos integrados}

Uma questão bastante pertinente a este estudo é o fato do layout ser eficiente apenas para aquele momento e não conseguir se adaptar a mudanças do sistema, seja por parte das empresas ou por parte dos resíduos gerados. Assim o arranjo físico aqui desenvolvido está condicionado as condições especificadas no momento do planejamento, perdendo suas características em caso de alterações no sistema.

Desta forma entende-se que o resultado final aqui obtido possui baixa flexibilidade a adaptações do sistema. Para isso criou-se uma ideia que resolvesse este problema, porém esta necessita de mais estudos.

A ideia parte do princípio de proximidade geográfica, utilização de resíduos, redução de custos e flexibilidade para adaptações do sistema. A geração de resíduos é proveniente dos processos produtivos de cada empresa, os quais são baseados nos produtos fabricados por cada uma delas. Os processos produtivos são compostos por recursos produtivos que são organizados com um dado arranjo físico que basicamente melhore o fluxo produtivo e reduza os custos.

Portanto pode-se organizar um local no centro do parque onde os processos produtivos de cada empresa que gerasse resíduos ou subprodutos fossem estruturados próximos dos processos produtivos de outras que empresas que consumissem os resíduos e subprodutos gerados. Desta maneira o fornecimento e recebimento dos resíduos e subprodutos passam a ser just in time. 
Um parque com esta nova configuração possibilitaria a integração máxima das empresas, a proximidade ideal dos processos geradores e consumidores de resíduos, o menor custo com transporte, estocagem e movimentação desses e forneceria flexibilidade para mudar as linhas de produção, retirar e incorporar novas no sistema.

É uma forma prática de arranjar os processos geradores e consumidores de resíduos e subprodutos, elevando o nível da SI no sistema, facilitando sua aplicação e transformando ela no foco principal do parque, juntamente com a integração e cooperação das empresas participantes.

A gestão desses processos requereria uma integração bem elevada, visto que a SI é o fator que liga todos os processos, portanto as decisões de para cada processo produtivo afeta aqueles que estão ligados a esse, fazendo com que qualquer mudança altere o panorama global. A diferença é que neste caso o foco é a SI e por isso ele possui maior importância no planejamento e a flexibilidade dos processos é maior. Para a empresa retirar um processo do local especifico ou acrescentar outro, ela não necessitará alterar toda sua extensão e recursos, facilitando a mudança. As decisões para aplicação de melhorias que tragam aumento ou diminuição da geração ou consumo de resíduos devem ser tomadas em conjunto, buscando sempre a SI.

Outro benefício seria a cooperação, visto que os processos ocorrem com elevada interdependência, a operação correta e a eficiência de cada um influenciam diretamente no desempenho do sistema.

A possibilidade de reduzir distâncias e consequentemente custos, de aumentar integração e cooperação são o ponto forte desta ideia. Esta entretanto necessita de estudos mais aprofundados, pesquisa de campo, sendo assim considerada como oportunidade de trabalhos futuros.

\subsubsection{Considerando uma cadeia de suprimentos no sistema}

Um ponto importante a ser discutido é que neste trabalho, o procedimento elaborado considerou apenas a SI, ou seja, os fluxos dos resíduos, e não considerou os fluxos produtivos. Isto é viável no caso em que as empresas estejam em cadeias de suprimentos diferentes, desta forma o fluxo dos produtos não necessita ser considerado pois as empresas fornecedoras e clientes não estão no mesmo parque.

Este procedimento pode não ser suficiente para obtenção do melhor layout caso empresas participantes de uma mesma cadeia logística pertençam ao parque. Nesta situação, a não ser que o foco seja a realização da SI, deve-se considerar o fluxo produtivo destas empresas, 
analisando o fluxo dos produtos das fornecedoras para as clientes. $\mathrm{O}$ arranjo final portanto precisa contemplar as duas questões, a SI e o fluxo da cadeia logística presente no sistema.

Há duas formas de considerar o fluxo da cadeia no sistema e com este procedimento. A primeira delas é simples, porém trabalhosa, deve-se realizar este procedimento e obter um layout satisfatório com foco na SI e realizar em paralelo o método SLP de Muther (1973) para o fluxo dos produtos. Após a obtenção dos layouts deve-se compará-los e optar por arranjar o parque de acordo com os dois resultados obtidos, sempre ponderando as escolhas de acordo com a estratégia adotada pelo sistema.

Outra forma seria considerar o fluxo dos produtos juntamente com o procedimento desenvolvido nesta pesquisa. Porém para isso é necessário maiores estudos e um aprofundamento deste procedimento com o modelo original de planejamento de layout. Basicamente acrescenta-se o fluxo dos produtos na carta De-Para e no diagrama de interrelações e desenvolve-se os seis passos, considerando que as decisões que surgirem devem ser tomadas mediante a estratégia adotada, podendo ser com foco na SI com o fluxo de resíduos ou subprodutos ou no fluxo dos produtos.

\subsubsection{SI e EIP no sistema}

Essa pesquisa relaciona SI em um parque industrial qualquer. Porém, sabe-se que de acordo com a literatura, um EIP favoreceria e facilitaria a ocorrência da SI no sistema. Um EIP é planejado com foco na SI e na EI, possui forte apelo ambiental, e busca cooperação das empresas situadas em seu interior para obter maiores ganhos, principalmente em custos e aspectos ambientais.

Desta forma, entende-se que o planejamento do layout para um parque industrial normal provavelmente é diferente de um EIP, por este segundo possuir mais informações e características para que os aspectos ambientais sejam maximizados e a gestão ocorra com esse objetivo, tornando-o mais suscetível a SI. Como o layout neste caso favorece os relacionamentos e trocas simbióticas, este também será mais eficiente se planejado em um EIP.

Um EIP colocaria mais questões para serem consideradas no procedimento, como a utilização conjunta de água e tratamento desta, o compartilhamento de recursos, como energia, áreas naturais, centros de tratamento, vapor, entre outros recursos. Esses compartilhamentos devem ser incluídos no procedimento desenvolvido por esta pesquisa. 
Porém, esta questão deve ser pesquisada futuramente e deve-se realizar um estudo de caso que compare a aplicação do procedimento desenvolvido nesta pesquisa em um parque industrial comum e em um EIP.

Os benefícios que são conseguidos com a aplicação do EIP foram discutidos nesta pesquisa e merecem atenção para trabalhos futuros. A integração, cooperação e colaboração que o EIP traz consigo facilita e melhora o planejamento do layout e especialmente a implantação do procedimento, a qual não é abordada neste estudo.

$\mathrm{Na}$ ideia de incluir os processos produtivos num mesmo local para aumentar a eficiência do layout, o EIP proporcionaria um cenário extremamente propício para um layout cujo foco e eficiência dependem diretamente da SI, num ambiente onde os resíduos devem ser reaproveitados, os fluxos devem ser eficientes e a geração de descarte de materiais a natureza precisa ser mínima. 


\section{Capítulo 6. Conclusão}

A SI é um conceito importante situado no universo da EI, que através da realização de trocas simbióticas reduz a quantidade de resíduos que são gerados pelas empresas e dispostos na natureza e consequentemente diminui a quantidade de recursos naturais extraídos do meio ambiente. Ela traz comprovadamente resultados benéficos as empresas que a utiliza, através da redução da poluição e de custos, além de colocar a organização como ambientalmente responsável.

Como a SI busca a utilização de recursos ao máximo dentro de um sistema, de forma que este fique cíclico e não linear, ela utiliza de trocas simbióticas entre empresas que participam deste sistema. Ao longo do tempo essas empresas que realizam trocas e compartilham recursos passam a ter uma comunicação melhor, consequentemente uma maior integração e por fim cooperação, tornando-as mais fortes do que quando consideradas isoladamente.

Porém, a SI necessita de um local que propicie a proximidade requerida para que essas empresas tenham custos baixos e maior integração e que favoreça a continuidade e o estabelecimento das trocas simbióticas. Para melhorar o sistema neste quesito, este trabalho buscou informações e conceitos no planejamento do layout, o qual objetiva encontrar a melhor disposição física de recursos dentro de um local definido, neste caso, empresas dentro de um parque industrial.

Definiu-se que o conceito de layout fornece sua maior contribuição na fase de planejamento, pois nesta etapa ocorre a definição e estruturação do melhor arranjo de acordo com as características e objetivos definidos na estratégia do sistema. Neste caso o objetivo é considerar a SI no planejamento, de forma a favorece-la desde a concepção do parque.

Desta forma, encontrou-se alguns modelos de planejamento de layout que serviram de base para este estudo, com especial atenção ao modelo de Muther (1973), o qual foca justamente no fluxo de materiais entre recursos e no relacionamento entre eles. A revisão sistemática de SI não retornou algum estudo onde se considerasse o estudo de SI e Layout, apenas resultados de estudos de caso e informações gerais a respeito do tema de SI.

Com isso, foi possível desenvolver seis passos para serem seguidos no planejamento do layout com foco na SI. O modelo de Muther (1973) foi adaptado para considerar empresas (chamadas no procedimento de unidades produtivas), resíduos e as trocas simbióticas.

Portanto, para responder ao objetivo foi criado um procedimento composto por seis passos que estrutura o planejamento do layout de unidades participantes da SI dentro de um 
sistema com limites definidos. Após a leitura em estudos de SI e a análise dos modelos de planejamento de layout desenvolveu-se seis passos, sendo eles: obter os dados de entrada, realizar o matching, analisar o fluxo de materiais, elaborar a inter-relação das unidades produtivas, elaborar a inter-relação das unidades produtivas com espaço e selecionar a melhor alternativa.

Os seis passos foram estruturados para serem aplicadas na sequência correta para obtenção dos resultados esperados. Estas possuem todos os passos e ferramentas necessários para planejar o layout e estruturar a SI conforme as informações estudadas na literatura disponível.

Uma aplicação do procedimento proposto foi realizada em um parque industrial real, porém em fase de planejamento, onde as empresas forneceram alguns dados necessários para a realização dos passos. O resultado final foi um arranjo físico das empresas com favorecimento a SI, onde as empresas que realizam trocas simbióticas ficaram próximas e melhor disposta dentro do local estudado.

O procedimento de planejamento do layout de empresas com foco na SI num parque que foi desenvolvido nesta pesquisa contribui para a estruturação de um local onde a disposição física dos elementos participantes da SI possuem preferência e estão próximos. Essa proximidade gera menor necessidade de transporte, de movimentação e controle desses materiais desde a saída de uma empresa até a entrada em outra. Com isso consegue obter maiores relacionamentos, maior cooperação, integração e participação efetiva das empresas no sucesso da SI.

Contudo, não foi possível implantar o resultado obtido com e procedimento para compreender os benefícios gerados. A comprovação da possível redução de custos, transporte, movimentação e a melhora nos relacionamentos e gestão dos resíduos não foi possível de ser realizada. Esses benefícios são enxergados teoricamente, sendo que as empresas que se relacionam estão situadas o mais próximo possível. Portanto entende-se que o transporte, a movimentação e seus custos são reduzidos e consequentemente melhora-se a troca de informações para gestão dos resíduos.

O procedimento contribuiu para o entendimento da SI em um parque, seus benefícios e suas características, mostrando a importância do estudo e compreensão dos resíduos, da realização do matching e do desenvolvimento das trocas simbióticas.

O procedimento buscou considerar a disposição geográfica das empresas e a compreensão e estruturação dos fluxos dos resíduos à SI, portanto este levou conceitos 
ambientais para redução da disposição de resíduos e para o ciclo fechado dos materiais ao layout e trouxe questões de proximidade e fluxos eficientes a SI.

Num ambiente com a SI, esta deve ser o foco do planejamento para que as empresas que a utilizem tenham favorecimento e consigam desenvolver trocas duradouras e lucrativas, e as que ainda não utilizem enxerguem a vantagem por trás deste conceito.

O procedimento sendo uma proposta conceitual atendeu o objetivo e conseguiu os resultados esperados. Este adequou os modelos de planejamento de layout com aspectos de SI, necessitando apenas de mais estudos em caso de empresas que tenham o fluxo de produtos entre elas dentro do parque também. Os seis passos desenvolvidos são capazes de gerar um arranjo físico no contexto apresentado, porém dados mais quantitativos a respeito de custos e distância percorrida pelos materiais para possíveis comparações com o uso do procedimento ou disposição aleatória dos elementos não foram passíveis de serem realizadas.

Após a análise e discussão realizada nesta pesquisa em relação ao procedimento desenvolvido, pode-se concluir que a literatura existente de SI não havia considerado questões presentes na literatura de planejamento de layout. Estes conceitos possuem um relacionamento, como pode ser observado neste trabalho, onde a busca por eficiência, eficácia, melhores interrelacionamentos e integração estão presentes nos dois conceitos e são objetivados por ambos.

A questão de proximidade geográfica e favorecimento de unidades que realizassem trocas ou comunicação sempre foi abordada, e a SI ainda não havia inserido estas questões em seu desenvolvimento. Estes temas possuem esta correlação que foi buscada nesta pesquisa, para que a SI fosse potencializada e assim, pesquisas que são consolidadas na engenharia de produção são integradas a novas propostas e artigos de pesquisa que surgem no cenário acadêmico mundial, tal como a EI.

Para trabalhos futuros deve-se considerar a estruturação do layout com aspectos de SI e dos fluxos dos produtos, considerando a presença de uma cadeia logística dentro do parque. Além de aplicar o procedimento proposto e acompanhar os benefícios conseguidos através deste em relação ao arranjo aleatório das empresas no sistema em questão.

Conclui-se que o objetivo desta pesquisa foi atingido de forma satisfatória, considerando que o procedimento proposto através de seis passos de fato utiliza técnicas do planejamento de layout e estrutura as trocas simbióticas, estabelecendo os relacionamentos necessários para a SI ocorrer de forma adequada. 


\subsection{Limitações para desenvolvimento desta dissertação}

As dificuldades encontradas na aplicação do procedimento ocorreram na fase de obtenção dos dados, pois as empresas restringiram as informações e não entraram em detalhes mais específicos sobre cada resíduo. As organizações não acharam interessante fornecer todos os dados requisitados por esta pesquisa, pois essas informações podem representar um fator de risco a elas em caso de resíduos que exigem controle e respeito a normas. Outro ponto é a representação de ineficiência produtiva em caso de grande quantidade de resíduos, ou até mesmo a descoberta de estratégia conforme os resíduos gerados.

O parque industrial estudado não tinha as empresas que adquiriram os terrenos instaladas e por isso o contato foi mais complicado, impossibilitando a realização de um estudo de caso. Com isso, os dados atuais do parque, como disposição atual, distâncias para transporte e movimentações não foram coletadas, e não possibilitaram comparações com as distâncias obtidas a partir da aplicação do procedimento.

Não foram fornecidos os dados de todos os materiais que entram e saem de cada empresa, por questões de sigilo e segurança de informações consideradas estratégicas. Desta forma, fatos qualitativos e restrições que influenciariam no procedimento na fase do diagrama de inter-relações não foram fornecidas. Por fim, a noção de custos foi um item importante para melhores análises que não foi obtido.

\subsection{Propostas para trabalhos futuros}

Uma proposta de trabalho futuro está em estudar a estruturação do procedimento com questões de compartilhamento de recursos energéticos e hídricos, além de centros de tratamento e reciclagem para reuso de materiais.

Um ponto importante está na pesquisa de como incluir o fluxo de informações neste trabalho, para assim mapear e compreender o parque de forma ampla e a SI como um todo, incluindo os relacionamentos, compartilhamentos, as cooperações e integrações que ocorrem, apenas com dados e informações. Deve-se entender como esses fluxos ocorrem e a forma de considera-los no procedimento, conjuntamente ou separadamente. Caso esses forem estipulados separadamente, qual o peso e importância de cada fluxo para o layout final.

Outro ponto é o desenvolvimento do layout considerando o fluxo de produtos das empresas. Caso estas sejam pertencentes a uma cadeia de suprimentos, elas terão seus fluxos de fornecimento e recebimento de produtos finais, necessitando de considerar isto no procedimento aqui desenvolvido de forma integrada ou não. Se estes forem estruturados de 
forma paralela, novamente deve-se estipular a importância e representatividade de cada um no arranjo físico final.

Portanto para pesquisas futuras deve-se considerar os fluxos de informações, o fluxo de produtos e o uso compartilhado de recursos entre outros relacionamentos criados pela SI. Estes podem ocorrer num ambiente propício para essas questões, que estimula e favorece seus desenvolvimentos, além de organizar as empresas dentro de uma estratégia comum, ou seja, em um EIP. Esses fluxos e relacionamentos podem ocorrer de forma diferente neste contexto, exigindo novos estudos e adequações para obter melhores resultados. 


\section{REFERÊNCIAS ${ }^{1}$}

AGARWAL, A.; STRACHAN, P. Literature review on eco-industrial development initiatives around the world and the methods employed to evaluate their performance/effectiveness. Consultancy Report prepared for Databuild Ltd. and National Industrial Symbiosis Programme, 2006.

ALFARO, J.; MILLER, S. Applying Industrial Symbiosis to Smallholder Farms. Journal of Industrial Ecology, v. 18, n. 1, p. 145-154, 2014.

ALLENBY, B. R. Implementing industrial ecology: the AT\&T matrix system. Interfaces v.30, p.42-54, 2000.

AMADO, R. F.; ROZENFELD, H. Análise da aplicabilidade do método DMAIC do modelo Seis-Sigma. In: Simpósio de Engenharia de Produção, Brasil, 2006.

AMATO NETO, J. Os desafios da produção e do consumo sob novos padrões sociais e ambientais. In: . Sustentabilidade e produção: Teoria e prática para uma gestão sustentável, São Paulo: Atlas, 2011.

APPLE, J. M. Plant layout and material handling. 3rd ed. Nova York: Wiley, 1977.

ASHTON,W. Understanding the organization of industrial ecosystems: A social network approach. Journal of Industrial Ecology. v.12(1), p.34-51, 2008.

ASHTON, W. S.; BAIN, A. C. Assessing the "Short Mental Distance" in Eco-Industrial Networks. Journal of Industrial Ecology, v. 16, n. 1, p. 70-82, 2012.

BEHERA, S. K.; KIM, J. H.; LEE, S. Y.; SUH, S.; PARK, H. S. Evolution of 'designed' industrial symbiosis networks in the Ulsan Eco-industrial Park: 'research and development into business' as the enabling framework. Journal of Cleaner Production, v. 29, p. 103-112, 2012.

BOONS, F.; SPEKKINK, W.; MOUZAKITIS, Y. The dynamics of industrial symbiosis: a proposal for a conceptual framework based upon a comprehensive literature review. Journal of Cleaner Production, v. 19, n. 9, p. 905-911, 2011.

BANSAL, P.; MCKNIGHT, B. Looking forward, pushing back and peering sideways: analyzing the sustainability of industrial symbiosis.Journal of Supply Chain Management, v. 45, n. 4, p. 26-37, 2009.

BIOLCHINI, J.; MIAN, P. G.; NATALI, A. C. C.; TRAVASSOS, G. H. Systematic review in software engineering. Rio de Janeiro, 2005. (report)

BOONS, F.; SPEKKINK, W. Levels of institutional capacity and actor expectations about industrial symbiosis. Journal of Industrial Ecology, v. 16, n. 1, p. 61-69, 2012.

\footnotetext{
${ }^{1}$ De acordo com: ASSOCIAÇÃO BRASILEIRA DE NORMAS TÉCNICAS. NBR 6023: informação e documentação: referências: elaboração. Rio de Janeiro, 2002.
} 
CAMAROTTO, J. A. Estudo das relações entre o projeto de edifícios industriais e a gestão da produção. Tese (Doutorado), FAU/USP. São Paulo, 1998.

CAMARotTo, J. A.; MENEGON N. L. Projeto de Unidades Produtivas: Apostila. 126p. Departamento de Engenharia de Produção, Centro de Ciências Exatas e de Tecnologia, Universidade Federal de São Carlos. São Carlos, 2006.

CARR, A. J. P. Choctaw Eco-Industrial Park: an ecological approach to industrial land-use planning and design. Landscape and Urban Planning, v. 42, n. 2, p. 239-257, 1998.

CHEN, X.; FUJITA, T.; OHNISHI, S.; FUJII, M.; GENG, Y. The impact of scale, recycling boundary, and type of waste on symbiosis and recycling. Journal of Industrial Ecology, v. 16, n. 1, p. 129-141, 2012.

CHERTOW, M. R. Industrial symbiosis: literature and taxonomy. Annual Review of Energy and Environment, v. 25, p. 313-337, 2000.

CHERTOW, M. R. Industrial symbiosis. In: Encyclopedia of Energy, edited by C. J. Cleveland. San Diego: Elsevier, 2004.

CHERTOW, M. R. “Uncovering” industrial symbiosis. Journal of Industrial Ecology, v. 11, n. 1, p. 11-30, 2007.

CHERTOW, M. R.; ASHTON, W. S.; ESPINOSA, J. C. Industrial Symbiosis in Puerto Rico: Environmentally related agglomeration economies. Regional Studies, v. 42.10, p. 1299-1312, 2008.

CHERTOW, M.; EHRENFELD, J. Organizing self-organizing systems - toward a theory of industrial symbiosis. Journal of industrial ecology, v.16(1), 2012.

CHERTOW, M. R.; LOMBARDI, D. R. Quantifying economic and environmental benefits of co-located firms. Environmental Science \& Technology, v. 39, n. 17, p. 6535-6541, 2005.

CHERTOW, M.; MIYATA, Y. Assessing collective firm behavior: comparing industrial symbiosis with possible alternatives for individual companies in Oahu, HI. Business Strategy and the Environment, v. 20, n. 4, p. 266-280, 2011.

CORREA, H. L.; CORREA, C. A. Administração de produção e operações. São Paulo, Atlas, 2007.

COSTA, I.; FERRÃO, P. A case study of industrial symbiosis development using a middleout approach. Journal of Cleaner Production, v. 18, n. 10, p. 984-992, 2010.

DESCHENES, P. J.; CHERTOW, M. An island approach to industrial ecology: towards sustainability in the island context. Journal of Environmental Planning and Management, v. 47, n. 2, p. 201-217, 2004.

DIAS, M. A. Administração de materiais: uma abordagem logística. 4 ed. São Paulo: Atlas, 1993. 
DOMÉNECH, T.; DAVIES, M. The role of embeddedness in industrial symbiosis networks: phases in the evolution of industrial symbiosis networks. Business Strategy and the Environment, v. 20, n. 5, p. 281-296, 2011.

DONG, L.; GU, F.; FUJITA, T.; HAYASHI, Y.; GAO, J. Uncovering opportunity of lowcarbon city promotion with industrial system innovation: case study on industrial symbiosis projects in China. Energy Policy, v. 65, p. 388-397, 2014.

DONG, L.; ZHANG, H.; FUJITA, T.; OHNISHI, S.; LI, H.; FUJII, M.; DONG, H. Environmental and economic gains of industrial symbiosis for Chinese iron/steel industry: Kawasaki's experience and practice in Liuzhou and Jinan. Journal of Cleaner Production, v. 59, p. 226-238, 2013.

FELÍCIO, M. C. Proposta de um indicador para monitorar a evolução da simbiose industrial em Parques Eco-Industriais segundo a perspectiva de sistemas dinâmicos. Dissertação (Mestrado), Programa de Pós-graduação em Engenharia de Produção e Área de concentração em processos e gestão de operações - Escola de Engenharia de São Carlos da Universidade de São Paulo, São Carlos, 2013.

FLEURY, A. Planejamento do projeto de pesquisa e definição do modelo teórico. In:

MIGUEL, P. A. C. (Coord.) Metodologia de pesquisa em engenharia de produção e gestão de operações. Rio de Janeiro: Elsevier, 2010.

FROSCH, R. A.; GALLOPOULOS, N. E. Strategies for Manufacturing. Scientific American, 189(3), p. 1-7, 1989.

GENG, Y.; ZHANG, P.; CÔTÉ, R.; FUJITA, T. Assessment of the national eco-industrial park standard for promoting industrial symbiosis in China. Journal of Industrial Ecology, v.13(1), p. 15-26, 2009.

GOLEV, A.; CORDER, G. D.; GIURCO, D. P. Industrial symbiosis in Gladstone: A decade of progress and future development.Journal of Cleaner Production, v. 84, p. 421-429, 2014

GONÇALVES FILHO, E. V. Arranjo Físico da Fábrica - Um modelo para o processo de projeto e um algoritmo genético para a formação de células de fabricação. Tese (LivreDocência). Escola de Engenharia de São Carlos, da Universidade de São Paulo. São Carlos, 2001.

GONELA, V.; ZHANG, J. Design of the optimal industrial symbiosis system to improve bioethanol production. Journal of Cleaner Production, v. 64, p. 513-534, 2014.

GUERREIRO, E. D. R. Estudo dos métodos de projeto de fábrica e sua aplicação no setor público de serviço: estudo de caso em escolas de educação infantil. Dissertação (mestrado), Universidade Federal de São Carlos, UFSCAR, São Carlos, 2005.

HEERES, R. R.; VERMEULEN, W. J. V.; WALLE, F. B. Ecoindustrial park initiatives in the USA and the Netherlands: First lessons. Journal of Cleaner Production. v.12(8-10), p.985-995, 2004.

HIETE, M.; LUDWIG, J.; SCHULTMANN, F. Intercompany energy integration. Journal of Industrial Ecology, v. 16, n. 5, p. 689-698, 2012. 
ILLSLEY, B.; JACKSON, T.; LYNCH, B. Promoting environmental justice through industrial symbiosis: developing pelletised wood fuel to tackle Scottish rural fuel poverty. Progress in Industrial Ecology, an International Journal, v. 4, n. 3, p. 219-232, 2007.

JENSEN, P. D.; BASSON, L.; HELLAWELL, E. E.; BAILEY, M. R.; LEACH, M. Quantifying 'geographic proximity': experiences from the United Kingdom's national industrial symbiosis programme. Resources, Conservation and Recycling, v. 55, n. 7, p. 703$712,2011$.

KOENIG, A. Quo Vadis EIP? How Eco-industrial Parks are Evolving. Journal of Industrial Ecology, v. 9, n. 3, p. 12-14, 2005.

LI, P. Notice of Retraction A case study of industrial symbiosis: The Beijiang Power Plant Complex in Tianjin, China. In: E-Business and E-Government (ICEE), 2011 International Conference on. IEEE, 2011. p. 1-3.

LIN, L. C.; SHARP, G. P. Quantitative and qualitative indices for the plant layout evaluation problem. European Journal of Operational Research, v. 116, n. 1, p. 100-117, 1999.

LIWARSKA-BIZUKOJC, E., BIZUKOJC, M., MARCINKOWSKI, A., DONIEC, A. The conceptual model of an eco-industrial park based upon ecological relationships. Journal of Cleaner Production, v.17(8), 732-741, 2009.

LOMBARDI, D. R.; LAYBOURN, P. Redefining industrial symbiosis. Journal of Industrial Ecology, v. 16, n. 1, p. 28-37, 2012.

LOWE, E. A. Eco-industrial park handbook for Asian developing countries. A Report to Asian Development Bank, Environment Department, Indigo Development, Oakland, CA, 2001.

LUZZI, A. A. Uma abordagem para projetos de layout industrial em sistemas de produção enxuta: um estudo de caso. Porto Alegre: UFRGS, 2004.

LYONS, D. I. A spatial analysis of loop closing among recycling, remanufacturing, and waste treatment firms in Texas. Journal of Industrial Ecology, v. 11, n. 1, p. 43-54, 2007.

MARTIN, S. A.; WEITZ, K. A.; CUSHMAN, R. A.; SHARMA A.; LINDROOTH, R. C.; MORAN, S. R. Eco-industrial parks: a case study and analysis of economic, environmental, technical, and regulatory issues: final report. Research Triangle Park, NC: Research Triangle Institute. 1996.

MARTINS, R. A. Abordagens Quantitativa e Qualitativa. In: CAUCHICK, P. M. (Coord.). Metodologia de pesquisa em Engenharia de Produção e Gestão de Operações. Rio de Janeiro: Elsevier, 2010.

MATTILA, T. J.; PAKARINEN, S.; SOKKA, L. Quantifying the total environmental impacts of an industrial symbiosis-a comparison of process-, hybrid and input- output life cycle assessment. Environmental science \& technology, v. 44, n. 11, p. 4309-4314, 2010.

MENEGON, N. L.; COSTA, M.; CAMAROTTO, J. A. A Abordagem utilizada pelo Grupo Simucad: Simulação \& CAD, no desenvolvimento de Instalações Industriais. ENEGEP Proc., Porto Alegre, RS, 1997. 
MEYERS, F. E.; STEPHENS, M. P. Manufacturing facilities Design and material handling. $2^{\mathrm{a}}$ Ed. Prentice Hall, New Jersey, 2000.

MIGUEL, P. A. C. Adoção do estudo de caso na engenharia de produção. In: Metodologia de pesquisa em engenharia de produção e gestão de operações. Rio de Janeiro: Elsevier, 2010.

MIRATA, M. Experiences from early stages of a national industrial symbiosis programme in the UK: determinants and coordination challenges.Journal of Cleaner Production, v. 12, n. 8, p. 967-983, 2004.

MIRATA, M.; EMTAIRAH, T. Industrial symbiosis networks and the contribution to environmental innovation: the case of the Landskrona industrial symbiosis programme. Journal of Cleaner Production, v. 13, n. 10, p. 993-1002, 2005.

MUTHER, R.; WHEELER, J. D. Planejamento sistemático e simplificado de layout. São Paulo: IMAM, 2000.

MUTHER, R. Planejamento do layout: Sistema SLP. Editora Edgard Blucher LTDA, São Paulo, 1973.

NASCIMENTO, D. E.; CASAGRANDE Jr., E. F.; MORAES, L. R.; RUTHES, S. Parque Eco-Industrial: Uma discussão sobre o futuro dos distritos industriais brasileiros. GEPROS. Gestão da Produção, Operações e Sistemas-ISSN 1984-2430, n. 1, p. Pag. 97, 2006.

OLIVÉRIO, J. L. Projeto de fábrica: produtos, processos e instalações industriais. Instituto Brasileiro do Livro Científico LTDA. São Paulo, 1985.

O'ROURKE, D.; CONNELLY, L.; KOSHLAND, C. P. Industrial ecology: a critical review. International Journal of Environment and Pollution, v. 6, n. 2-3, p. 2-3, 1996.

PAKARINEN, S.; MATTILA, T.; MELANEN, M.; NISSINEN, A.; SOKKA, L. Sustainability and industrial symbiosis - The evolution of a Finnish forest industry complex. Resources, Conservation and Recycling, v. 54, n. 12, p. 1393-1404, 2010.

PAQUIN, R. L.; HOWARD-GRENVILLE, J. The evolution of facilitated industrial symbiosis. Journal of industrial Ecology, v. 16, n. 1, p. 83-93, 2012.

PARK, H. S., RENE, E. R., CHOI, S. M., CHIU, A. S. Strategies for sustainable development of industrial park in Ulsan, South Korea-from spontaneous evolution to systematic expansion of industrial symbiosis. Journal of Environmental Management, v. 87, n. 1, 1-13, 2008.

PEARCE, J. M. Industrial symbiosis of very large-scale photovoltaic manufacturing. Renewable Energy, v. 33, n. 5, p. 1101-1108, 2008.

PEREIRA, A. S.; LIMA, J. C. F.; RUTKOWSKI, W. Ecologia industrial, produção e ambiente: uma discussão sobre as abordagens de inter-conectividade produtiva. In: Anais $1^{\text {st }}$ International Workshop Advances in Cleaner Production, v. 1, São Paulo, 2007. 
RAAFAT, T.; TROKANAS, N.; CECELJA, F.; BIMI, X. An ontological approach towards enabling processing technologies participation in industrial symbiosis. Computers \& Chemical Engineering, v. 59, p. 33-46, 2013.

RAMAN, D.; NAGALINGAM, S. V.; LIN, G. C. Towards measuring the effectiveness of a facilities layout. Robotics and Computer-Integrated Manufacturing, v. 25, n. 1, p. 191-203, 2009.

ROBERTS, B. H. The application of industrial ecology principles and planning guidelines for the development of eco-industrial parks: an Australian case study. Journal of Cleaner Production, v. 12, n. 8, p. 997-1010, 2004.

SALMI, O. Eco-efficiency and industrial symbiosis-a counterfactual analysis of a mining community. Journal of Cleaner Production, v. 15, n. 17, p. 1696-1705, 2007.

SHI, H.; CHERTOW, M.; SONG, Y. Developing country experience with eco-industrial parks: a case study of the Tianjin Economic-Technological Development Area in China. Journal of Cleaner Production v.18, p.191-199, 2010.

SILVA, E. L.; MENEZES, E. M. Metodologia da pesquisa e elaboração de dissertação. 4 ed. rev. atual. - Florianópolis: UFSC, 2005.

SIMBOLI, A.; TADDEO, R.; MORGANTE, A. Analysing the development of Industrial Symbiosis in a motorcycle local industrial network: the role of contextual factors. Journal of Cleaner Production, v. 66, p. 372-383, 2014.

SLACK, N.; CHAMBERS, S.; JOHNSTON, R. Administração da produção. 2. Ed. $7^{\text {a }}$ Reimpr. São Paulo: Atlas, 2008.

SOKKA, L.; PAKARINEN, S.; MELANEN, M. Industrial symbiosis contributing to more sustainable energy use-an example from the forest industry in Kymenlaakso, Finland. Journal of Cleaner Production, v. 19, n. 4, p. 285-293, 2011.

SOPHA, B. M.; FET, A. M.; KEITSCH, M. M.; HASKINS C. Using systems engineering to create a framework for evaluating industrial symbiosis options. Systems Engineering, v. 13(2), p.149-160, 2010.

STARLANDER, J.-E. 2003. Industrial Symbiosis: A Closer Look on Organisational Factors. A study based on the Industrial Symbiosis project in Landskrona, Sweden. IIIEE Reports 2003:4. Masters Thesis. The International Institute for Industrial Environmental Economics. Environmental Management and Policy. Lund, Sweden, 2003.

TAMIOTO, A. H. Proposta de simbiose industrial para minimizar os resíduos sólidos no Pólo Petroquímico de Camaçari. Dissertação (Mestrado Profissional em Gerenciamento e Tecnologias Ambientais no Processo Produtivo) - Universidade Federal da Bahia (UFBA), Salvador, 2004.

TIBBS, H. B. C. Industrial ecology-An agenda for environmental management. Pollution Prevention Review. v. 2(2): 167-180, 1992.

TOMPKINS, J. A.; WHITE, J. A.; BOZER, Y. A.; TANCHOCO, J. M. A. Facilities Planning. 4 ed. John Wiley \& Sons, Inc., USA, 2010. 
TORRES, I. Integração de ferramentas computacionais aplicadas ao projeto e desenvolvimento de arranjo físico de instalações industriais. Dissertação (mestrado), Programa de pós graduação em engenharia de produção, Universidade Federal de São Carlos, UFSCAR, São Carlos, 2001.

TORRES, I. Um formalismo relacional para o desenvolvimento de arranjo físico industrial. Tese 234f (Doutorado em Engenharia de Produção), Universidade Federal de São Carlos, UFSCar, São Carlos, 2007.

TORTORELLA, G. L. Sistemática para orientação do planejamento de Layout com apoio de análise de decisão multicritério. Tese (Doutorado), Escola de engenharia, programa de pós graduação em engenharia de produção, Universidade federal do Rio Grande do Sul, UFRGS, Porto Alegre, 2006.

TROKANAS, N.; CECELJA, F.; RAAFAT, T. Semantic approach for pre-assessment of environmental indicators in Industrial Symbiosis. Journal of Cleaner Production, 2013.

TUDOR, T.; ADAM E.; BATES, M. Drivers and limitations for the successful development and functioning of EIPs (eco-industrial parks): a literature review. Ecological Economics, 2007.

USÓN, S.; VALERO, A.; AGUDELO, A. Thermoeconomics and Industrial Symbiosis: Effect of by-product integration in cost assessment. Energy, v. 45, n. 1, p. 43-51, 2012.

VAN BEERS, D.; BOSSILKOV, A.; LUND, C. Development of large scale reuses of inorganic by-products in Australia: The case study of Kwinana, Western Australia. Resources, Conservation and Recycling, v. 53, n. 7, p. 365-378, 2009.

VEIGA, L. B. E.; MAGRINI, A. Eco-industrial park development in Rio de Janeiro, Brazil: a tool for sustainable development. Journal of cleaner production, v. 17, n. 7, p. 653-661, 2009.

YANG, S.; FENG, N. A case study of industrial symbiosis: Nanning Sugar Co., Ltd. in China. Resources, Conservation and Recycling, v. 52, n. 5, p. 813-820, 2008.

YANG, P. P.; LAY, O. B. Applying ecosystem concepts to the planning of industrial areas: a case study of Singapore's Jurong Island.Journal of Cleaner Production, v. 12, n. 8, p. 10111023, 2004.

YU, C.; JONG, M.; DIJKEMA, G. P. J. Process analysis of eco-industrial park development - the case of Tianjin, China. Journal of Cleaner Production. v.64, p.464-477, 2014.

YUAN, Z.; SHI, L. Improving enterprise competitive advantage with industrial symbiosis: case study of a smeltery in China. Journal of Cleaner Production, v. 17, n. 14, p. 1295-1302, 2009.

WANG, G.; FENG, X.; CHU, K. H. A novel approach for stability analysis of industrial symbiosis systems. Journal of Cleaner Production, v. 39, p. 9-16, 2013.

WON, J. Y.; KIM, J. H.; LEE, S. Y.; PARK, H. S. Industrial Symbiosis as an Integrated Business/Environment Management Process: The Case of Ulsan Industrial Complex. In: Strategic Technology, The 1st International Forum on. IEEE, 2006. p. 423-428. 
ZAOHUA, W.; BIN, Z.; GUILONG L. Research on industrial symbiosis patterns in EcoIndustrial Park Based on Industrial Ecology theory. CCASM 2010 - 2010 International Conference on Computer Application and System Modeling (ICCASM), IEEE Proceedings, 2010.

ZHANG, X.; STRØMMAN, A. H.; SOLLI, C.; HERTWICH, E. G. Model-centered approach to early planning and design of an eco-industrial park around an oil refinery. Environmental science \& technology, v. 42, n. 13, p. 4958-4963, 2008.

ZHANG, Y., ZHENG, H., CHEN, B., YANG, N. Social network analysis and network connectedness analysis for industrial symbiotic systems: model development and case study. Frontiers of Earth Science, v. 7, n. 2, p. 169-181, 2013.

ZHU, Q.; LOWE, E. A.; BARNES, D. Industrial symbiosis in China: a case study of the Guitang Group. Journal of Industrial Ecology. v.11, p. 31-42, 2007. 
ANEXO A - Classe do resíduo

Quadro 24 - Classe dos resíduos, (FELÍCIO, 2013)

\begin{tabular}{|c|c|c|}
\hline \multicolumn{3}{|c|}{ Classe do Resíduo } \\
\hline $\begin{array}{c}1 \text { - Não perigosos - Inertes } \\
\text { (Classe IIB) }\end{array}$ & $\begin{array}{l}3 \text { - Não perigosos - Não } \\
\text { inertes (Classe IIA) }\end{array}$ & 5 - Perigosos (Classe I) \\
\hline $\begin{array}{l}\text { São quaisquer resíduos que, } \\
\text { quando amostrados de uma } \\
\text { forma representativa, } \\
\text { segundo a Norma NBR } \\
10.007 \text {, e submetidos a um } \\
\text { contato estático ou dinâmico } \\
\text { com água destilada ou } \\
\text { desionizada, à temperatura } \\
\text { ambiente, conforme Norma } \\
\text { NBR 10.006, não tiverem } \\
\text { nenhum de seus constituintes } \\
\text { solubilizados a concentrações } \\
\text { superiores aos padrões de } \\
\text { potabilidade de água, } \\
\text { excetuando-se aspecto, cor, } \\
\text { turbidez, dureza e sabor, } \\
\text { conforme anexo X da Norma } \\
\text { NBR 10.004. }\end{array}$ & 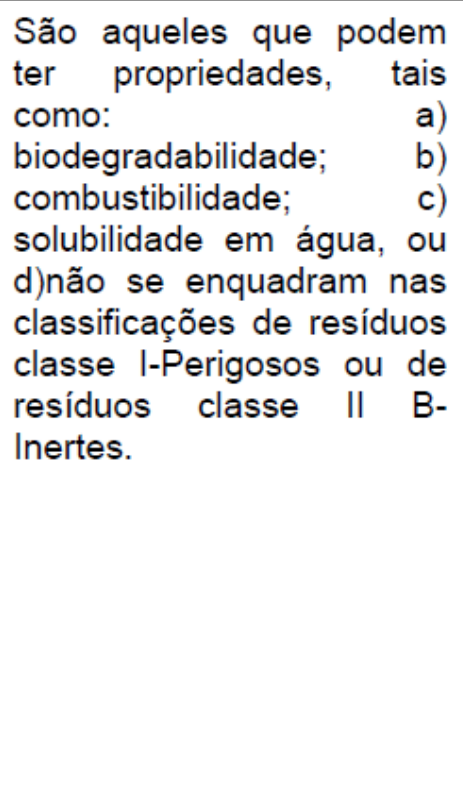 & $\begin{array}{l}\text { São aqueles requisitos que se } \\
\text { enquadram em uma ou mais } \\
\text { situações descritas abaixo: } \\
\text { a)Requisito Legal, de nível } \\
\text { federal, estadual ou municipal, } \\
\text { classificados como "específicos", } \\
\text { ou seja, requisitos que } \\
\text { estabelecem "o que deve ser } \\
\text { feito"; b)Requisito de norma } \\
\text { técnica referenciada por algum } \\
\text { diploma legal específico; c) } \\
\text { Outros requisitos subscritos } \\
\text { constantes em: Licenças } \\
\text { Ambientais/ do Exército/ da } \\
\text { Política Federal, Termos de } \\
\text { Ajustamento de Conduta, } \\
\text { Programas de auto } \\
\text { monitoramento e ou solicitações } \\
\text { formais do órgão competente. }\end{array}$ \\
\hline
\end{tabular}




\section{APÊNDICE A - Protocolo da Revisão Bibliográfica Sistemática (RBS)}

Quadro 25 - Protocolo da RBS sobre SI.

\begin{tabular}{|c|c|c|}
\hline \multirow{8}{*}{$\begin{array}{l}\text { Formulação } \\
\text { da Questão }\end{array}$} & Objetivo & $\begin{array}{l}\text { Identificar principais benefícios, características e ferramentas da Simbiose } \\
\text { Industrial. } \\
\text { Identificar relação com o planejamento de layout. }\end{array}$ \\
\hline & $\begin{array}{l}\text { Problema de } \\
\text { Pesquisa }\end{array}$ & $\begin{array}{l}\text { Compreender a importância da Simbiose Industrial na literatura e melhorar } \\
\text { o entendimento a respeito dela, quanto esta contribuiu para a academia? } \\
\text { Quais ferramentas fazem parte dela? } \\
\text { Existe relação com o planejamento do layout? }\end{array}$ \\
\hline & $\begin{array}{l}\text { Referências } \\
\text { Primárias }\end{array}$ & Chertow (2000; 2004; 2007), Ashton (2008) e Felício (2013). \\
\hline & $\begin{array}{l}\text { Questão de } \\
\text { Pesquisa }\end{array}$ & $\begin{array}{l}\text { Quais são os principais benefícios, características da Simbiose Industrial? } \\
\text { Existem ferramentas a ser utilizadas em seu desenvolvimento? O artigo } \\
\text { possui relação com o planejamento do layout? }\end{array}$ \\
\hline & $\begin{array}{l}\text { Palavras- } \\
\text { chave }\end{array}$ & Industial Symbiosis. \\
\hline & $\begin{array}{l}\text { Base de dados } \\
\text { selecionadas }\end{array}$ & $\begin{array}{l}\text { SCOPUS (Endereço virtual: http://www.scopus.com) e Web of Knowledge } \\
\text { (Endereço virtual: http://isiknowledge.com). }\end{array}$ \\
\hline & $\begin{array}{l}\text { Método de } \\
\text { Busca }\end{array}$ & $\begin{array}{l}\text { Uso de strings definidos de forma a retornem resultados que contenham a } \\
\text { palavra-chave em questão, que por si só compreende todo o tema a ser } \\
\text { levantado, nos campos de busca: título, resumo ou palavras-chave. A } \\
\text { definição das strings é adequada a cada base de dados pesquisada, uma vez } \\
\text { que o mecanismos de busca é diferente em cada base. Busca no título, } \\
\text { palavras-chave e resumo. }\end{array}$ \\
\hline & $\begin{array}{l}\text { Ajustes da } \\
\text { Busca }\end{array}$ & $\begin{array}{l}\text { As aspas foram acrescentadas na palavra chave para refinar os resultados e } \\
\text { buscar os mais pertinentes a pesquisa. }\end{array}$ \\
\hline \multirow[t]{4}{*}{$\begin{array}{l}\text { Seleção dos } \\
\text { Estudos }\end{array}$} & $\begin{array}{l}\text { Critérios de } \\
\text { Inclusão e } \\
\text { Exclusão }\end{array}$ & $\begin{array}{l}\text { - Estar em português ou inglês. } \\
\text { - Pertinência: Tema principal relacionado a Simbiose Industrial } \\
\text { - Disponibilidade de arquivo completo para download } \\
\text { - Serão excluídos os estudos em duplicatas } \\
\text { - Serão aceitos todos os tipos de estudo: artigos de periódicos e } \\
\text { publicações de conferências. }\end{array}$ \\
\hline & $\begin{array}{l}\text { Critérios de } \\
\text { Qualificação }\end{array}$ & $\begin{array}{l}\text { - } \text { Tipo de estudo } \\
\text { - Objetivo do estudo } \\
\text { - } \text { Resultados obtidos com a SI } \\
\text { - } \text { Discussão a respeito da SI } \\
\text { - } \text { Conclusões sobre a SI } \\
\text { - } \\
\text { Relações entre SI e planejamento do Layout. }\end{array}$ \\
\hline & \multirow[b]{2}{*}{ Filtros } & $\begin{array}{l}\text { Filtro preliminar: os estudos ainda na base de dados são submetidos aos } \\
\text { seguintes critérios de inclusão e exclusão: Estudos em língua inglesa e } \\
\text { disponibilidade de arquivo completo para download. }\end{array}$ \\
\hline & & $\begin{array}{l}\text { O Filtro } 1 \text { consiste na leitura de título, resumo e palavras-chave para a } \\
\text { avaliação dos critérios de inclusão e exclusão: } \\
\text { - Exclusão de duplicatas } \\
\text { - Pertinência: relação do estudo ao tema de interesse da pesquisa } \\
\text { (Simbiose Industrial). } \\
\text { - Verificação de língua em que o estudo foi escrito } \\
\text { - Disponibilidade de arquivo completo para download }\end{array}$ \\
\hline
\end{tabular}




\begin{tabular}{|c|c|}
\hline \multirow[t]{2}{*}{$\begin{array}{l}\text { Seleção dos } \\
\text { Estudos }\end{array}$} & $\begin{array}{l}\text { No Filtro } 2 \text { é efetuada a leitura de introdução e conclusão dos estudos } \\
\text { selecionados, além de dar início à qualificação. São aplicados os critérios de } \\
\text { classificação: } \\
\text { - Estudos que abordarem a Simbiose Industrial. } \\
\text { - Deixar somente artigos de periódicos e publicações de } \\
\text { conferências. } \\
\text { - Estudos que apliquem a SI. } \\
\text { Estudos disponíveis para download. } \\
\text { Objetivo principal do filtro 2: Identificar estudos de SI ou com sua aplicação. } \\
\text { Objetivo secundário do filtro 2: Identificar ferramentas utilizadas em seu } \\
\text { desenvolvimento ou planejamento. } \\
\text { Objetivo terciário: Identificar relacionamentos entre SI e planejamento do } \\
\text { layout. }\end{array}$ \\
\hline & $\begin{array}{l}\text { No Filtro } 3 \text { é feita a leitura do texto na íntegra e tem como objetivo extrair } \\
\text { informaços específicas dos estudos relacionadas a SI, sendo os, os } \\
\text { benefícios, as características e as ferramentas, os pontos do tema a serem } \\
\text { observados. Além de tentar identificar relacionamentos dela com o layout. }\end{array}$ \\
\hline
\end{tabular}


APÊNDICE B - Formulário para cadastro dos dados de entrada (input e output)

Quadro 26 - Formulário para cadastro dos dados de entrada.

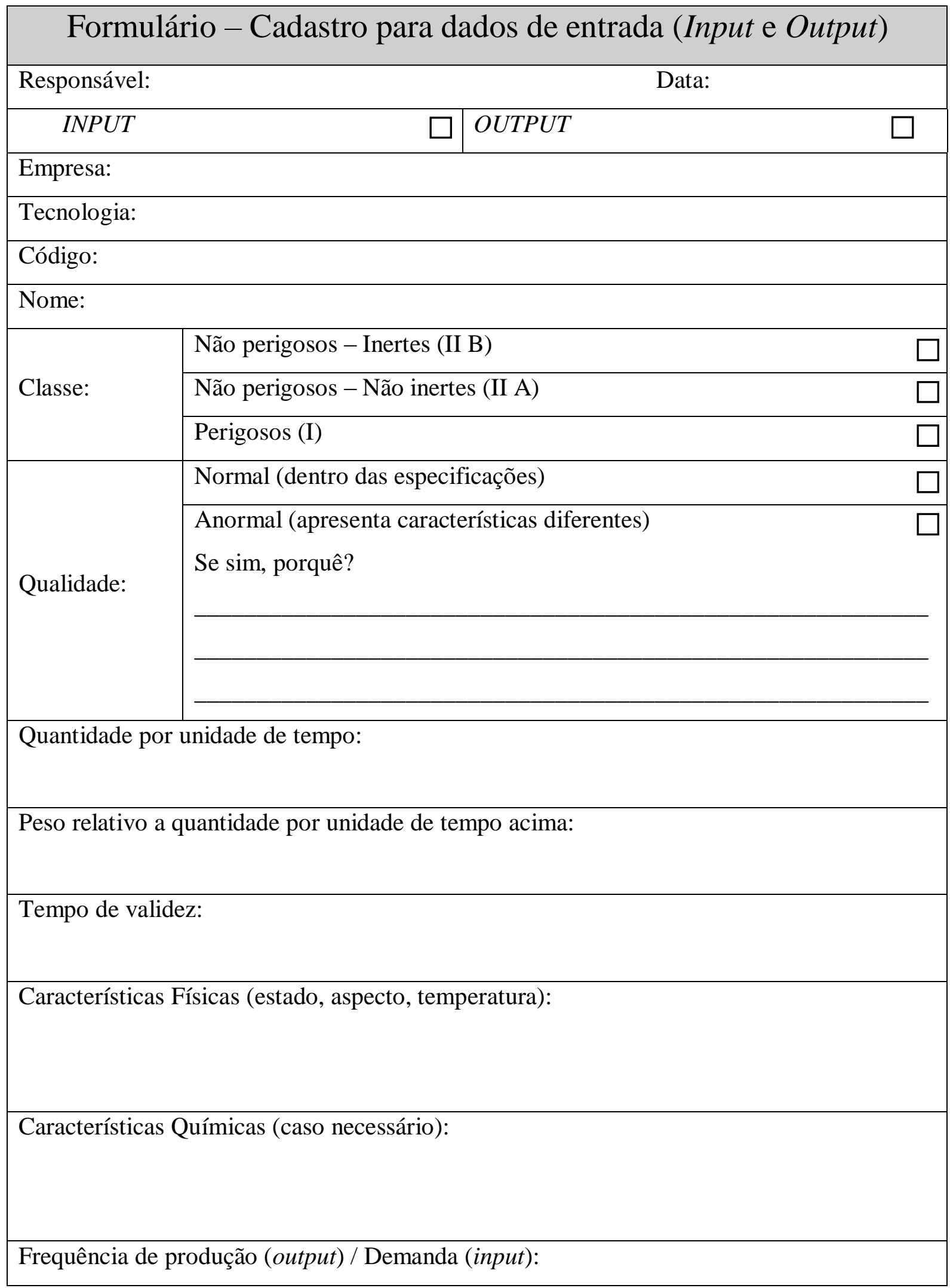


Requisitos:

Nível de perigo:

Padrão de recebimento/ fornecimento:

Requisitos de transporte:

Observações: 